\title{
ENHANCED COAL HYDROGASIFICATION VIA OXIDATIVE PRETREATMENT
}

Contract Number \#DE-FG22-89PC89777

University Coal Research Program

United States Department of Energy

FINAL TECHNICAL REPORT

prepared by

Dennls J. Miller

Department of Chemical Engineering

Michlgan State Unlversity

East Lansing, MI 48824

April 16, 1992 


\title{
EXECUTIVE SUMMARY
}

DOE \#DE-FG22-89PC89777

"ENHANCED COAL HYDROGASIFICATION VIA OXIDATIVE PRETREATMENT"

\author{
Principal Investigator: Dennis J. Miller \\ Department of Chemical Engineering \\ Michigan State University \\ East Lansing, MI 48824
}

The gasification of coal char by hydrogen is much slower than in steam or carbon dioxide; moreover, hydrogasification rate in pure hydrogen decreases sharply with conversion for most carbons. To overcome this kinetic behavior, the oxidation of the char prior to and during hydrogasification has been investigated as a means of enhancing hydrogasification rate. Kinetic rate studies under well-characterized conditions have been complemented by careful surface analyses to characterize oxygen on the char surface prior to and during hydrogasification.

Oxidation via partial burnoff in air has little effect on hydrogasification rate of as-prepared Saran or coal char, but the same oxidation on partially hydrogasifled or heat-treated chars results in as much as a three-fold rate enhaincement. The enhanced rate propogates for five to ten percent carbon conversion but then decay back to the unoxidized rate. Mineral matter in coal has little effect on uncatalyzed hydrogasification rate.

Potassium carbonate is an excellent hydrogasification catalyst, resulting in a rate enhancement as much as 400 -fold for ash-free chars at solid conversions above $50 \%$. Coal mineral matter greatly inhibits $\mathrm{K}_{2} \mathrm{CO}_{3}$-catalyzed hydrogasiilca-tion rate via catalyst deactivation.

Hydrogasification leaves a residual char surface that becomes progressively less reactive as conversion proceeds; oxidation (or the presence of catalyst) results in a char surface structure that is more reactive toward hydrogen. It appears that a different carbon structure results from oxidation than from hydrogasification, and that strongly chemisorbed hydrogen does not limit rate. 


\section{PROJECT SUMMARY}

This research project was conducted primarily in the principal investigator's laboratory located in the Department of Chemical Engineering at Michigan State University. The X-ray photoelectron spectroscopis analyses were conducted on the PHI 5400 XPS instrument located In the Composite Materlals and Structures Center in the College of Engineering at MSU. Ultimate analyses of the prepared chars were conducted by Commercial Testing and Engineering, Inc. of South Holland, Illinois. The starting materials to prepare chars were obtained from the Penn State Coal Bank and from Dow Coming Corp.

Two graduate students and one undergraduate student participated ir. this project. Mr. Michael Lussier (graduate student) was supported as a research assistant using funds from the grant; he prepared the chars and conducted the oxidation and gasification experiments. The second graduate student participating was Capt. Martiri Toomajian, an officer in the U.S. Army who received support from the Army for graduate study at Michigan State. Capt. Toomajian conducted the surface analyses of the chars, particularly the active surface area measurements and the XPS analyses. Both Mr. Lussier and Mr. Toomajlan eamed their Master of Sclence in Chemical Engineering degrees during the course of the grant. Mr. Lussier is staying in my research group to work on his Ph.D. in the area of coal; Capt. Toomajian must complete an assignment as an instructor of chemistry at West Point Milltary Academy before he will continue his education in pursult of his Ph.D. One undergraduate student, Mr. Mark Benedict, worked during Summer, 1991 to conduct additional surface analyses. He was supported jointly by the College of Engineering and through the DOE grant.

In the broadest sense, this grant is an extension of our previous work with model carbons and chars, in which we first observed the effects of oxidation on hydrogasification. The support from DCË, however, allowed us to widen our scope of experiments and conduct additional surface analyses. Results of research conducted under this DOE contract has answered many questions and generated many more. We are currently seeking funding to conduct isotopic studies on hydrogen gasification; the Department of Chemical Engineering has recently purchased a mass spectrometer for use in our coal research. 
I. INTRODUCTION

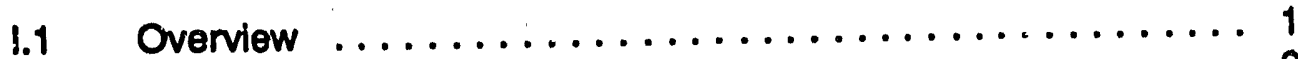

1.2 Literature Review $\ldots \ldots \ldots \ldots \ldots \ldots \ldots \ldots \ldots \ldots \ldots \ldots$

1.2.! Uncatalyzed Hydrogasification ............. 2

1.2.2 Catalyzed Gasification .................

1.3 Rationale and Objectives of Research $\ldots \ldots \ldots \ldots \ldots$

II. EXPERIMENTAL METHODS

II.1 Starting Materials . . . . . . . . . . . . . . . . 8

11.2 Sample Preparation and Oxidative Treatments ......... 8

II.2.1 Quartz tube reactor .................. 8

II.2.2 Pyrolysis procedure $\ldots \ldots \ldots \ldots \ldots \ldots \ldots \ldots$

II.2.3 Partlal oxidation . . . . . . . . . . . . . . . 9

11.3 Demineralization $\ldots \ldots \ldots \ldots \ldots \ldots \ldots \ldots \ldots \ldots \ldots \ldots \ldots$

11.3 .1 Mothod I . . . . . . . ................ 10

11.3 .2 Method $11 \ldots \ldots \ldots \ldots \ldots \ldots \ldots \ldots \ldots \ldots \ldots \ldots \ldots$

11.4 Catalyst Impregnation $\ldots \ldots \ldots \ldots \ldots \ldots \ldots \ldots \ldots \ldots \ldots \ldots$

II.5 Hydrogasification ........................ 11

II.5.1 Gasification reactor specifications . . . . . . . . . 11

il.5.2 Hydrogasification kinetic experiments $\ldots \ldots \ldots \ldots \ldots 13$

11.5 .3 Outgassing . . . . . . . . . . . . . . . . . . 13

$11.6 \quad$ Surface Analysis $\ldots \ldots \ldots \ldots \ldots \ldots \ldots \ldots \ldots \ldots \ldots \ldots \ldots$

$11.6 .1 \mathrm{pH}$ measurements . . . . . . . . . . . . . . . . 14

II.6.2 X-ray photoelectron spectroscopy ............ 14

II.6.3 Active surface aréa measurement . . . . . . . . . 18

II.6.4 Total surface area measurement . . . . . . . . . . . 20

III. RESULTS OF GASIFICATION EXPERIMENTS

III.1 Effect of Temperature ................... 23

III.2 Base Case Char Reactivity ................. 23

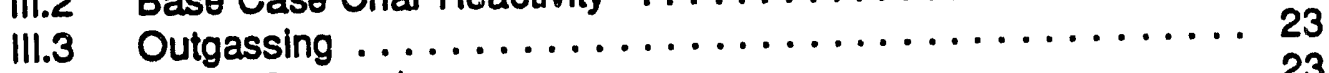

III.3.1 Saran char . . . . . . . . . . . . . . . . 23

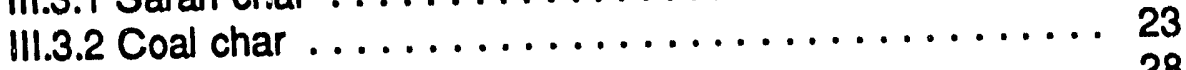

III.4 Oxidative Treatments ..................... 28

III.4.1 Oxidative pretreatment by partial combustion ...... 28

III.4.2 Other oxidative pretreatments $\ldots \ldots \ldots \ldots \ldots \ldots \ldots 28$

III.4.3 Intermittent Oxidative Treatments ............ 36

III.4.4 Continuous Addition of Oxygen ............ 36 
III.5 Hydrogen Addition at Steady State Reaction Temperature ... 41

III.6 Reduced Gasiflcation Temperature ................ 41

III.7 Hydrogen Pretreatments .................. 41

III.8 Catalyst Addition ......................44 41

III.8.1 Catalyzed base cases .................. 41

III.8.2 Preoxidation of catalyzed chars . . . . . . . . . 49

III.8.3 Intermittent oxidation of catalyzed chars . . . . . . . 49

-IV. DISCUSSION

IV.1 General Observations ................... 50

IV.1.1 Temperature effects $\ldots \ldots \ldots \ldots \ldots \ldots \ldots \ldots \ldots \ldots$

IV.1.2 Total surface area ................. 50

IV.1.3 Active surface area . . . . . . . . . . . . . 50

IV.1.4 Oxidation effects ................... 55

IV.1.5 Catalyst effects . . . . . . . . . . . . . . . 62

IV.1.6 Normalization of hydrogasification rate ......... 62

IV.2 Mechanistic Considerations .................6 62

IV.2.1 Proposed model . . . . . . . . . . . . . . . . . 62

IV.2.2 Supporting observations ............. 63

V. COMMENTS OF METHODOLOGY AND PROBLEMS ENCOUNTERED 65

VI. CONCLUSIONS ....................... 66

VII. REFERENCES $\ldots \ldots \ldots \ldots \ldots \ldots \ldots \ldots \ldots \ldots \ldots$

APPENDIX A: HYDROGASIFICATION RATE CALCULATIONS . . . . . . . 73

APPENDIX B: SCHEMATICS OF EQUIPMENT USED $\ldots \ldots \ldots \ldots \ldots \ldots 77$ 


\section{INTRODUCTION}

\subsection{Overview}

Continuing consumer demand for fossil fuels-based energy dictates that coal will eventually become the major source of heating and transportation fuels in the United States. Of the coal conversion processes developed for producing fuels, steam gasification is attractive in several aspects: it is simple to carry out, produces gases which can be further converted to a number of products, and is environmentally favorable. The major drawbacks to steam gasification are the high temperatures needed to attain reasonable reaction rates and the endothermicity of the reaction. In this regard, much steam gasification research has focused on accelerating gasification rate via introduction of catalysts, alteration of the coal structure, and removal of poisons so as to allow lower temperatures and pressures for conversion.

The hydrogen gasification of coal has not been studied as extensively as steam gasification, primarily because the reaction is not commonly viewed as a competitive route to gaseous fuels. Relative to steam gasification, hydrogasification requires higher pressures to make the reaction thermodynamically favorable; more importantly, hydrogen is presently too valuable a commodity to be considered a viable reactant for large-scale coal conversion.

On the other hand, it must be recognized that hydrogasification is a direct, highiy selective, exothermic route to a premiumi fuel product, methane.

$$
\mathrm{C}+2 \mathrm{H}_{2}=\mathrm{CH}_{4} \quad(-\Delta \mathrm{H}=19.7 \mathrm{kcal} / \mathrm{gmol \theta})
$$

The reaction occurs readily at temperatures $(1000-1200 \mathrm{~K})$ at or slightly above those used in steam gasification and at pressures (1-10 MPa) commonly used in the chemical process industry. Although the reaction is thermodynamically limited at high temperatures and low pressures, acceptable conversions can be obtained at reasonable conditions. Indeed, the reaction forms the basis of the HYDROCARB process [1], which produces clean solld fuels from coal.

As the world energy supply shifts from petroleum to coal and emphasis on supplying hydrogen for both liquefaction and gasification intensifies, coal hydrogasification will play a larger role in gasification processes such as the EXXON process [2] and could become the favored route for methane production. Methane will continue to be the preferred gaseous pipeline fuel, as it contains over three times the energy of syngas or hydrogen per unit volume. To become the favored route to methane, however, it is necessary to understand coal-hydrogen chemistry and develop catalysts which will make hydrogasification preferable to other, multi-step routes.

In addition to potential as a favored route to methane, the study of hydrogen gasification is warranted for two further reasons. First, the carbon-hydrogen reaction is an important side reaction in steam gasification, both to reduce endothermicity and to enhance the fuel value of the product gases. It has been recently reported that methane is formed in steam gasification via the direct reaction of carbon and hydrogen and not by secondary reactions [3]; this suggests that hydrogen gasification occurs more readily than previously thought.

Second, hydrogen gasification offers a unique reaction environment in which to study the behavior of gasification catalysts, particularly the alkall metal salts. With hydrogen as reactant gas, the amount of oxygen present is limited to that initially in the catalyst and coal. The importance of oxygen in stabilizing and activating the alkali metal, which has received much attention in the past few years, can be effectively studied in a hydrogen environment. 


\subsubsection{Uncatalyzed Hydrogasification}

\subsubsection{General}

Much of the pioneering work on coal hydrogasification was done by J.D. Blackwood et al. They were able to determine that reaction rate is proportional to hydrogen partial pressure during Inittal stages of carbon conversion [4-7], and that rate is not a strong function of char type $[4,8,9]$. Other researchers also determined that methane formation rate is first order in hydrogen partial pressure [10]. The uncatalyzed hydrogasification rate decreases rapidly with carbon conversion $[5,7,11-14]$, which led some researchers to claim that the initial rate is diffusion controlled [15]. Activation energles reported include values of $43 \mathrm{kcal} / \mathrm{mol}$ [4] and $27 \mathrm{kcal} / \mathrm{mol}$ [10], but the extent of carbion conversion where the rate data were taken is not specified. Other researchers reported activation energies of $36 \mathrm{kcal} / \mathrm{mol}$ initially to $51 \mathrm{kcal} / \mathrm{mol}$ at steady state [15], and $15 \mathrm{kcal} / \mathrm{mol}$ Initially to $50 \mathrm{kcal} / \mathrm{mol}$ at steady state [16]. Activation energles of the cleavage of carbon-carbon bonds in steam and carbon dioxide char gasification include values of $80.5 \mathrm{kcal} / \mathrm{mol}$ [17] and 61.4 $\mathrm{kcal} / \mathrm{mol}$ [18] respectively.

Almost all chars possess a high internal surface area resulting from a complex pore network. The char base structure can be thought of as a collection of small randomly aligned graphite crystallites [19]. Porosity and thus surface area is the result of poor crystallite packing due to random alignment. Total char surface area as determined by BET analysis, however, correlates very weakly or does not correlate at all with gasification rate. This has been shown for oxygen gasification [20], carbon dioxide gasification, $[21,22]$ as well as hydrogasification $[9,23]$. In the case of oxygen gasification, developing pores include those in the micro-and mesopore range, which restrict molecular diffusion [20]. In the case of hydrogasification, macropore surface area does not increase untll about $55 \%$ carbon conversion. Widening of the micro- and mesopores is the main reason for the increase [24].

Structure on the molecular level appears to be much more important in determining hydrogasification rate. Several two-stage reactions have been proposed by researchers to explain the rapld rate decay in hydrogasification. One claim is that the initial high rato results from reaction of hydrogen with amorphous carbon atoms which were deposited during pyrolysis [8]. Prior to pyrolysis, most of the char intemal volume is filled with compounds that are volatile relative to the char base structure. During pyrolysis, some of these compounds completely volatilize, and some carbonize. The carbonized char coats part of the char surface in an amorphous form. This amorphous, or "secondary carbon," tends to be more saturated with hydrogen and less saturated with chemical bonds in general. The low steady state rate is due to resction of hydrogen with the graphite-like char base structure [8]. The same researchers have proposed a similar model in which initial high reaction rate results from gasification of carbons associated with oxygen functional groups [25]. Other researchers used unpyrolyzed chars and make the claim that high initial rate is due to pyrolysis of aliphatic side chalns and oxygenated functional groups followed by hydrogenation of intermediate pyrolysis products. The low steady state rate is due to direct attack of rosidual aromatic base char structures [26].

A strong preference for reaction of hydrogen with edge carbon atoms, as opposed to basal plarie carbon atoms, has also been shown [27]. This is because of unpaired sigma electrons on edge carbon atoms which make them more reactive than those of the basal plane. It may also result in part from diffusion of impurities which serve as catalysts or leave vacancies if they desorb from edge carbons [28]. Further probing into the reactivity of edge carbon atoms by etch pit analysis of graphite shows that hydrogen greatly prefers to attack the "armchair" edge carbons (<112b edge plane) over the "zig-zag" edge carbons (<101 b edge plane) in hydrogasification and steam gasification [29-32], while oxygen and carbon dioxide show no edge preference in 


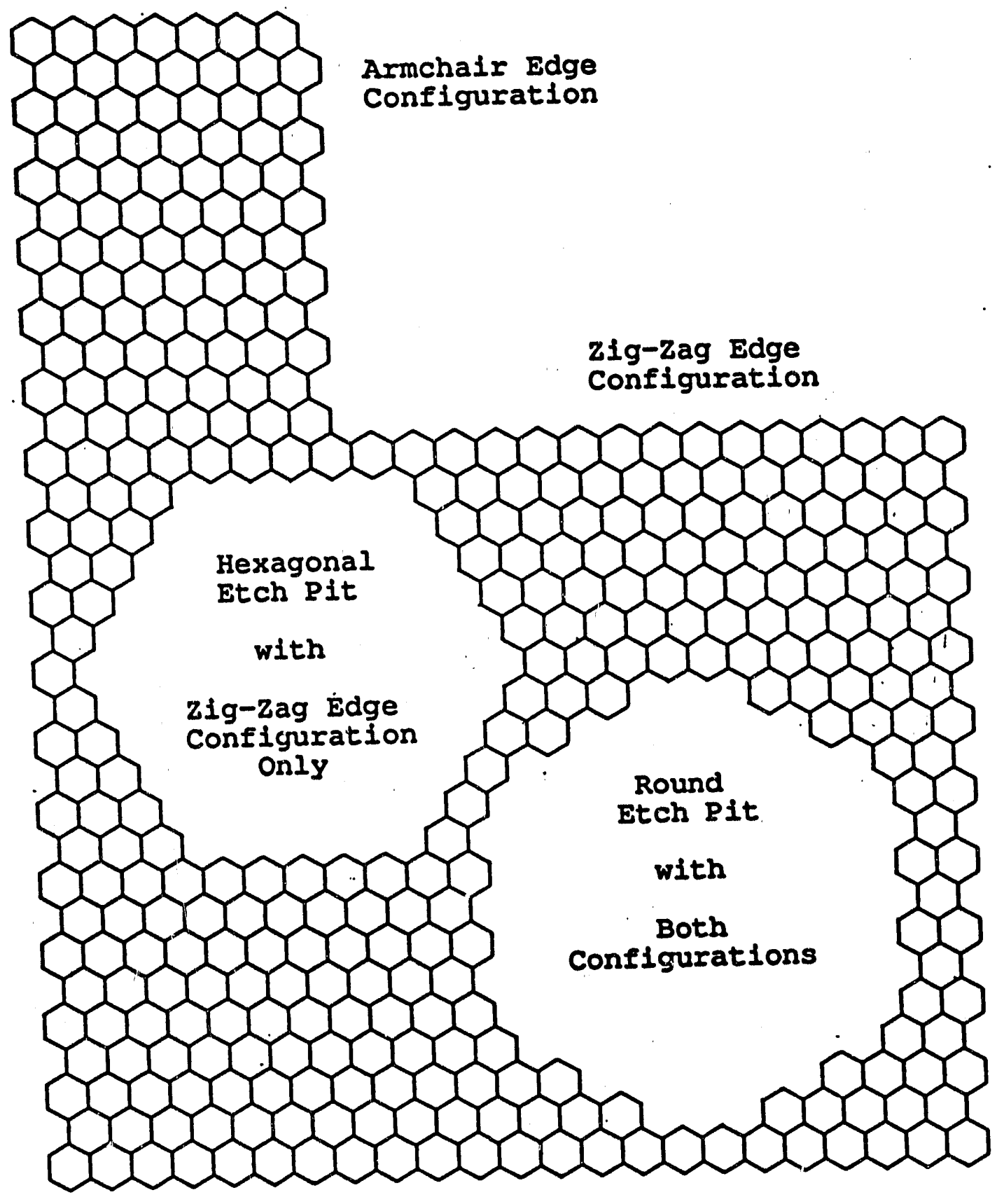

Figure-1: Various Edge Configurations on the Graphite Basal Plane 
gasification [29,32]. Etch pits formed during hydrogasification and steam gasification were hexagonal, oriented such that all edges were composed of zig-zag configurations. Etch pits formed during oxygen and carbon dloxide gasification were round, indicating both configurations on the pit edge. Although coal is not graphite, it is highly aromatic, and can be assumed graphitic on a local level [19]. Various edge and pit configurations are lllustrated in Figure 1.

Understanding the way in which hydrogen adsorbs onto the char surface is also an important part of determining what takes place during reaction. Several researchers have suggested successive dissociative hydrogen chemisorption onto adjacent carbon atoms [16,33]. Some have gone further and suggested that the breakage of the bond between adjacent carbons, which is caused by the adsorption of the third pair of hydrogen atoms, is the rate limiting step [30]. Associative hydrogen chemisorption has also been suggested as a possible methanation mechanism. Two hydrogen molecules successively adsorb onto the same carbon atom, completely enriching it [34]. It has also been suggested that dissociative hydrogen chemisorption occurs first followed by associative chemisorption, with the dissociative step being rate limiting [6].

Understanding the role of hydrogen in gasification of chars is also important because it has been shown to inhibit steam and carbon dioxide gasification [35-41]. It may' also be part of the cause of rapid deactivation of hydrogasification rate due to dissociative adsorption [42].

With the idea of associative hydrogen chemisorption, these researchers have also introduced the concept of an active site [6]. It is generally defined as a carbon atom on the char surface that is not completely saturated with chemical bonds, or a carbon with free or unpaired electrons [9]. An active site is where hydrogen associatively adsorbs, and when the carbon is saturated with hydrogen and cleaved from the char surface another active site is be generated on an adjacent carbon.

\subsubsection{Role of oxygen}

It is generally belleved that the major source of active sites in all gasiflcation reactions comes from the desorption of oxygen functional group from the char surface. These groups desorb in the form of carbon monoxide and carbon dioxide when samples are heated to reaction temperature [7,43-50], and in the form of water during reaction [7]. The desorption of carbon monoxide and carbon dioxide is considered the rate limiting step in oxygen gasification [51], and determines the rate of this reaction [23]. Hydrogasification rate has been shown to be a strong function of the oxygen content of various chars [4,7,52], and initial rate a strong function of oxygen surface concentration [48,53]. It has also been shown to be a strong function of char preparation temperature $[4,8,9,54]$, because char oxygen content is a strong function of preparation temperature $[4,7]$.

There are several methods of fixing oxygen onto char surfaces in an attempt to increase the active surface area, and therefore the gasification rate $[46,47]$. One method is partial combustion in oxygen before carbon dioxide gasification $[55,56]$ and hydrogasification [48$50,57,58]$. Chemical methods include treatment with nitric acid $[48,59,60]$, peracetic acid [61], or hydrogen peroxide [62]. Continuous oxidation can be performed by addition of low concentrations of oxygen or carbon dioxide to the reactant gas in hydrogasification [63].

The most widely used general description of oxygen functional groups on char surfaces is the $\mathrm{pH}$ of these sites, which is determined by their formation conditions [64]. Groups generally tho:Jght of as acidic include carboxyl and phenolic hydroxyl groups [64,65] and lactone groups [66-59]. Acidic groups are formed during partial combustion in oxygen at temperatures ranging from $300^{\circ} \mathrm{C}$ to $450^{\circ} \mathrm{C},[70]$ or to $500^{\circ} \mathrm{C}[70-73]$. Some researchers have claimed that the optimum oxidation temperature is $400^{\circ} \mathrm{C}[72,74]$. Acidic groups generally desorb as carbon dioxide during sample heatup [70]. Nitric acid treatments generally fix acidic functional groups onto char surfaces [50], but basic groups can be fixed as well $[62,75]$. Among the groups fixed by nitric 
acid are carboxyl, phenol, amine, carbonyl, and ester groups [76]. Hydrogen peroxide can also form a mixture of functional groups $[62,75]$. Groups generally thought of as basic include pyronelike structures and chromenes [65,68], while neutral groups include carbonyls [71]. Basic groups are formed during partial combustion in oxygen at temperatures ranging from $700^{\circ} \mathrm{C}$ to $800^{\circ} \mathrm{C}$ [62], or at $750^{\circ} \mathrm{C}[77,78]$. Basic and neutral groups generally desorb as carbon monoxide during sample heatup [65,71]. It is possible that the chromine groups, which oxidize to lactone groups [68], may cause the low char reactivity during the later stages of sample conversion during hydrogasification up to temperatures of $870^{\circ} \mathrm{C}$ [66].

Char reactivity can be decreased by heating samples to temperatures near $1000^{\circ} \mathrm{C}$. This has been shown to greatly anneal char surfaces [79], and decrease actlve surface area [80]. Outgassing, which involves heating chars to high temperatures under vacuum, cleans carbon black of all acidic functional groups [58]. It has also been shown to decrease hydrogasification rates by a facter of six and reduce surface oxygen concentrations to nearly zero [57].

\subsubsection{Catalyzed Gasification}

There are a number of catalysts that can be used for increasing the gasification rate of chars. Catalysts include alkall carbonates and most of the transition metals in groups IIIB-VIIIB. Transition metal catalysts are more effective than alkall carbonates [81-84], but they are also much more expensive $[37,85,86]$. Examples of transition metals used include nickel and iron [8789], copper [90], and platinum [91,92].

Potassium appears to be the best choice among the alkall metals. Rubidium and cesium are more active than potassium, but are very expensive. Sodium is cheaper than potassium, but the greater catalytic activity of potassium more than compensates for this [93]. The advantage of potassium over alkall earths such as calcium is the fact that potassium will evenly disperse itself over the char surface due to its high mobility, while calcium must be atomically. dispersed to create comparable activity [94].

Several imechanisms have been proposed for potassium carbonate catalysis of steam and carbon dioxide gasification. A number of researchers have suggested a redox cycle with decomposition and reformation of the carbonate [40,41,95-98]. Intermediates of alkall hydroxide in steam gasification, and alkall oxide in carbon dioxide gasification are included. Other researchers have proposed that an alkall metal non-stoichiometric oxide serves as a center for the capture of oxygen from the gas phase and electrons from the char, which greatly increases the reaction of adsorbed oxygen atoms [99-101]. Potassium hydroxide has been suggested as an intermediate during this mechanism [40]. Another mechanism involving potassium-intercalation compounds has been proposed [102].

Further research in this area has indicated that surface oxygen is essential for catalyst activity [3], and is therefore involved in the mechanism [52,53,103]. Some researchers have claimed that the potassium to carbon ratio is what determines gasification rate [103], but others have shown that the surface oxygen concentration is what determines the amount of retained potassium on the char [52]. The proposal of C-O-K complexes determining gasification rates has been supported by many researchers [104,105]. These complexes have been shown to be stable to $700^{\circ} \mathrm{C}$ and directly proportional to steam gasification rate [39]. A redox cycle has been proposed that involves the complex [106]. A possible mechanism for carbon dioxide gasification that includes the C-O-K complex consists of an alteration of the active catalyst between the complex and potassium metal. Carbon and oxygen are exchanged with the gas phase [107].

Much less research has been done in the area of potassium carbonate catalysis in char hydrogasification. Significant rate enhancements have been observed $[58,108,109]$, but application of the above proposed mechanisms to catalyzed hydrogasification is limited because the oxidizing reactant gases, which support redox cycles, are not present [93]. A mechanism has been proposed which includes formation of the C-O-K complex by interaction between the catalyst and some basic surface groups [58]. 
Another obstacle that must be overcome in catalyzed hydrogasification of coal chars is the strong inhibition caused by mineral matter in the ash. Catalyst poisoning with small amounts of sulfur has been observed during hydrogasification using potassium, as well as transition metals [110]. Aluminosillcates, mostly in the form of the clay minerals illite and kaolinite, poison potassium catalyzed steam gasification [111,112].

\subsection{Rationale and Objectives of Research}

Work conducted in our laboratory [48-50] on hydrogen gasification of carbon blacks and blomass chars prior to work conducted under this DOE contract allowed us to develop a significant understanding of the reaction system. That prior work focused on alkall metal salts as catalysts in hydrogasification and the effect of surface oxygen and oxidation on hydrogasification rate. Most importantly, we showed that oxidizing the carbon surface before hydrogasification reduces catalyst loss and results in enhanced gasification rate for both catalyzed and uncatalyzed gasification. The effects of oxidation on hydrogasification rate were retained for substantial carbon conversion following treatment; active sites resulting from desorption of oxygen were therefore not just removed or consumed upon exposure to hydrogen but were retained or propogated to substantial carbon conversion. These results suggested that surface oxygen plays a key role in promoting the carbon-hydrogen reaction and in stabilizing alkali metal catalysts on the surface.

These conclusions were based on experiments with "model" carbon reactants having low ash and impurity contents. We therefore submitted a proposal, and were awarded a contract with DOE, to extend our research to oxidation and hydrogasification of actual coal samples. An important objective of the research was to separate the influence of impurities in coal from those of surface oxidation and alkali metal salt catalysts. This objective and others are outlined in the paragraphs below.

To determine the catalytic activity of coal mineral matter in hydrogeri gasification, experiments were conducted to compare reactivity of "as-received" coal with coal which was demineralized by acid washing. The demineralization was carries out strictly to elucidate the catalytic or poisoning effects of ash on both catalyzed and uncatalyzed hydrogasification rate.

Although gasification rate enhancement resulting from surface oxidation of model carbons had been previously demonstrated by us, the question arose for coal as to what extent rate would be enhanced by bulk oxygen in coal versus added surface oxygen. A second goal of this study was therefore to distinguish between the effect of bulk oxygen in coal and added surface oxygen. To do this, experiments were performed using a model carbon, Saran char, in addition to asreceived and demineralized coal. The study of high-purity Saran char, which contains essentially no bulk oxygen, was necessary to separate the effects of added oxygen frorn bulk oxygen. By studying both model carbons and actual coals, a better fundamental understanding of the effects of oxygen was developed than by studying coal alone.

Yet another goal of the research was to study the tendency of added surface oxygen to remain on the coal during gasification. This topic has important ramifications as to how oxidation could be carried out in a large-scale process. Three possible processes for oxidation could be used, depending on the tendency for oxygen to remain on the solid: oxidative pretreatment before gasification, a cycling of hydrogen and air reactant gases to periodically replenish oxygen, or continuous addition of air to hydrogen at a composition below the explosive limit. Experiments simulating each of these modes of oxygen addition were performed. From a process standpoint, the question of carbon loss during oxidation and thus reduced methane yields is one of economics: the small loss in yield may be offset by a large increase in gasifier throughput.

All of these experiments were complemented by careful characterization of the coal char, demineralized coal char, and Saran chars before and after treatment and gasification. Total surface area measurement via $\mathrm{CO}_{2}$ adsorption gave structural information about the coal and Saran chars used. Oxygen chemisorption provided a measure of active surface area of each sample as well as a means of introducing a controlled amount of oxygen onto the solid. In 
addition, X-ray photoelectron spectroscopy (XPS) of selected samples was carried out to determine amount and approximate bonding state of oxygen and potassium on the solid surface.

The functional oxygen groups which accelerate carbon gasification were also studied by $\mathrm{pH}$ measurements to gain a semiquantitative measure of the amount of acidic surface oxygen groups present on the coal chars. In addition, XPS measurements provided important information about quantity of oxygen and which form of oxygen promotes reaction.

In summary, the overall hypothesis of this work was that surface oxygen plays an important role in hydrogasification of coal, and that rate can be enhanced by oxidizing the coal surface prior to exposure to hydrogen. This overall hypothesis was explored and verified via completion of the specific experimental studies outlined in the preceding paragraphs. 


\section{EXPERIMENTAL METHODS}

\section{II.1 Starting Materials}

The starting materials used in this investigation were a Dow Saran MA 127 Resin and an Illinois "6 (PSOC-1493) high-volatile bituminous coal. The Saran was choser as a model compound because it chars to a relatively pure carbon with an extremely low ash content and displays reactive and structural properties similar to the coal chosen for this investigation. The coal has been selected because it is very well characterized and besn widely used in other studies.

\subsection{Sample Preparation and Oxidative Treatments}

Detalls of the equipment and methods to prepare and treat the solid reactants used in this study are given below. Starting materials were pyrolyzed in the quartz tube furrace and then subjected to various treatments before and after gasification.

\subsubsection{Quartz tube reactor}

The quartz tube reactor was used for pyrolysis of starting materials and low pressure oxidative treatments. It consists of a $4.8 \mathrm{~cm}$ ID quartz tube placed in a 1400 watt Lindberg Electric Furna:e (Model 54232). The tube is $91 \mathrm{~cm}$ in length with a $0.6 \mathrm{~cm}$ nipple on the upstream end and a removable flange on the downstream end. Temperature is controlled with an Omega Series CN-2010 Programmable Temperature Controller. Firebrick plugs inside the quartz tube at both ends help minimize heat loss.

Gases used in sample preparation include AGA 99.99\% Nitrogen which passed through an Airco Single Stage Argon-Nitrogen-Helium Regulator for pressure control, and AGA Compressed Air U.S.P. which passed through a Rego Single Stage Regulator for pressure control. Gas flow rate was controlled by two rotameters in series. For high flow rate purging a 2-S-150 Fisher Scientific Laboratory Flow Meter was used, wh'le for tightly curitrolled flow rates a Cole Parmer Model G Rotameter with a $420 \mathrm{cc} / \mathrm{min}$ maximum flow rate was used. Exhaust gas was sent through two water-filled $1000 \mathrm{ml}$ Erlemeyer side-arm flasks in series to trap potentially hazardous products, then into a laboratory tume hood.

The samples were placed in Coors U.S.A. Alumina Chemical-Porcelain Ware Ceramic trays $(4.0 \mathrm{~cm} \times 3.0 \mathrm{~cm} \times 0.5 \mathrm{~cm})$ or boats $(10.4 \mathrm{~cm} \times 2.5 \mathrm{~cm} \times 1.5 \mathrm{~cm})$ during the reactions and were stored under nitrogen in capped glass bottles inside a desiccator.

\section{II.2.2 Pyrolysis procedure}

All starting materials were pyrolyzed because we wishred to focus ofi char gasification; it is the slow step in the overall conversion of coal. Samples were pyrolyzed by heating from $25^{\circ} \mathrm{C}$ to $900^{\circ} \mathrm{C}$ at $10^{\circ} \mathrm{C} / \mathrm{min}$, soaking at $900^{\circ} \mathrm{C}$ for 30 minutes, and cooling from $900^{\circ} \mathrm{C}$ to $100^{\circ} \mathrm{C}$ at $10^{\circ} \mathrm{C} / \mathrm{min}$. The actual cooling time was several hours because of the heavy insulation and large thermal mass of the furnace. Nitrogen flow rate was kept constant at $400 \mathrm{cc} / \mathrm{minute}$ and atmospheric pressure throughout all runs.

With a reactor volume of $1650 \mathrm{cc}$, purge rate was about one reactor volume every four minutes. An average of 51 grams of coal per run was loaded into the quartz tube reactor, with a yield of $61 \%+1 \%$. An average of 12 grams of Saran powder was loaded per run with an average yield of $25.5 \%+0.5 \%$. The Saran forms a greatly expanded foam-like structure of carbon when charred, which must be ground into a powder before use. Ultimate analyses of Saran char and coal char are given in Table 1. 
(Weight \% on Dry Basis)

\begin{tabular}{|c|c|c|c|c|}
\hline Element & $\begin{array}{l}\text { Saran } \\
\text { Char }\end{array}$ & $\begin{array}{l}\text { Coal } \\
\text { Char }\end{array}$ & $\begin{array}{l}\text { Demin. } 1 \\
\text { Char }\end{array}$ & $\begin{array}{l}\text { Demin..11 } \\
\text { Char }\end{array}$ \\
\hline $\begin{array}{l}\text { \% Carbon } \\
\% \text { Hydrogen } \\
\% \text { Nitrogen } \\
\% \text { Sulfur } \\
\% \text { Ash } \\
\% \text { Oxygen (diff) }\end{array}$ & $\begin{array}{c}96.36 \\
0.53 \\
1.04 \\
0.43 \\
0.08 \\
1.56 \\
\end{array}$ & $\begin{array}{c}75.30 \\
0.53 \\
1.34 \\
3.55 \\
17.33^{1} \\
1.95 \\
\end{array}$ & $\begin{array}{c}88.59 \\
0.69 \\
1.40 \\
2.32 \\
0.66^{2} \\
6.34 \\
\end{array}$ & $\begin{array}{r}92.00 \\
0.39 \\
3.50 \\
1.21 \\
1.36 \\
1.54 \\
\end{array}$ \\
\hline & 100.00 & 100.00 & 100.00 & 100.00 \\
\hline $\begin{array}{l}\% \text { Chlorine } \\
\text { Fluorine } \mu \mathrm{g} / \mathrm{g}\end{array}$ & & & $\begin{array}{l}0.25 \\
163\end{array}$ & \\
\hline HHV, BTUAb & 14073 & 11300 & 12847 & 13471 \\
\hline
\end{tabular}

'Correct dry ash content is $20.81 \%$ because $3.48 \%$ sulfur is retained in

the ash.
${ }^{2}$ Correct dry ash content is $2.94 \%$ because $2.28 \%$ sulfur is retained in the ash.

\section{II.2.3 Partial oxidation}

Partial combustion in air was used as the main method of oxidizing char surfaces. All oxidations were performed in the quartz tube reactor using slightly different methods to achleve varying degrees of oxidatiori. The soak temperature used for most chars was $375^{\circ} \mathrm{C}$, while $725^{\circ} \mathrm{C}$ was used in a few runs. Chars were held at the soak temperature for 0.5-3 hours and were subject to various combinations of air and nitrogen flow rates, or stagnant conditions, depending upon the desired conversion and the amount of char to be treated. Sacrificial carbon was used In some cases so not all of tha oxygen will react with the sample of interest. Oxidation was used as a pretreatment or an intermittent treatment for some hydrogasifications.

\subsubsection{Oxidative Pretreatment}

One procedure has been used for oxidative pretreatment of most chars. Five of the $0.5 \mathrm{~cm}$ deep ceramic trays were loaded into the quartz tube reactor, each containing 0.5 gram of Saran char or 1.0 gram of coal char. The reactor was heated from $25^{\circ} \mathrm{C}$ to $375^{\circ} \mathrm{C}$ at a rate of $10^{\circ} \mathrm{C} / \mathrm{min}$ and held at $375^{\circ} \mathrm{C}$, for a designated time period. The reactor was, purged with air at a flowrate of $50 \mathrm{cc} / \mathrm{min}$ during the heat ramp and soak, and then $250 \mathrm{~cd} / \mathrm{m}$.in of nitrogen during the time it took the reactor to cnol down to room temperature, which was usually overnight. One batch of char was oxidized at $725^{\circ} \mathrm{C}$, but the air was kept stagnant to prevent excessive conversion of the char. Shallow trays and small amounts of char were used to avoid large oxidation gradients within individual trays that would be caused by mass transfer limitations. Some conversion gradients were caused between trays because of the parabolic temperature profile within the heated zone of the reactor. 


\section{II.2.3.2 Intermittent oxidative treatment}

The air flow rate for most intermittently oxidized samples was kept stagnant because the total mass of these samples was much less than that of the preoxidized chars. Intermiltently oxidized samples had weights less than 0.3 gram in the case of Saran char and 1.0 grams in the case of coal char, compared to 2.5 grams of Saran char and 5.0 grams of coal char for oxidative pretreatments. Two to three grams of sacrificial char were included in the reactor with most intermittent oxidations to prevent excessive sample conversion during oxidation.

\section{$\underline{11.3 \text { Deminerallization }}$}

Some of the coal samples in this study were demineralized in order to study the effect of ash on both uncatalyzed and catalyzed coal char hydrogasification. Two methods of demineralization were used on the starting materials.

\section{II.3.1 Method I}

The first method was based on one taken from a paper on determination of coal mineral matter by Bishop and Ward [114] and has been designated as Demineralization Method I. It included a hydrofluoric acid bath and a hydrochloric acid bath of previously pyrolyzed coal. Eighty grams of coal was mixed with $500 \mathrm{ml}$ of a $49 \%$ hydrofluoric acid solution at $60^{\circ} \mathrm{C}$ for 1 hour while being stirred every 5 minutes. The slurry was vacuum filtered, then the filter cake was combined with $1000 \mathrm{ml}$ of a $37 \%$ hydrochloric acid solution under the same conditions. The new slurry was then vacuum filtered, washed with $5 \mathrm{~L}$ of distilled water, and left overnight in $2000 \mathrm{ml}$ of distilled water under constant agitation. The next day it was vacuum filtered, washed with $5 \mathrm{~L}$ of distilled water, and dried at $110^{\circ} \mathrm{C}$ under nitrogen overnight. On the third day it was pyrolyzed for a second time. This method did not work well for the coal used in this set of experiments. This may be due to ash particle encapsulation during initial pyrolysis and/or pyrites that resist both hydrofluoric and hydrochloric acids. An ultimate analysis of Demineralization Method I coal char is in Table 1.

\section{II.3.2 Method II}

The second method was developed to achieve a more complete demineralization than the first, and has been designated as Dernineralization Method II. It contains most of the steps found in the iirst method, and also includes a nitric acid bath to dissolve any pyrite that may be left by the other acids. The other major difference is that the coal was not pyrolyzed before the demineralization treatment in Method II to avoid encapsulation of ash particles. An ultimate analysis of Demineralization Method II coal char is in Table -

The second coal demineralization method began with . al that has not been charred. It incluoe $d$ the same concentrated hydrofluoric and hydrochloric icid baths as in the first method. The third bath of demineralization method II was a $1000 \mathrm{ml} 18 \%$ nitric acid bath at $60^{\circ} \mathrm{C}$, lasting for 1 hour while being stirred every 5 minutes. The resulting filter cake was washed with $10 \mathrm{~L}$ of distilled water, stirred overnight with $2 L$ of distilled water, washed again and pyrolyzed.

\section{II.4 Catalyst Impregnation}

Potassium carbonate catalyzes the hydrogasification of coal chars particulariy well. A 10 $w t \%$ catalyst loading was used on all catalyzed chars to achieve a KJC ratio of 0.02 . This was done by combining 0.5-10 grams of sample with the appropriate amount of $0.1 \mathrm{MK}_{2} \mathrm{CO}_{3}$ solution in a drying oven at $90^{\circ} \mathrm{C}$. The samples were stirred every 45 minutes and removed when they appeared dry and no longer lost weight due to water evaporation. 


\subsubsection{Gasification reactor specifications}

The hydrogasification reactor used for these experiments is an externally heated differential fixed bed reactor. A schematic of the reaction system is given in Figure B.1 in Appendix $B$. The pressure vessel has been designed for simultaneous operation at $1000 \mathrm{psi}$ and $1000^{\circ} \mathrm{C}$ and consists of a 0.875 inch ID by 2.0 inch OD by 22 inch long Haynes Alloy 605 tube sealed with a water-cooled flange. The pressure vessel is lined with a quartz tube to minimize the inter?ction of reactant gas with the metal wall. The pressure vessel is externally heated by a Lindberg tube furnace and controller.

Carbon samples are positioned are placed in a sample holder affixed to the end of the center gas exit tube (1/4" OD Inconel); two thermocouples extend from the exit tube to measure sample temperature. Reactant gas flows into the reactor and down the annulus where it is heated, over the carbon sample, and out the center exit tube to product gas analysis.

The product gas collection system consists of several liquid nitrogen traps in parallei; a series of solenold switching valves is used to direct product gas into a desired trap. To determine reaction rate, product gas is routed through a trap for a desired period of time where condensible species are collected. The contents of the trap are injected by another series of valves to the carrier gas stream of a gas chromatograph where the amount of product in the trap is determined. Gasification rate is thus measured as the amount of product evolved per unit time; rates as low as $0.01 \mathrm{ml} \mathrm{CH} / \mathrm{min}$ of methane can be measured using this apparatus. The reactor, sample collection, and analysis systems are described in detail by Zoheidl [93]. Hydrogasiflcation rate calculations are given in Appendix $A$.

\subsubsection{Gas chromatograph}

One of two modifications on the existing hydrogasification equipment during the course of this experimentation was the replacement of the F\&M Model 810 Research Chromatograph with a Varian Analytical Instruments Model 3300 Gas Chromatograph. This chromatograph uses a thermal conductivity detector with a reference cell, and a Supelco 80/100 Carbosieve S-11 stainless steel column, $5^{\prime} \times 1 / 8^{\prime \prime}$, in parallel with a blank column. It also has an auto zero function which automatically establishes a baseline for the chart recorder. This makes interpretation of the raw data charts much easier. The column oven heating cycle used for all sample analyses consisted of an initial soak at $50^{\circ} \mathrm{C}$ for 2 minutes, an increase from $50^{\circ} \mathrm{C}$ to $175^{\circ} \mathrm{C}$ at $20^{\circ} \mathrm{C} / \mathrm{min}$, and a final soak at $175^{\circ} \mathrm{C}$ for 2 minutes for a total time of 10.25 minutes.

\subsubsection{Sample holder}

The other modification to the existing equipment was a newly designed sample holder. The sample holder used in past studies was a ceramic hemispherical trough, $2.6 \mathrm{~cm}$ long, with a bed depth of $3 \mathrm{~mm}$. It required a 325 mesh 316 stainless steel screen to be placed over the sample to help prevent blowout by high gas velocities. Disadvantages of this design included possible mass transfer limitations, small sample size, potential sample blowout, and metal in contact with the sample.

These problems were minimized or eliminated by using a cylindrical quartz chamber capped at both ends by 40-60 micron porous quartz frits. A diagram of the new sample holder is given in Figure 2. No metal parts come in contact with the chars. The reactant and purging gases are able to flow through the sample bed instead of over it, and cannot blow char out of the holder. A quartz wool gasket seals the ring of contact between the two quartz components to prevent sample from being entrained. The components are held together by springs to ensure a tight seal. 

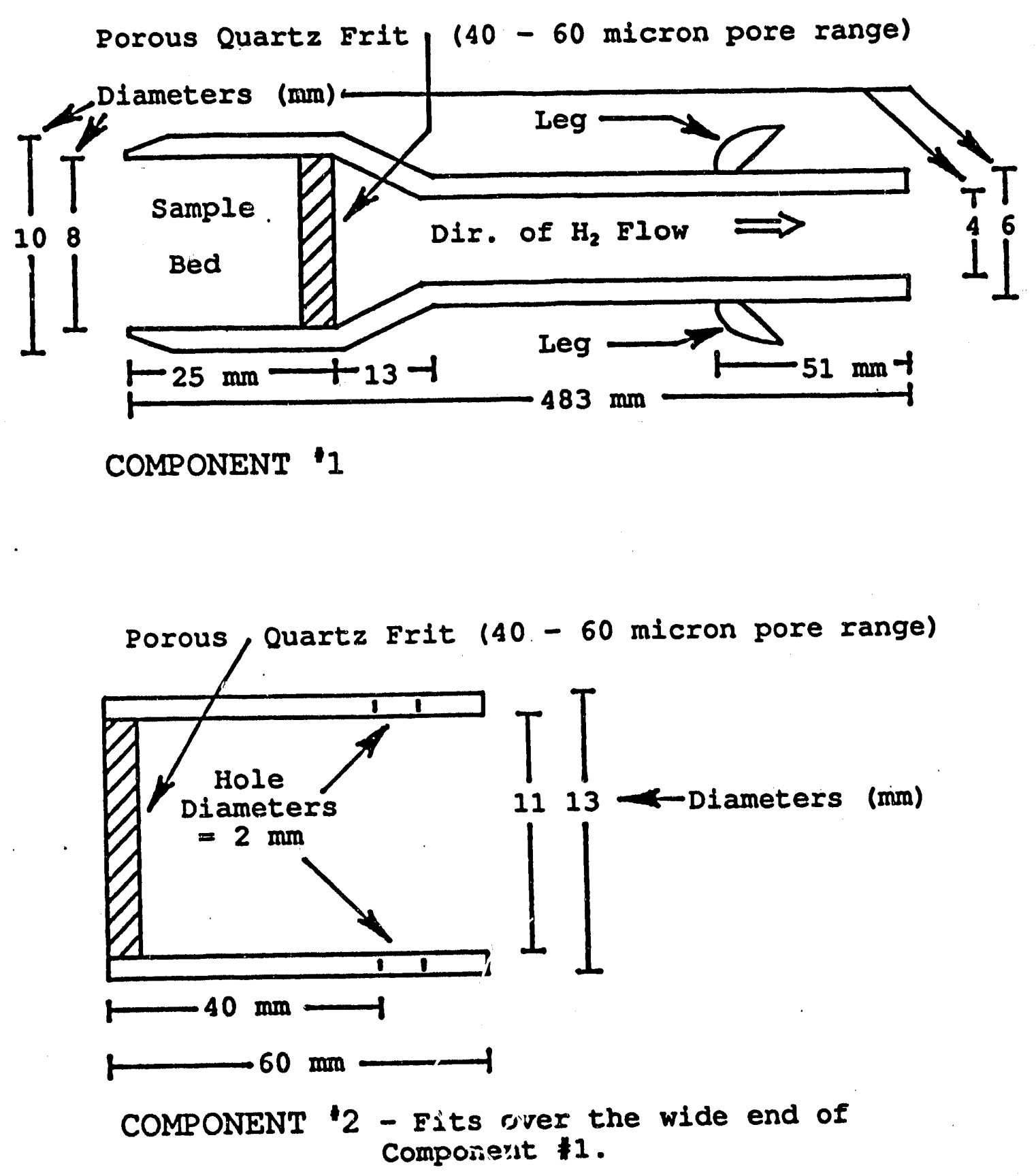

Figure 2: Newly Designed Sample Holder Material of Construction - Quartz (figure not drawn to scale) 
The sample chamber volume is over four times greater than that of the ceramic sample mount, is variable, and does not require metal parts to come in contact with the chars. Insertion of small quartz frits and tubes in the chamber allows sample mass to vary greatly without causing empty spaces in the chamber. The only disadvantage is that chars must be sleved to greater than 200 mesh size so that smaller sampie particles do not clog or pass through the frits. This eliminates roughly half of the prepared char mass that can be used for hydrogasification.

\section{II.5.2 Hydrogasification kinetic experiments}

\subsubsection{Conditions}

All gasification experiments were conducted at $725^{\circ} \mathrm{C}$ and $500 \mathrm{psig}$ under pure hydrogen at a flowrate of $300 \mathrm{cc}(\mathrm{STP}) / \mathrm{min}$ unless otherwise indicated. A temperature of $725^{\circ} \mathrm{C}$ was used because temperatures lower than this result in reaction rates that are too slow, while temperatures higher than this can result in mass transfer limitations for this reaction system. A pressure of 500 psig was used because pressures below this result in slow reaction rates, while pressures above this approach the safety limitations of the reaction vessel, and methane may not remain the greatly favored product [7]. A flowrate of $300 \mathrm{cc}(\mathrm{STP}) / \mathrm{min}$ ensures that fractional conversion of hydrogen will be low enough to observe intrinsic kinetics, and the influence of methane on the reaction can be minimized.

\section{Ii.5.2.2 Procedure}

Samples were weighed and loaded into the reactor which was then purged with helium before gasification. After $15-20$ minutes the reactor was evacuated to $30^{\mathrm{N}} \mathrm{Hg}$ vacuum and the furnace was turned on to a setpoint of $600^{\circ} \mathrm{C}$. Another helium purge was started after the evacuation. During this time the sample traps and gas chromatograph columns were cleaned, then a calibration run was made. The calibration gas used for all runs was $4.8 \% \mathrm{CH}_{4}, 4.9 \% \mathrm{CO}$, $4.9 \% \mathrm{CO}_{2}$, and balance $\mathrm{He}$. The furnace typically reached a temperature of about $525^{\circ} \mathrm{C}$ by the end of the calibration, at which time it was set to $725^{\circ} \mathrm{C}$. The helium purge was stopped, the reactor was filled with hydrogen when it reached a temperature of $600^{\circ} \mathrm{C}$, and the first sample was taken at $650^{\circ} \mathrm{C}$. Most sffluent gas sample collection times were one minute with 15-20 minites between collections, but times varied depending upon the rate of methane formation during a particular reaction. Other procedures varied slightly depending upon gasification temperature, pressure, and intermittent treatments. At the end of a designated time period the furnace and hydrogen were both shut off simultaneousiy, and the reactor was purged with helium for 15-20 minutes and allowed to $\mathrm{cool}$ to room temperature overnight. Most gasifications proceeded for 2.25 hours, but some proceeded longer for higher conversions.

\subsubsection{Outgassing}

Outgassing was used as a pretreatment or an intermittent treatment to remove oxygen functional groups from Saran char and coal char surfaces. This was done to study tho reactivity of the bulk char and the effects of surface annealing. Ten to fifteen grams of sample were set inside the hydrogasification reactor, which was purged with helium. The reactor was then placed under $30^{\circ} \mathrm{Hg}$ vacuum and heated to $1000^{\circ} \mathrm{C}$ for 16 hours, during which vacuum was continuously being applied. It was then followed by another hellum purge. Outgassing was used as a pretreatment or an intermittent treatment for some hydrogasifications. 
The surface of each of the samples was characterized by four analysis techniques. These techniques measured the surface $\mathrm{pH}$, surface oxygen concentration, active surface area, and the total surface area of the chars. Each method is described in the following sections.

\section{II.6.1 pH measurements}

Sample pH determines the general nature of oxygen groups on the char surfaces, le. whether they are acidic or basic. Since the chars are solids at standard conditions, ASTM method D3838-80 is used to determine the sample pH. The procedure is as follows:

1. Immerse the char samples in a 0.1 molar potassium chloride $(\mathrm{KCl})$ solution (approximately $50 \mathrm{mg}$ of char to $20 \mathrm{ml}$ of solution in a $25 \mathrm{ml}$ Erlenmeyer flask). Potassium chloride (KCl) is used because model carbons will generally wet in $\mathrm{KCl}$ when they will not wet in water.

2. Boil the char suspensions under reflux for two hours along with a reference solution of $\mathrm{KCl}$.

3. Cool the solutions to room temperature under reflux. A water bath will speed this process.

4. Measure the sample $\mathrm{pH}$ and final temperature of each solution. Record the Individual $\mathrm{pHs}$ and the changes in $\mathrm{pH}$ between the coal suspension and the standard $\mathrm{KCl}$ solution. The $\mathrm{pH}$ of the solutions were measured using a Fisher Scientific Accumet $950 \mathrm{pH} / \mathrm{ion}$ Meter. The solution temperature at which the $\mathrm{pH}$ was measured was generally $23^{\circ} \mathrm{C} \pm 1^{\circ} \mathrm{C}$. This temperature is important because sample $\mathrm{pH}$ varies with temperature.

The change in $\mathrm{pH}(\Delta \mathrm{pH})$ is more important than individual $\mathrm{pH}$ because $\mathrm{pH}$ of each sample, including the standard $\mathrm{KCl}$ solution, varies with temperature. The $\triangle \mathrm{pH}$ determines if the oxygen groups on the carbon surface are acidic or basic: basic oxygen groups increase the $\mathrm{pH}$ of the $\mathrm{KCl}$ solution and the acidic groups decrease $\mathrm{pH}$ of the $\mathrm{KCl}$ solution.

\subsubsection{X-ray photoelectron spectroscopy}

\section{II.6.2.1 General information}

A Perkin-Elmer Model 5400 PHI X-ray photoelectron spectrometer (XPS) located in the Composite Materials and Structures Center at Michigan State University. XPS is used to study the char surfaces in this study. Specifically, the XPS is used to find the surface oxygen to carbon ratio $(\mathrm{O} / \mathrm{C})$ of char samples and to determine how this ratio changes with different pretreatments. Two types of analysis scans can be performed with the XPS. The first scanning method usually conducted is a survey scan. Survey scans collect and analyze data over a wide range of energy levels to determine all of the different elements present on the char surface. Once the survey scan is complete and the gross surface concentrations of surface elements is known, a multiplex scan is conducted. A multiplex scan is more accurate than a survey scan because it only scans small ranges of energy levels to specifically look for the elements identified during the survey scan. Information on the bonding states of surface elements can be generated from the muitiplex scans. 
- The XPS system hardware has neutralizer control, a monochromated X-ray source (A) source), and an ion gun (04-300). The neutralizer aids in analyzing samples that build-up a high surface charge and the ion gun enables surface spultering to analyze the layers initially under the surface. Also, a Zalar Rotation 8 sample mount with auto-tilt stage control permits multiple sample analysis and angle resolve to limit bulk penetration during the analysis.

The XPS has both a magnesiurn and aluminum $x$-ray source. Early tests used the magneslum source, while the later analysis used the aluminum source which provided a better C1s peak for curve fitting. The magnesium source has an anode energy of $1253.6 \mathrm{eV}$ and an anode power of 400 watts, whereas the aluminum source has an anode energy of $1486.6 \mathrm{eV}$ and an anode power of 600 watts. Both sources have an X-ray voltage of $15 \mathrm{KV}$. The analyzer/detector parameters used in these studies are as follows:

\section{Detector:}

Input Lens:

Omni Focus lens area:

Aperture:

ISS scattering angle (Deg):
Position Sensitive

Omni Focus II

Small

3 or 4

123

\subsubsection{Survey analysis}

The following parameters were used in the survey scans:

$\begin{array}{cl}\text { Upper limit (eV) } & 1000.0 \\ \text { Range (eV) } & 1000.0 \\ \text { Split energy } & 200.0 \\ \text { Resolution - Survey } & \\ \text { eV/Step } & 0.5 \\ \text { 1st scan Time/Step (ms) } & 50.0 \\ \text { 2nd scan Time/Step (ms) } & 200.0 \\ \text { Pass energy (eV) } & 44.7 \\ \text { Acquisition time (Min) } & 10.0 \\ \text { X-ray Anode Mg (W) } & 400.0 \\ \quad \mathrm{Al}(\mathrm{W}) & 600.0\end{array}$

\section{II.6.2.3 Multiplex analysis settings}

The exact settings used for each multiplex run varied depending on the principal elements found during the survey scan. The most common elements scanned and their parameters are given below in Table 2 .

TABLE 2.

Parameters for Multiplex Analyses

Element Name
Acqulsitlon window
Upper limit (eV)
Range (eV)
Resolution
eV/Step
Time/Step (ms)
Pass/Step (eV)
Sweeps

$\begin{array}{lllll}\mathrm{O} & \mathrm{C} & \mathrm{S} & \mathrm{N} & \mathrm{K} \\ 545.0 & 300.0 & 178.0 & 414.0 & 307.0 \\ 20.0 & 20.0 & 20.0 & 20.0 & 20.0 \\ \text { UTIL } & \text { UTIL } & \text { UTIL } & \text { UTIL } & \text { UTIL } \\ .100 & .100 & .100 & .100 & .100 \\ 50 & 50 & 50 & 50 & 50 \\ 35.75 & 35.75 & 35.75 & 35.75 & 35.75 \\ 6 & 6 & 6 & 6 & 6\end{array}$


Curve fitting a multiplexed analysis peak provides : :ome insight into the types of surface functional groups present. Performing a curve fit on the $\mathrm{C} / \mathrm{s}$ peak gives insight into the bonding state of oxygen that is bound to the surface carbon atorns; ie. if the oxygen complexes are phenolic, quinone, or carboxylic type structures. In doing a curve fit, the following analysis assumptions are implemented: the $\mathrm{C} 1 \mathrm{~s}$ curve is asymmetric with a $90 \%$ gaussian shape, the background is integrated, the full width/half mast (FWHM) setting is 1.3, all invariance settings are preset to zero, and the lateral movement of the peaks is severely limited. A broad peak signifies oxygen groups bound to the carbon surface and a narrowing of the peak indicates a decrease in the amount of carbon-oxygen bonds.

\subsubsection{Sample preparation and transfer}

\section{A. SAMPLE MOUNTING}

Prior to XPS analysis, char samples must first be secured to a sample mount sultable for use in both the vacuum pretreatment reactor (VPR) and the XPS instrument. Different methods of securing the samples to the XPS sample mounts were used in the analyses. In earlier work, Treptau [48] formed carbon black samples into pellets using a hydraulic press; however, neither the coal char nor the Saran char would form a pellet. A nitrogen glove box was used to transfer some samples to an XPS sample mount after outgassing; however, XPS analysis showed that oxygen contamination occurred during the transfer. Two methods were useful in securing the samples.

The first method uses standard double-sided tape to mount the chars on the sample mounts. This method limits the outgassing temperature that the chars can be heated in the vacuum pretreatment reactor to $120^{\circ} \mathrm{C}$ because the mounting tape will melt at higher temperatures. The procedure is as follows:

1. Preheat Scotch brand mounting tape to $120^{\circ} \mathrm{C}$ in an oven to preshrink it prior to mounting the sample.

2. After preshrinking the tape, transfer it to the sample mount and press a char sample into the tape, covering a $1.4 \mathrm{~cm}^{2}$ area.

3. Introduce the sample mount into the VPR and heat it to $120^{\circ} \mathrm{C}$ under vacuum for four hours.

The second method for mounting the sample, used for high temperature runs $\left(200^{\circ} \mathrm{C}\right.$ to $800^{\circ} \mathrm{C}$ ), involves using a high temperature adhesive (AREMCO 503) to secure the sample onto the mount. To prevent the adhesive from permanently adhering to the sample mounts, it was first mounted on thin strips of tungsten which were then secured to the sample mounts. The high temperature mounting procedure is as follows:

1. Cut a $0.5 \mathrm{~cm}$ by $1.3 \mathrm{~cm}$ strip of tungsten and cover the strip with a $1 \mathrm{~mm}$ thick layer of adhesive. Allow the adhesive to dry in air for one hour at room temperature.

2. Press the sample into one side of the adhesive and cure it for four hours at $120^{\circ} \mathrm{C}$ in a furnace.

3. When the samples are finished curing, attach them to the XPS mount using a tungsten mask and transfer the mount to the vacuum pretreatment reactor. 
XPS analysis of samples mounted with the adhesive showed a larger amount of surface oxygen than the samples mounted on the tape. This analysis also showed a large amount of phosphorous on the surface. Since there is no significant concentration of phosphorous in the chars, the XPS is detecting phosphorous from the adhesive that either migrates to the sample or is exposed in the gaps between char particles. If the XPS scan is analyzing the adhesive through gaps in the char layer, it will record an incorrectly high oxygen concentration, as the adhesive surface is composed of about $60 \%$ oxygen. If the increase in phosphorous is due to migration, then oxygen will also likely migrate from the adhesive, causing artificially high surface concentrations.

To account for the increased oxygen content resulting from the adhesive, char samples were analyzed together with uncovered adhesive to determine a ratio of phosphorous to oxygen on the adhesive. This ratio was used to correct the surface oxygen on the char sample by multiplying the ratio of oxygen to phosphorous on the adhesive by the concentration of phosphorous found on the sample.

\section{B. VACUUM PRETREATMENT REACTOR}

Prior to XPS analysis, a vacuum pretreatment reactor (VPR) is used to outgas the weakly physisorbed surface contaminants. The VPR also can be used to profile the desorption of surface oxygen from the sample by analyzing samples outgassed at increasingly higher temperatures up to the hydrogasification temperature.

Treptau [48] designed and built the original VPR and he gives a complete description in his dissertation. The VPR can maintain a vacuum less than $1 \times 10^{-8}$ Torr at $25^{\circ} \mathrm{C}$ or heat samples to $1000^{\circ} \mathrm{C}$ at pressure up to atmospheric.

Several changes were made to Treptau's design for this study. First, a $6^{n} \times 18^{n}$ stainless steel tube, open at both ends, replaced the original furnace chamber. The thermocouple and heater feedthrough now enters one end of the furnace chamber, while samples are introduced into the other end. The design changes eliminates a snagging problem caused by the sample mount catching on thermocouple and heater element lines when both are introduced into the same end of the furnace. Second, stainless steel interior heat shields replaced the original nickelchrome alloy shields, but the shield configuration remains unchanged. The new heat shields reduce the heat transfer to the external surface of the reactor. The external surface temperature did not exceed $140^{\circ} \mathrm{C}$ even after several hours of heating at a furnace temperature of $850^{\circ} \mathrm{C}$. Previously, the external temperature would approach $200^{\circ} \mathrm{C}$ within six hours. The new reactor configuration is shown in Figure B.2.

\section{SAMPLE HEATING AND TRANSFER}

Once the chars were mounted on the VPRIXPS sample mount, they were introduced into the VPR and heated under vacuum for four hours. For normal XPS analyses, char samples were heated to $120^{\circ} \mathrm{C}$. Higher temperatures were used in studies of outgassing. The initial pressure during heating was generally $5 \times 10^{-6}$ Torr, but after heating for just two hours, the pressure was usually less than $9 \times 10^{-7}$ Torr. After cooling and pumping overnight, the system pressure was generally less than $1 \times 10^{-8}$ Torr, the lowest pressure that the system could record.

The transfer to the vacuum transfer vessel occurred at pressures less than $5 \times 10^{-8} \mathrm{Torr}$; however, the vacuum transfer vessel can only maintain pressures at approximately $1 \times 10^{-4}$ Torr. The vacuum transfer vessel was used to transfer and introduce the sample into the XPS. The XPS introduction pressure was generally $2 \times 10^{-7}$ Torr and the analysis pressure was generally less than $4 \times 10^{-8}$ Torr. 


\section{II.6.3 Active Surface Area Measurement}

The measurement of active surface area of carbon samples is accomplished by oxygen chemisorption. The ASA of each sample was determined by first outgassing it at the hydrogasification temperature in hellum to prevent any combustion or oxidation of the char surface. The gasification temperature of $725^{\circ} \mathrm{C}$ was used because this will determine the ASA avallable during reaction, but not necessarily the total ASA. Outgassing at higher temperatures and for longer periods of time may lead to higher ASA; however, the additional area would not available during hydrogasification and would not be a good indicator of sample reactivity. The ASA experiments consist of carefully outgassing the char surface, then chemisorbing oxygen onto the active surface area. Detalls of each step are given in the following sections.

\section{II.6.3.1 Sample outgassing}

The sample surface must be "cleaned" prior to determining the active surface area (ASA). This is done by heating the sample under high purity helium to remove the bound surface oxygen which occupies the active sites constituting the ASA. It is extremely important to prevent exposure of the sample to oxygen during outgassing, which could lead to active site reduction and low ASA measurements. This is especially important while the sample is at a high temperature because oxygen chemisorption is an activated process.

Several methods were used to outgas char samples and transfer them to the oxygen chemisorption apparatus. The first method used a separate pretreatment furnace to outgas char samples. The furnace has two 525 Watt Mellen (clam shell) tubular heaters (Model 12-200) which have a maximum temperature of $1200^{\circ} \mathrm{C}$. High temperature firebrick encases the heaters; the sample tube enters through an opening in the top brick. An Omega Series $\mathrm{CN}-2010$ programmable temperature controller and a K-type thermocouple control the ramp and soak temperatures. A helium flow rate of $10 \mathrm{cc} / \mathrm{min}$ prevents the sample from oxidizing as it heats to the soak temperature. The helium was Linde Ultra High Purity $(99.999 \%$ pure). The method used to outgas and transfer the sample using the pretreatment furnace is as follows:

1. Insert the sample into the sample tube and weigh it with the end stoppers and support cup. The amount of sample varies with the ASA of the sample. Generally, $50 \mathrm{mg}$ of coal char and $100 \mathrm{mg}$ of Saran char is sufficient to determine the ASA. A small Styrofoam cup is used to hold the sample tube upright on the balance, which eliminates weighing errors caused by the sample tube extending over the edge of the weighing pan.

2. Attach the sample tube to the furnace and pass helium over the sample to purge the tube of air.

3. Heat the sample to the specified pretreatment temperature at $5^{\circ} \mathrm{C} / \mathrm{min}$ and hold for 30 minutes. Quench the sample to room temperature, remove the downstream tube connection and plug the end with a stopper. This permits helium to flow over the sample while it is being removed. Quenching is extremely important because oxygen chemisorption is an activated process, which occurs extremely slowly at room temperature.

4. Remove the upstream tube connection and quickly plug the end. Weigh the sample tube, stoppers, and cup to find the in al sample weight for the ASA measurement. 
5. Attach the sample tube to the chemisorption apparatus and purge the tube with helium to remove any air that may have entered during the transfer.

6. Conduct the ASA measurement using the procedure described in Section 3.3.3.3.

In the second outgassing method, samples were heated under vacuum instead of helium in a special sample tube which permitted the transfer to the chemisorption apparatus while maintaining the vacuum. The sample tube is a large U-tube with two three-way stopcocks which form a bridge between the two sides of the U-tube. Closing the stopcocks seals the sample so It can be weighed and transferred without exposure to air. Before opening the stopcocks, the bridge is purged of air using the carrier gas from the chemisorption apparatus. When the bridge is purged, the stopcocks are opened and the sample is exposed to hellum.

This method had two problems. First, the vacuum tended to pull the sample out of the sample tube. This was prevented by plugging the tube ends with glass wool. The second problem was sample contamination. The vacuum must have pulled air into the sample tube because the ASA measured by this method were much smaller than those measured using the first method.

The third method used was similar to the first, except that the sample was in a special extended U-tube attached to the chemisorption apparatus directly. This special U-tube eliminated the need to transfer the sample and was configured to prevent the high outgassing temperatures from damaging the apparatus. This third method also enable appears to be the method of choice for continuing chemisorption studies.

\section{II.6.3.3 Oxygen chemisorption}

A Micromeritics Pulse Chemisorb 2700 was used to determine the active surface area using oxygen chemisorption. The Pulse Chemisorb 2700 determines the amount of oxygen that chemisorbs onto the char surface by injecting a known volume of oxygen over the sample and measuring the amount of oxygen that exits the system (the oxygen volume can be varied by changing the injection loop size). The apparatus reads the difference in thermal conductivity between the oxygen pulse and a carrier gas and reports this difference as an electronic signal which is read by an LED meter and a chart recorder. The meter reading is used to determine the volume of oxygen that by-passes the sample, which is then subtracted from the total amount injected to give the amount of oxygen adsorbed.

The complete apparatus consists of a Micromeritics Pulse Chemisorb 2700 with model 2300 FC flow controller, a Sargent strip chart recorder with an electronic integrator, and Linde ultra high purity $(99.999 \%)$ gas cylinders of helium, oxygen, and nitrogen.

The chemisorption temperature for most of the runs was $295^{\circ} \mathrm{C}$. This temperature was high enough to activate the chemisorption process, yet not cause any significant combustion of the char. A makeshift gas chromatograph (GC) was inserted downstream of the apparatus in several experiments to determine if any combustion occurred during the oxygen chemisorption. The GC consisted of a $1 / 8$ by 18 inch column with Spherocarb $100 / 120$ mesh packing placed in a $90^{\circ} \mathrm{C}$ water bath. The chemisorption procedure was conducted as follows:

1. Outgas the sample using one of the methods described in Section 3.3.3.1.

2. Pass hellum over the sample at $10 \mathrm{cc} / \mathrm{min}$ using the mass flow controller until the detector meter stops fluctuating. This ensures that all gas contaminants are removed from the U-tube prior to heating. 
3. Heat the sample to the chemisorption temperature $\left(295^{\circ} \mathrm{C}\right)$. Zero the detector meter and peak area signal meter, set the sensitivity to $10 \mathrm{X}$, the relative condition to negative, and wait until the system comes to steady state.

4. Inject a pulse of oxygen into the stream flowing over the char. In most experiments, oxygen pulse size was $0.047 \mathrm{cc}$. Leave the injection lever in the "inject" position.

5. When the detector finishes sensing the peak and the meter reading returns to zero, record the peak area. Continue subsequent injections until there is no change in peak area for several injections. This ensures that the active sites are saturated with oxygen and the procedure is complete. Usually, about 15 injections are sufficient to saturate the char surface with oxygen.

6. Find the volume of oxygen adsorbed on the sample and the active, surface area using the following equations:

a. For each injection:

$$
\underset{\text { injected }}{\text { Volume } \mathrm{O}_{2}-\text { (peak area) }^{\star} \mathrm{K}=}=\begin{aligned}
& \text { Volume } \mathrm{O}_{2} \\
& \text { adsorbed }
\end{aligned}
$$

Where: $K=$ peak correlation factor

$$
K=\frac{\mathrm{O}_{2} \text { Volume injected }}{\text { Max Peak Area }}
$$

b. Sum the volumes of $\mathrm{O}_{2}$ adsorbed for each injection and convert the total volume to standard conditions.

c. Determine the active surface area by the following equation:

$$
A S A=\frac{\left(V_{\text {ep }}\right) \cdot(M)}{\text { (wolght of sample) }}
$$

Where:

$$
V_{\text {atp }}=\text { Volume } \mathrm{O}_{2} \text { adsorbed at STP. }
$$

$M^{\text {atp }}=$ Area covered by one cc of oxygen $\left(4.37 \mathrm{~m}^{\wedge} 2 / \mathrm{ml} \mathrm{O}_{2}\right)$

\subsubsection{Total Surface Area Measurement}

\section{II.6.4.1 Carbon dioxide physisorption}

Surface areas determined by nitrogen and $\mathrm{CO}_{2}$ adsorption differ in carbons possessing ultra-fine structures (pores with entrances less than $4.2 \AA$ ). Nitrogen is unable to diffuse through the small openings at $77^{\circ} \mathrm{K}$ in a reasonable time, making analysis difficult. The use of $\mathrm{CO}_{2}$ at higher temperatures is much more likely to give accurate results than nitrogen at $77^{\circ} \mathrm{K}$. $\mathrm{A}$ temperature of $273^{\circ} \mathrm{K}$ or $293^{\circ} \mathrm{K}$ is better than $195^{\circ} \mathrm{K}$ for CO2 physisorption [51] because adequate isotherm coverage at can take weeks at $195^{\circ} \mathrm{K}$, but takes less than a day at $273^{\circ} \mathrm{K}$ or $293^{\circ} \mathrm{K}$. Past researchers [51] compared the applicability of the Dubinin equation versus BET theory for 
surface area measurements of carbon samples, and found that the Dubinin equation gives a better representation of the surface area of carbons than the BET equation.

Carbon dioxide physisorption at $293^{\circ} \mathrm{K}$ was conducted in a Sartorius Model 4436 Electronic Microbalance to find total char surface area. The apparatus consists of the microbalance, a Heath-Zenith model SR-20R strip chart recorder, a vacuum pump (CencoMegaval GM-1917), and assorted pressure gauges. Figure 3.2 shows the complete system.

Prior to analysis, chars were outgassed under vacuum at $150^{\circ} \mathrm{C}$ in the balance to remove water and other weakly bound contaminants which occupy some of the pore volume. These contaminants cause erroneously low surface areas if they are not removed.

The basic procedure for determining the total surface area is as follows:

1) Fill the quartz sample boat with approximately $50 \mathrm{mg}$ of char.

2) Load sample boat onto the microbalance, seal the system (close valves $1,2,3$, and 5) and wait until the balance stabilizes (2-4hr).

3) Start the vacuum pump and zero the balance.

4) Open valve \#3 slowly to pump down the system. When the pressure is less than 1 torr, heat the sample to $150^{\circ} \mathrm{C}$. When the sample stops losing weight (approximately 30 minutes), quench the sample to room temperature in a water bath.

5) When the temperature stabilizes $\left(18-22^{\circ} \mathrm{C}\right)$, close valve \#3, record the total char weight loss and the bath temperature, and rezero the balance.

6) Open valve \#1 slowly to add $\mathrm{CO}_{2}$ to the system in predetermined pressure increments. Record the total weight gain of the sample at each pressure. Typical pressures at which readings were taken are: 200,500, 1000, and 1500 torr and 30 and 50 psig.

7) When the system pressure reaches 1500 Torr, close valve \#4 and open valve \#5 to take the high pressure readings.

8) When all readings are complete, slowly open valve \#2 to vent the system. Open the system and replace the sample.

The Dubinin-Radushkevitch method was used to analyze the data and find the sotal surface area. A brief description of the method follows:

1. Find the monolayer volume $\mathrm{W}_{0}$ of the $\mathrm{CO}_{2}$ adsorbed on the sample by plotting log $W$ versus $\log ^{2}\left(P_{0} / P\right)$ and locating the intercept $\left(\log W_{0}\right)$.

$$
\log W=\log W_{0}+\log ^{2}\left(P^{\circ} / P\right)
$$

Where:

$$
\begin{aligned}
& W=\text { Volume of } \mathrm{CO}_{2} \text { adsorbed on sample } \\
& W_{0}=\text { Monolayer volume of } \mathrm{CO}_{2} \text { adsorbed (micropore volume) } \\
& P^{\circ}=P_{\text {Pressure corresponding to sample weight }} \\
& P^{\circ}=\mathrm{CO}_{2} \text { saturation pressure. }
\end{aligned}
$$


2. Find the total surface area $\left(\mathrm{m}^{\wedge} 2 / \mathrm{g}\right)$ of the sample. In this calculation it is assumed that one $\mathrm{CO}_{2}$ molecule occupies $16.3 \AA^{2}$ on the carton surface and the liquid density of $\mathrm{CO}_{2}$ is $1.9768 \mathrm{mg} / \mathrm{ml}$ ).

\subsubsection{Nitrogen physisorption}

The Pulse Chemisorb 2700 can also be used to determine the total surface area of a sample via nitrogen physisorption. A suggested procedure follows:

1. Prepare sample by heating to $120^{\circ} \mathrm{C}$ under hellum for 30 minutes and then quench to room temperature.

2. Set nitrogen/helium mixture $5 \%$ nitrogen $/ 95 \%$ hellum.

3. Set relative condition to positive and zero peak area meter.

4. Place liquid nitrogen bath around the sample and take peak area reading when counting stops.

5. Set relative condition to negative and zero peak area meter.

6. Remove liquid nitrogen bath and place a room temperature water bath around the sample to desorb the nitrogen.

7. Take peak area reading whon the counting stops.

8. Repeat the procedure at higher nitrogen concentrations, usually $10 \% \mathrm{~N}_{2}$ and $20 \%$ $N_{2}$

9. Calculate the B.E.T. surface area using the same standard BET equations. 


\section{RESUL.TS OF GASIFICATION EXPERIMENTS}

Results of primary gasification experiments are presented in this section. Results of surface analyses and additional gasification experiments which support particular hypotheses or which aid in interpretation are presented in the Discussion (Section IV) which follows.

After establishing that kinetic rate measurements were dominated by reaction and not mass transfer, the effects of outgassing, preoxidation, and intermittent oxidation are reported. Following these, results at lower temperature, rates following hydrogen pretreatment, and effects of catalyst addition are given.

\section{III.1 Effect of Temperature}

Figure 3 contalns rate data on the hydrogasification of coal char at $7 \%$ conversion. Temperature varies from $800^{\circ} \mathrm{C}$ at the far left to $700^{\circ} \mathrm{C}$ by increments of $25^{\circ} \mathrm{C}$. A conversion of $7 \%$ was chosen because the reaction does not reach steady state until $6 \%$ conversion at $800^{\circ} \mathrm{C}$, and conversions higher than $7 \%$ do not give as large a separation between rate data points because of the rapid deactivation of the reaction. The maximumi temperature at which diffusion limitations do not affect the reaction rate is $775^{\circ} \mathrm{C}$. The temperature of all hydrogasifications performed in this investigation was at or below $725^{\circ} \mathrm{C}$ to remain well within kinetic rate limitations. The activation energy based on a slope which excludes the data point on the far left is 76 $\mathrm{kcal} / \mathrm{mol}$ carbon, which is close to values reported for intrinsic gasification rates by other investigators [17,18].

\section{III.2 Base Case Char Reactivity}

Hydrogasification rate is shown as a function of carbon conversion in Figure 4 for Saran char and three coal chars. The Saran char and coal char were just pyrolyzed, while the other coal chars were demineralized. The Saran char has been gasified for 8 hours. The coal char and Demin. II coal char have both been gasified for 9 hours, while the Demin. I coal char has been gasified 2.25 hours. Rate is reported as cubic centimeters of methane (STP) per minute per gram carbon present. All chars react at similar rates and have similar rate decay patterns. The Demin. II char rate curve is shifted outward slightly frorn the others. This may be due to residual effects of $\mathrm{HNO}_{3}$ oxidation [48] that survived pyrolysis, or a greater amount of active surface area exposed by the removal of ash particles.

\section{III.3 Outgassing}

\section{III.3.1 Saran char}

The effect of outgassing on the hydrogasification rate of Saran char is shown in Figure 5. The 8 hour base case run was not pretreated, but has been included as a basis for comparison. The outgassed Saran char was gasified for 4 hours, at a rate that was about an order of magnitude less than the base case Saran Char. The intermittent treatment consisted of a flash desorption to $1000^{\circ} \mathrm{C}$ for 15 minutes in helium under a $30^{\prime \prime} \mathrm{Hg}$ vacuum after 2.25 hours of gasification. This treatment decreased the reaction rate of the Saran char to about $1 / 5$ the rate of the base case.

\section{III.3.2 Coal char}

The effect of outgassing on the hydrogasification rate of coal char is shown in Figure 6 , and the results are similar to those of Saran char. The outgassed coal char reacted at a rate 


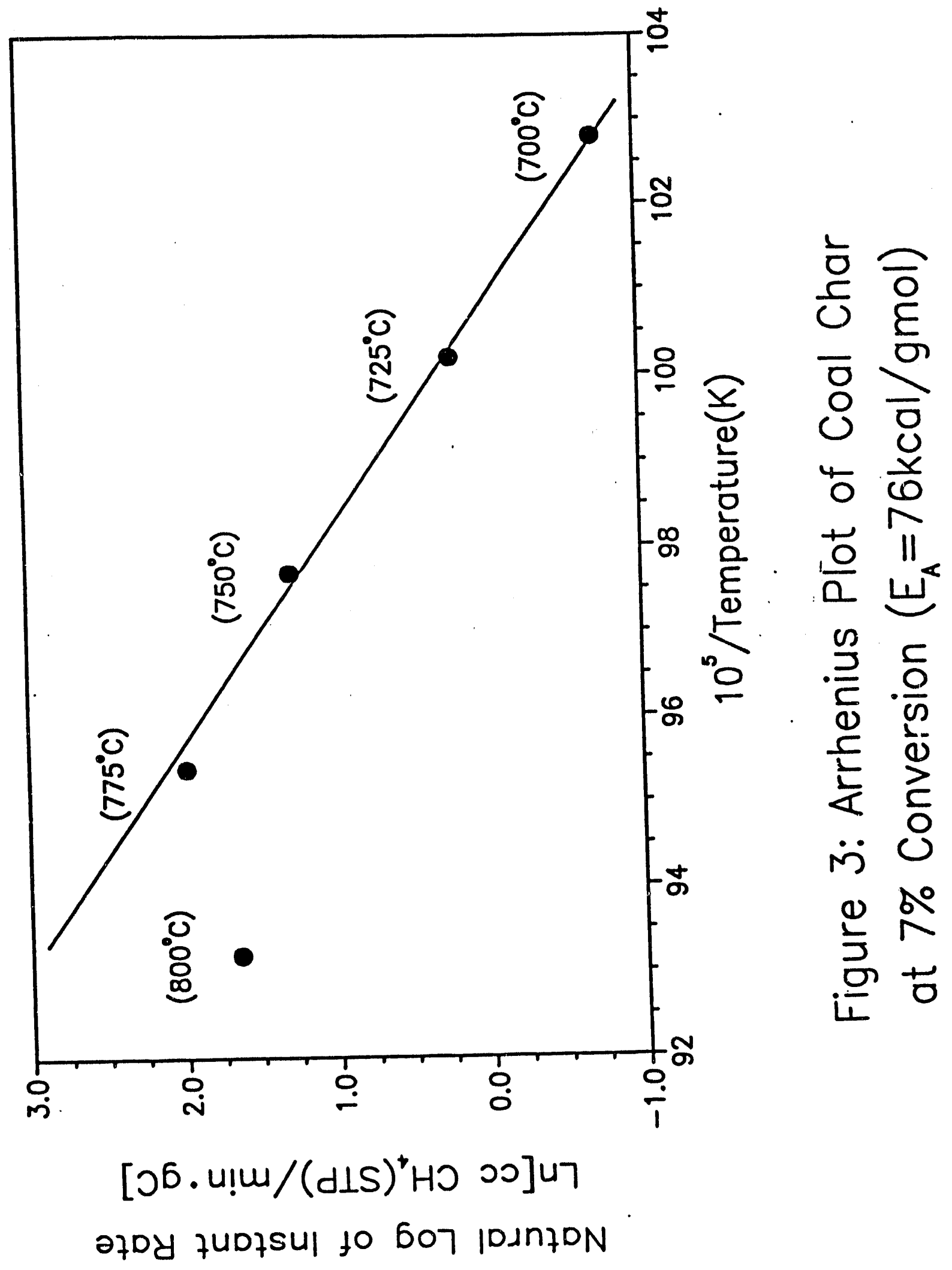




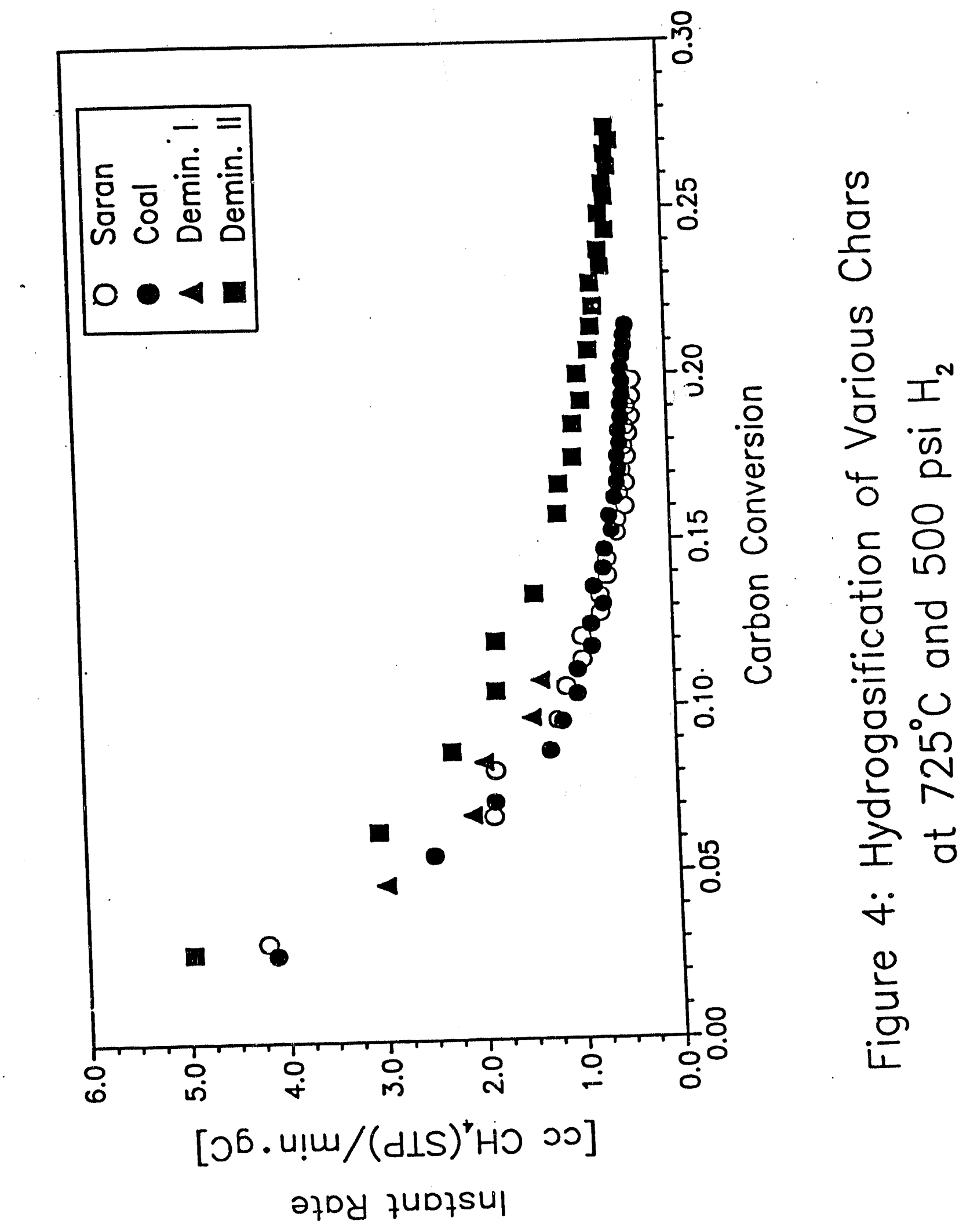




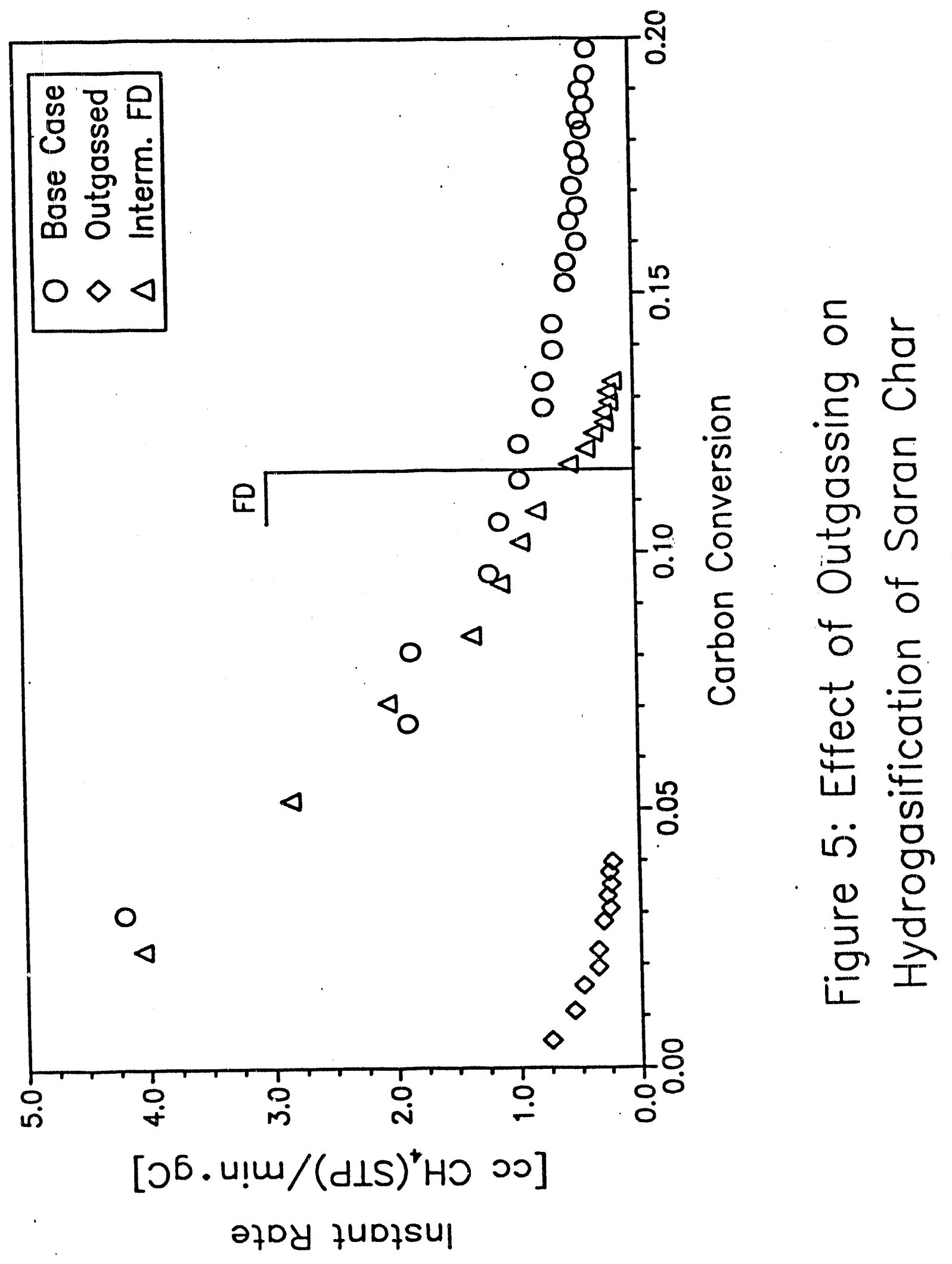




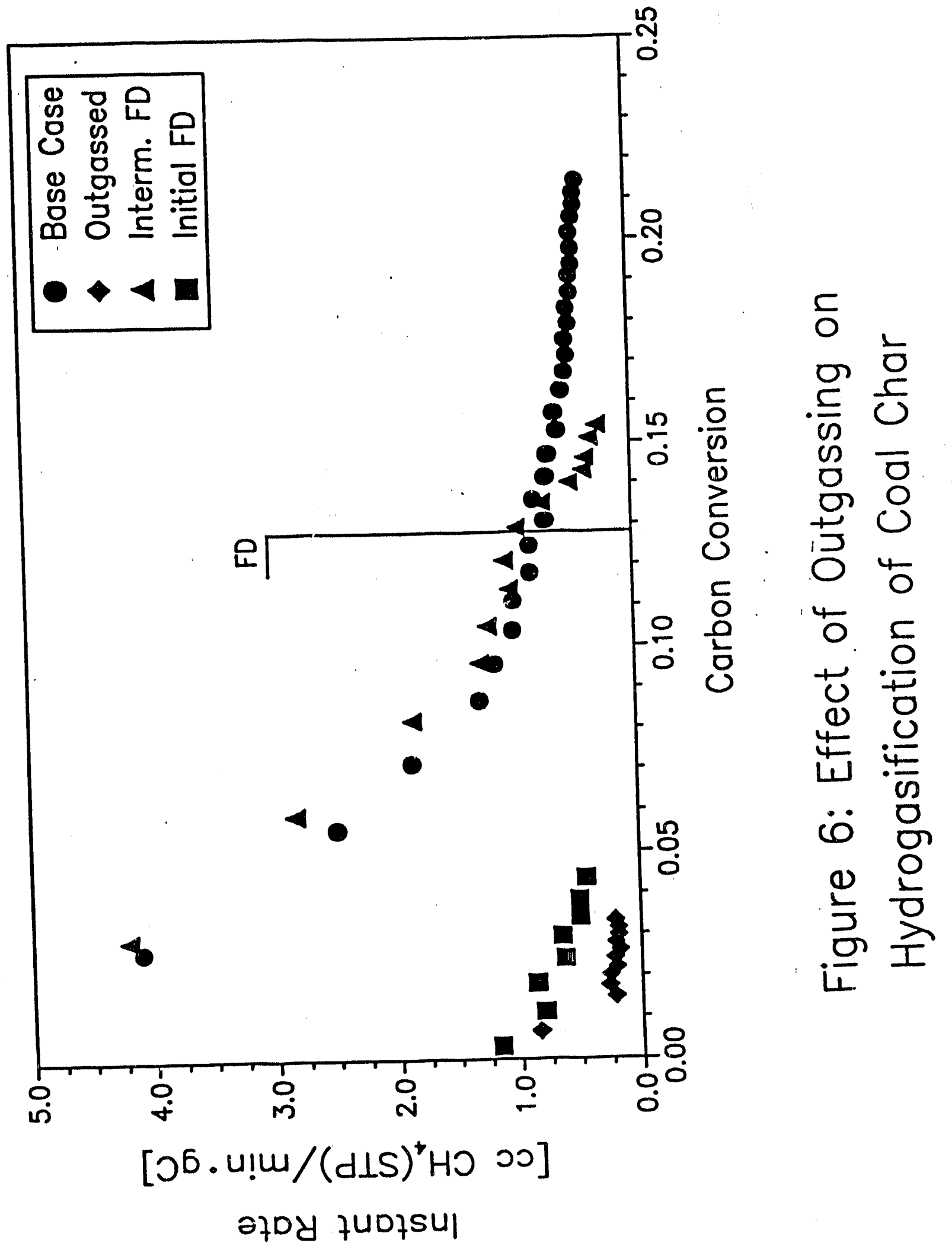


which was an order of magnitude less than the base case, and the intermittent flash desorption decreases the reaction rate to about half that of the base case.

\section{III.4 Oxidative Treatments}

\section{III.4.1 Oxidative pretreatment by partial combustion in air}

Figures 7 and 8 show the results of oxidative pretreatment of various chars by partial combustion in air. Figure 7 shows percent weight loss of chars as a function of the length of time they have been exposed to flowing air at $375^{\circ} \mathrm{C}$. The percent weight loss is a weighted average of all five trays which contain char during oxidation. The relationship between time of air flow and percent weight loss appears to be fairly linear over the range of data present. Figure 8 shows the same six partial oxidation runs, but the percent weight loss for each run is broken down into Individual trays. The trays were numbered in order from one to five and arranged so that the direction of air flow was always from tray " 1 to tray " 5 . Most plots are parabolic in shape, with maxima at tray " 3 . This results from the parabolic temperature profile within the heated zone of the furnace.

\section{III.4.1.1 Saran char}

Figure 9 gives the effects of oxidative pretreatments on the hydrogasiflcation rates of Saran char. Two samples were partially oxidized in air at $375^{\circ} \mathrm{C}$. One lost $3.1 \mathrm{wt} \%$ upon partial combustion, while the other lost $7.7 \mathrm{wt} \%$ because it was burned longer. The rate curves may be shifted slightly, but there was basically no observable enhancement in gasification rate at $725^{\circ} \mathrm{C}$ resulting froni these pre-oxidations. The other sample was first outgassed, then oxidized in air at $375^{\circ} \mathrm{C}$ before hydrogasification. The outgassed Saran char sample that was not preoxidized is included as a basis for comparison. The rate of the outgassed, then preoxidized sample was several times lower than the base case, but was 2-3 times higher than the outgassed sample.

\section{III.4.1.2 Coal char}

The effects of oxidative pretreatment upon the hydrogasification rates of coal char can be seen in Figures 10 and 11. The first oxidation method used was partial combustion in air at $375^{\circ} \mathrm{C}$ for two different time periods. Weight losses were $0.1 \mathrm{wt} \%$ and $5.7 \mathrm{wt} \%$ during oxidation. The second method was partial combustion in air at $725^{\circ} \mathrm{C}$ to $3.7 \mathrm{wt} \%$ burnoff. The third was an oxygen chemisorption, while the fourth was an outgassing followed by a partial combustion in air at $375^{\circ} \mathrm{C}$. As with Saran char, preoxidation of coal char did not result in any observable rate enhancement at $725^{\circ} \mathrm{C}$. The sample that had been outgassed and then preoxidized in air at $375^{\circ} \mathrm{C}$ did show some hydrogasification rate enhancernent over the coal char that had just been outgassed, but the enhancement was not as great as that of the Saran char.

\section{III.4.1.3 Demineralized coal char}

The effect of oxidative pretreatment on the hydrogasification rate of coal char demineralized via Method I is shown in Figure 12, and via Method II in Figure 13. All pretreated samples were partially reacted in air at $375^{\circ} \mathrm{C}$ for varying lengths of time. Neither of the demineralized coal chars show measurably enhanced rates at $725^{\circ} \mathrm{C}$ from oxidative pretreatment.

\section{III.4.2 Other oxidative pretreatments}

Two oxidative pretreatments were used other than partial oxidation in air in order to study 


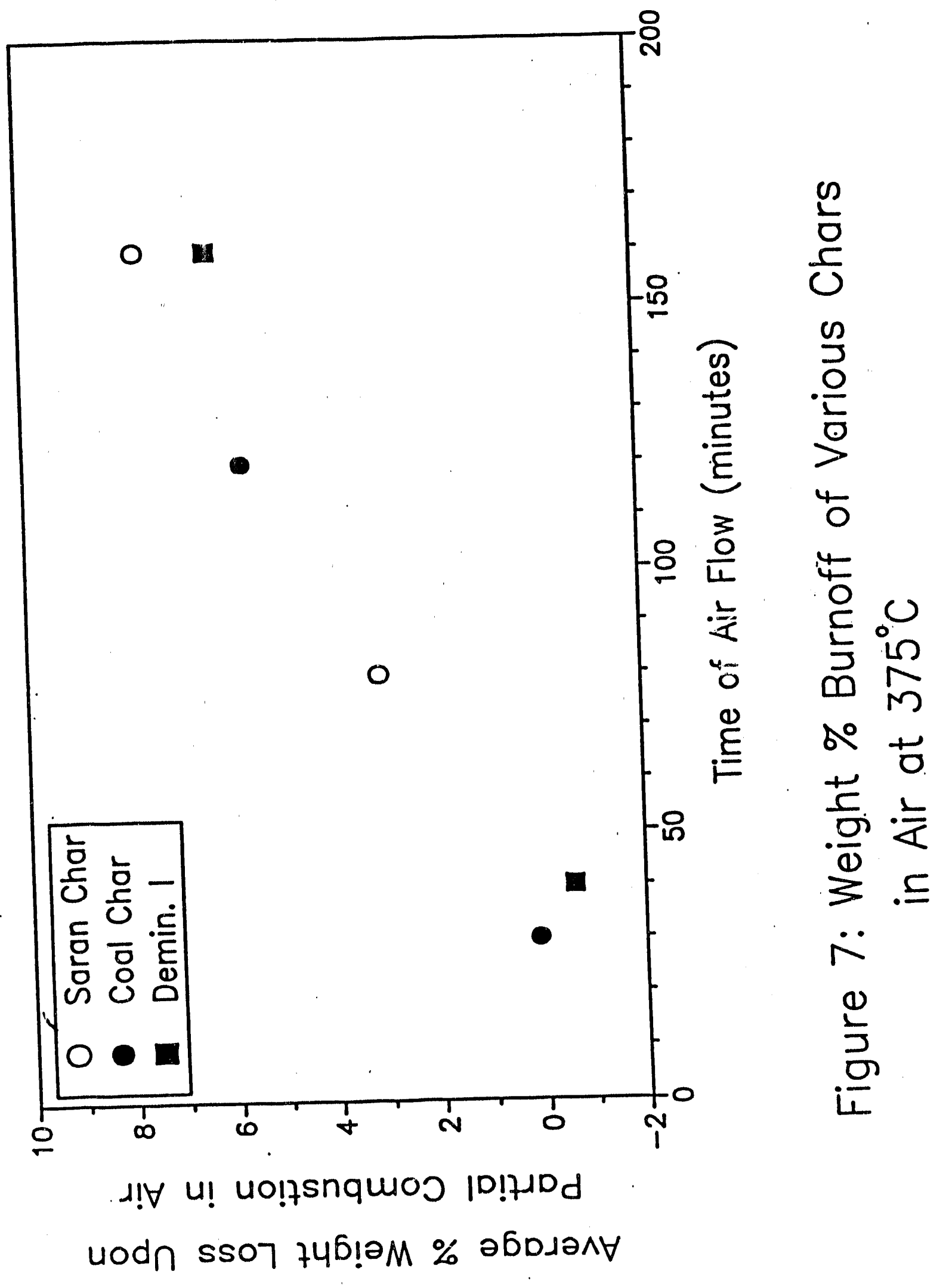




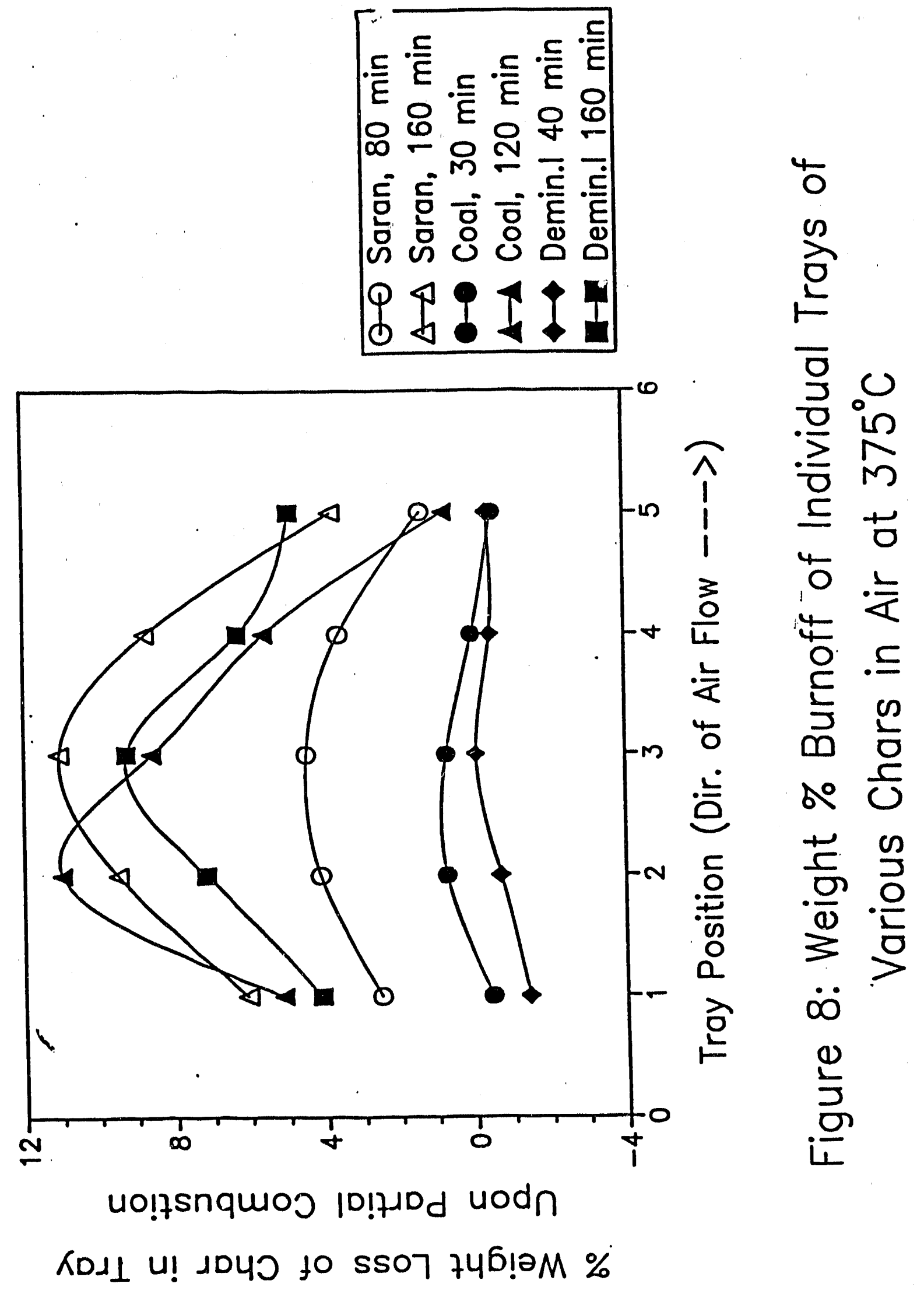




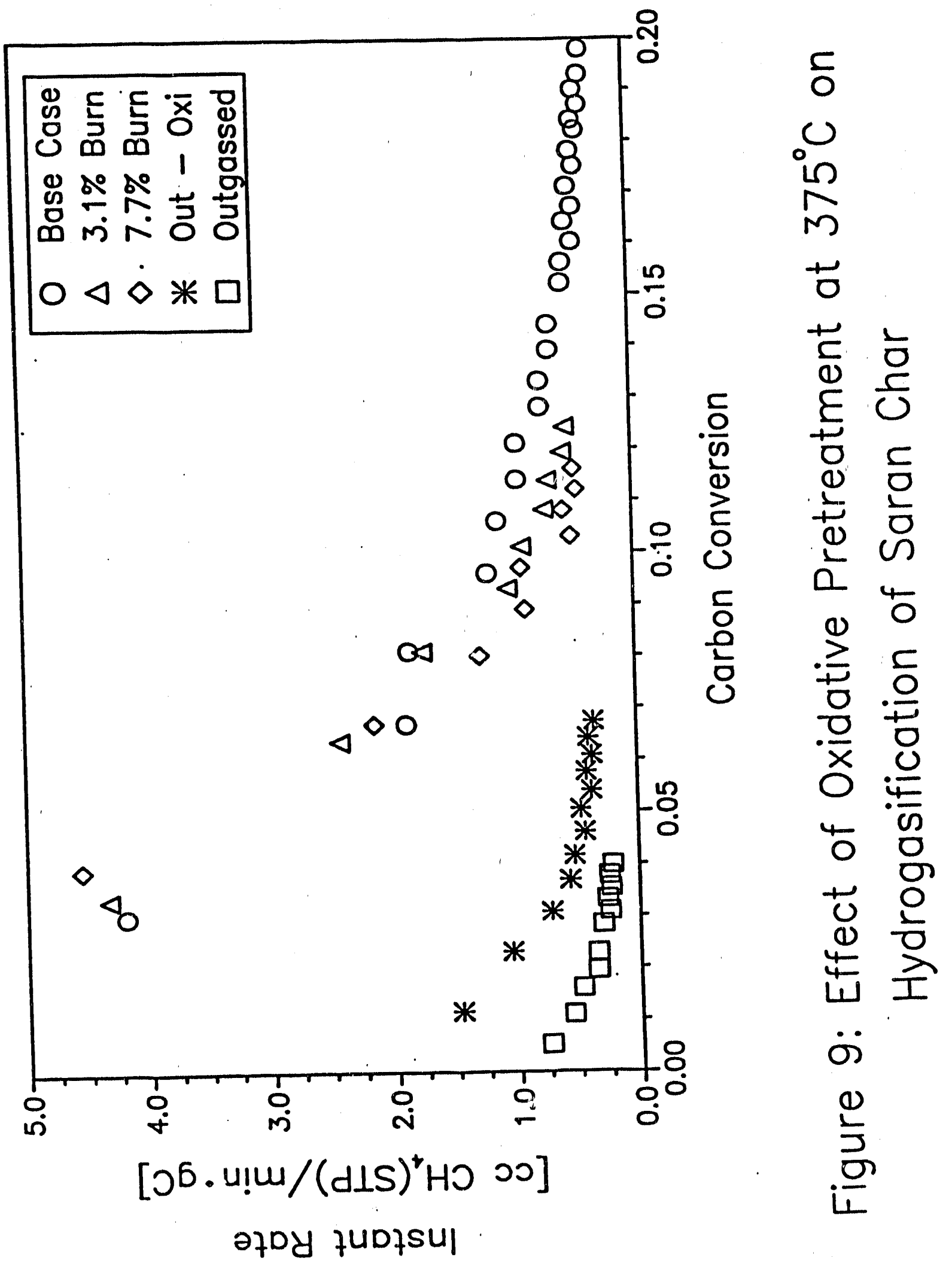




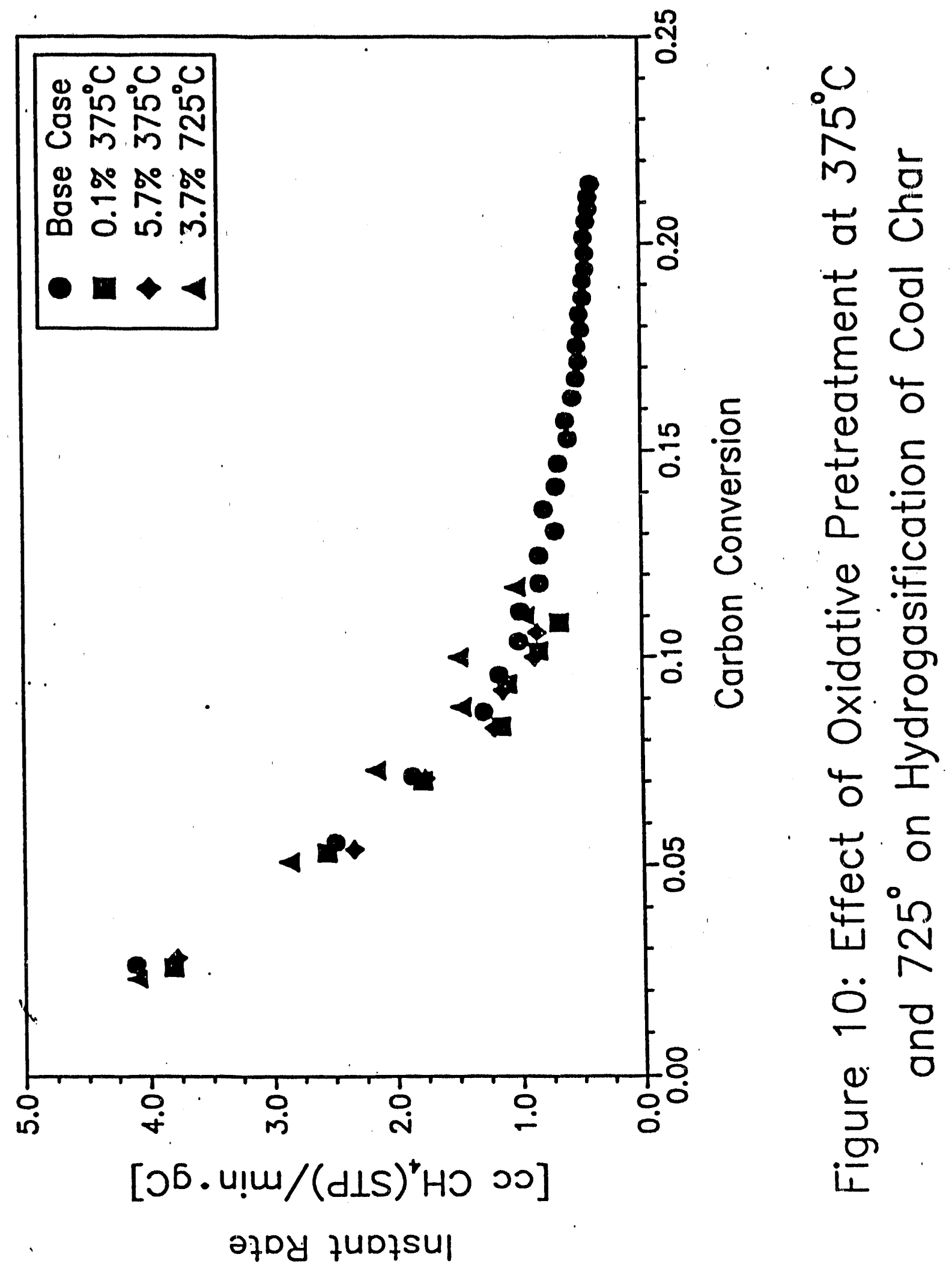




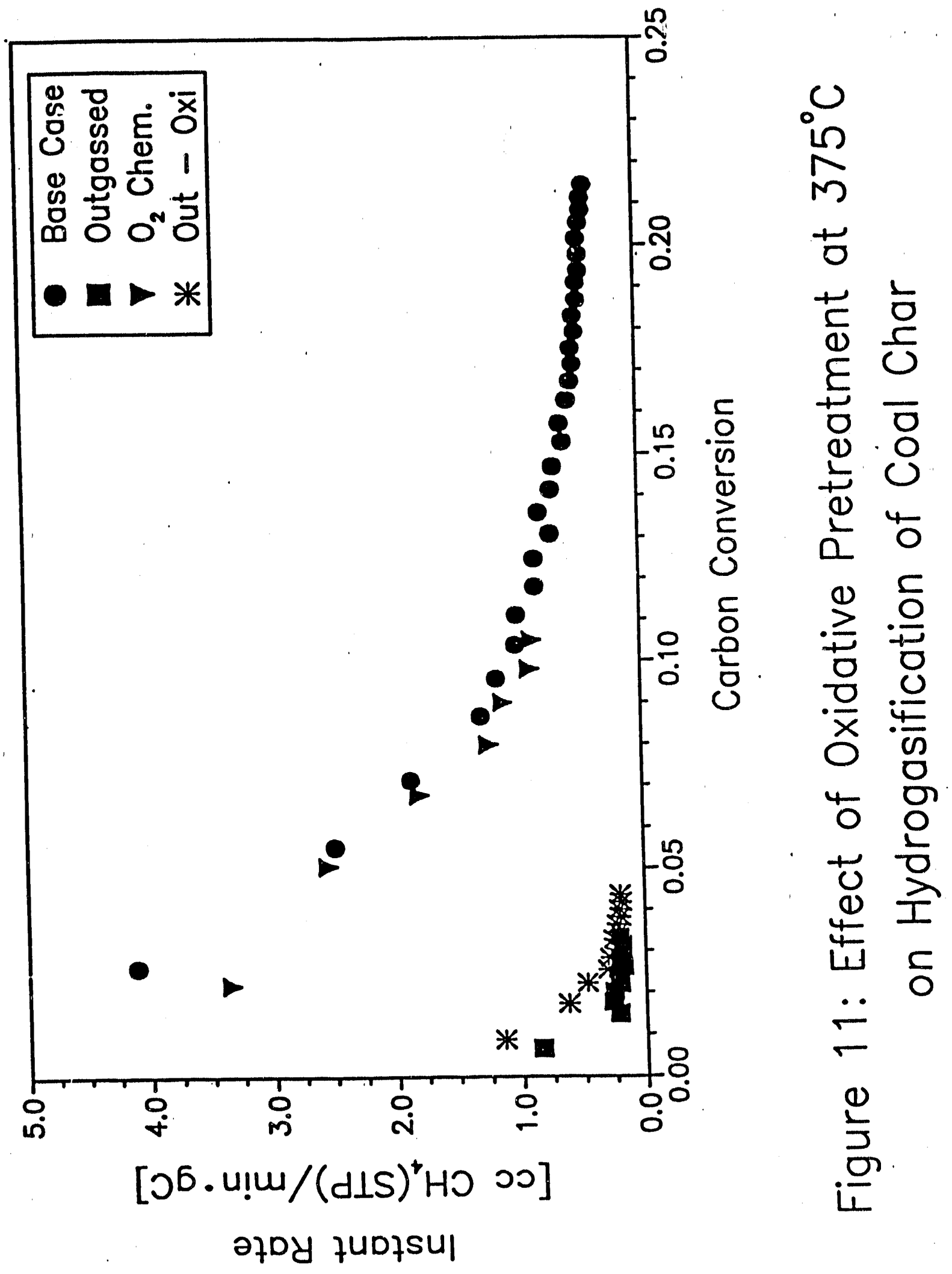




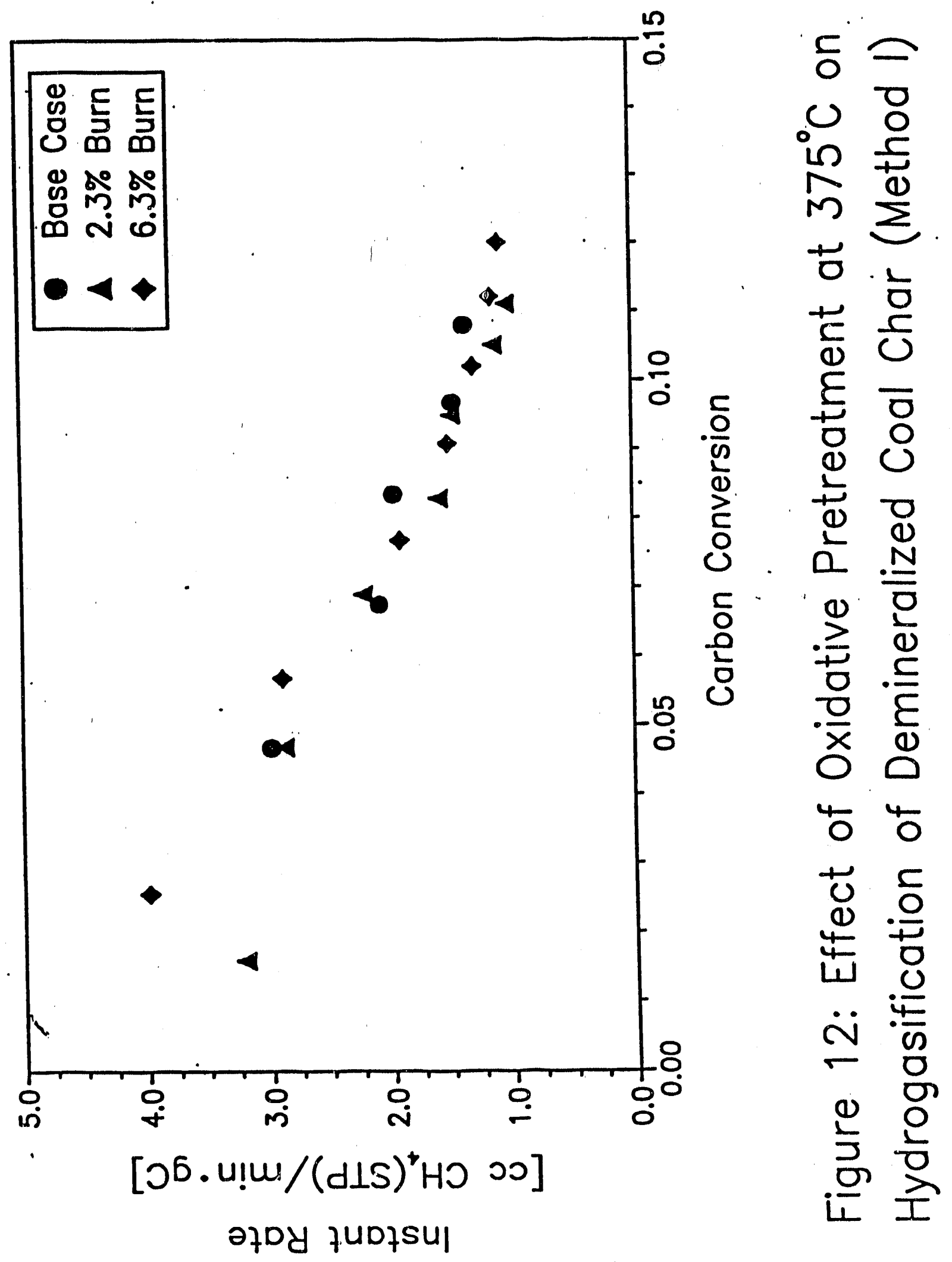




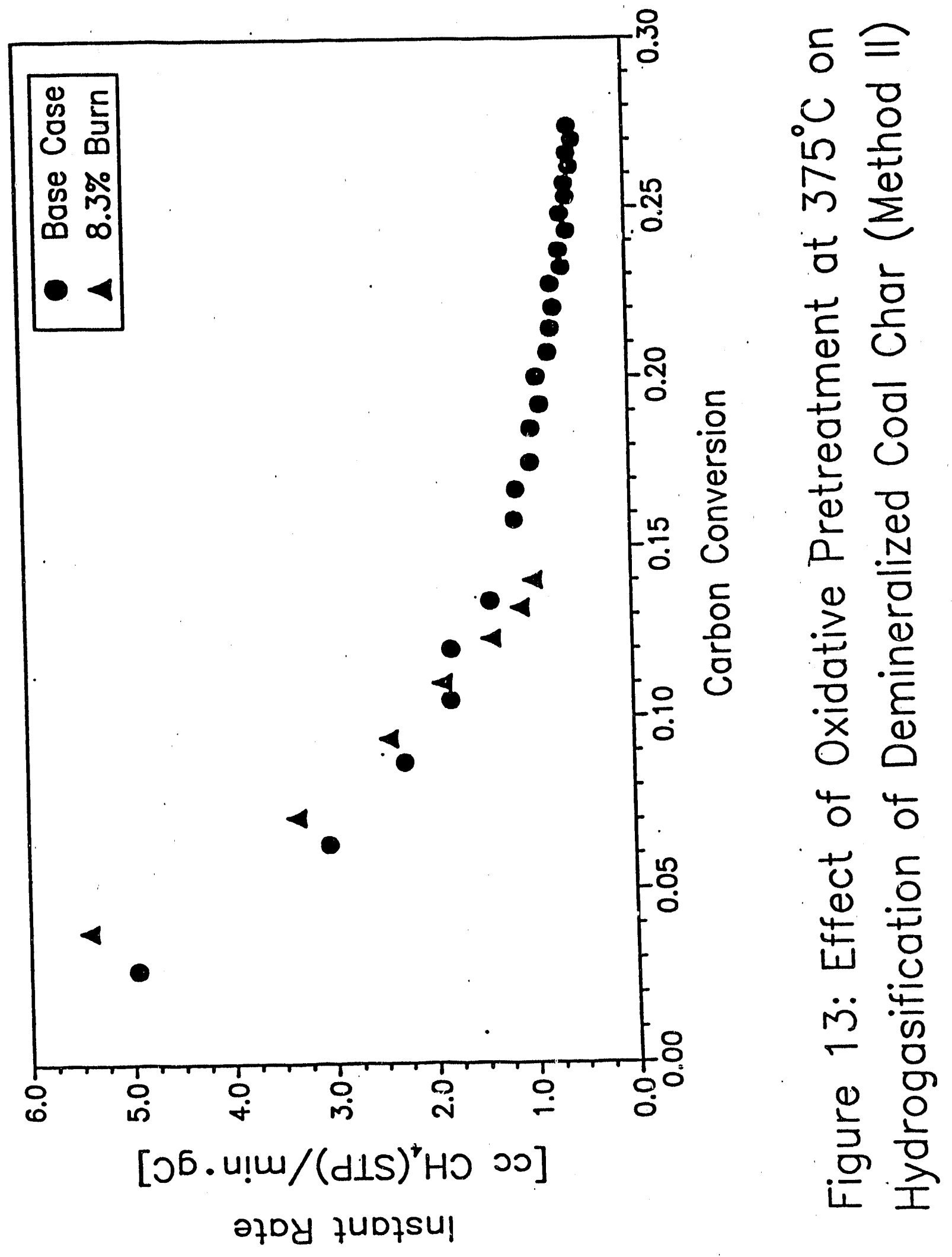


the potential of adding oxygen to the char surface without consuming carbon. These include char oxidation by immersion in concentrated $\mathrm{HNO}_{3}$ at ambient temperature, and oxidation by partial chemisorption of oxygen in the Pulse Chemisorb 2700 used for active surface area measurements. Both of these methods were carried out for as-prepared coal char, and then the oxidized char was subjected to hydrogasification. No rate enhancement was observed following oxidation by either of these methods, hence no graphs or figures are included of the results.

\section{III.4.3 Intermittent Oxidative Treatments}

\section{III.4.3.1 Saran char}

Figure 14 shows the effect of intermittent oxidation at $375^{\circ} \mathrm{C}$ on the hydrogasification rate of Saran char. Gasification proceeded for 2.25 hours between successive oxidations. The first intermittently treated sample gained $2 \mathrm{wt} \%$ upon oxidation, while the second sample was intermittently treated longer and lost 1 wt\% during each oxidation. Figure 15 shows the effect of intermittent oxygen chemisorption on the hydrogasification rate of Saran char. After all intermittent oxidations, the rates increased 2-3 fold over the base case, but decayed back to the base rate after about $5 \%$ carbon conversion.

\section{III.4.3.2 Coal char}

Intermittent oxidative treatments are shown for coal char in Figures 16 and 17. Gasification proceeded for 2.25 hours between successive oxidations. The samples in Figure 16 were oxidized two times at $375^{\circ} \mathrm{C}$ during each reaction. The first lost $7 w$ t\% both times upon combustion in air, and the second lost 5 wt\% during each oxidation. Figure 17 gives the hydrogasification rare curve for coal char that has been partially burned in air at $725^{\circ} \mathrm{C}$. This sample lost 3 wt\% during the oxidation. As with the Saran char, all rates increased 2-3 times over the base case following intermittent treatment and decayed back to the base rate after approximately $5 \%$ carbon conversion.

\section{III.4.4 Continuous Addition of Oxygen during Hydrogasification}

To test the potential of continuously adding small quantities of oxygen to hydrogen during gasification and thus continually oxidizing the char surface, we purchased a custom mixture of $92 \mathrm{ppm} \mathrm{O}_{2}$ in UHP hydrogen from AGA gas. We chose this low concentration (100 ppm nominal) to be certain we avoided explosive limits and because we calculated that, at typical flow rates, this amount of oxygen would convert $1-2 \%$ carbon per hour, significant to the $5-10 \%$ conversion per hour from hydrogen.

We conducted initial tests to determine the amount of oxygen that passed through the reactor unreacted at various temperature and in the presence and absence of char. Essentially all oxygen passed through the reactor at low temperature without sample present. At gasification temperature without the sample present, about $60 \%$ of the oxygen made it through the reactor without reacting, indicating that there was some oxidation or water formation occuring.

When we placed a char sample in the reactor, we were not able to detect any oxygen leaving the reactor at gasification conditions. This is strong evidence that the char is being oxidized, as we had hoped. Unfortunately, we did not observe any enhancement in methane formation rate over that in pure hydrogen. It is likely that the concentration of oxygen used was too small to have much affect on the char; either the oxygen could not alter the char structure or it was being converted to water on the char surface before it could react with carbon. We did not pursue these possibilities further. 


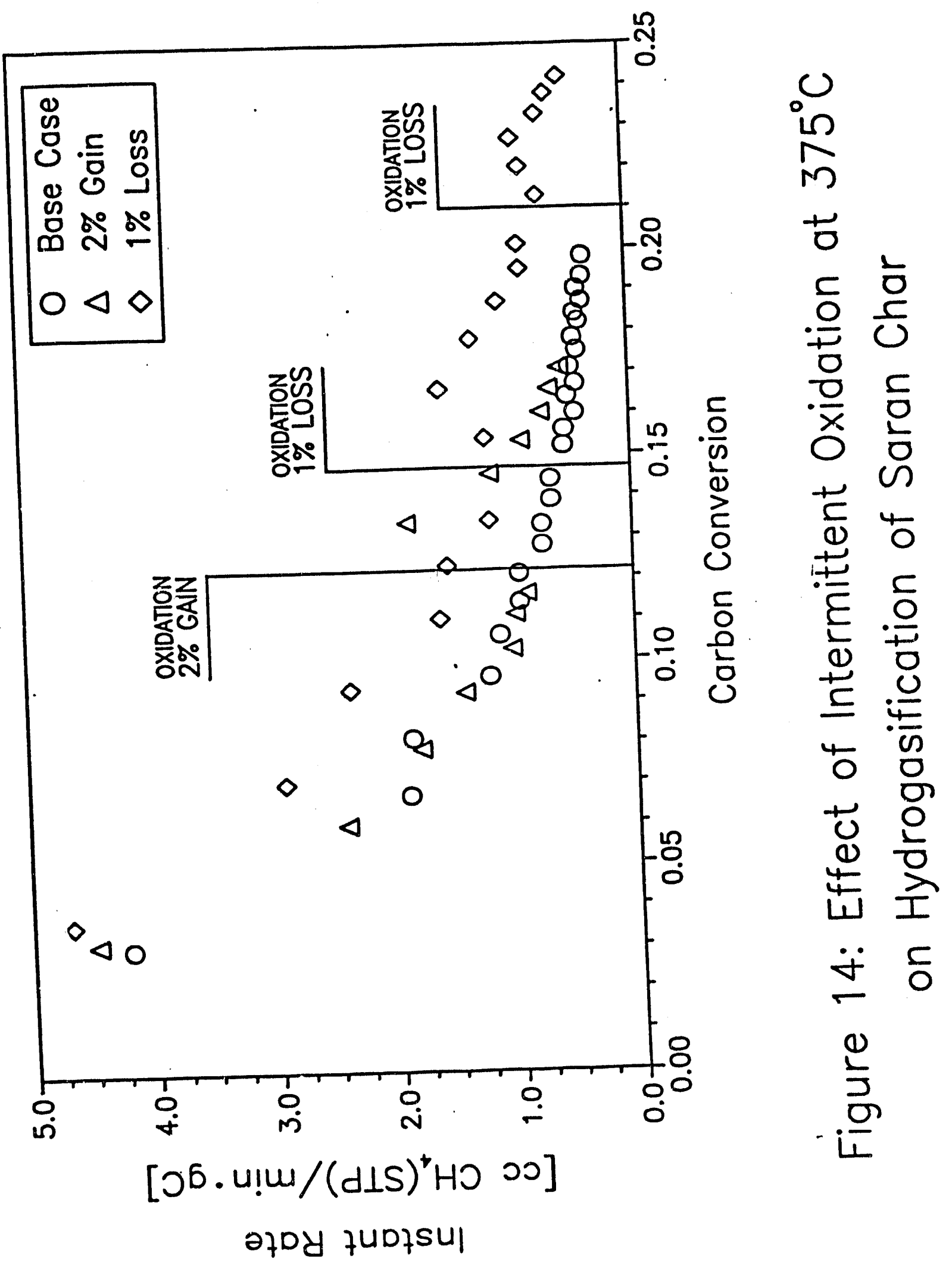




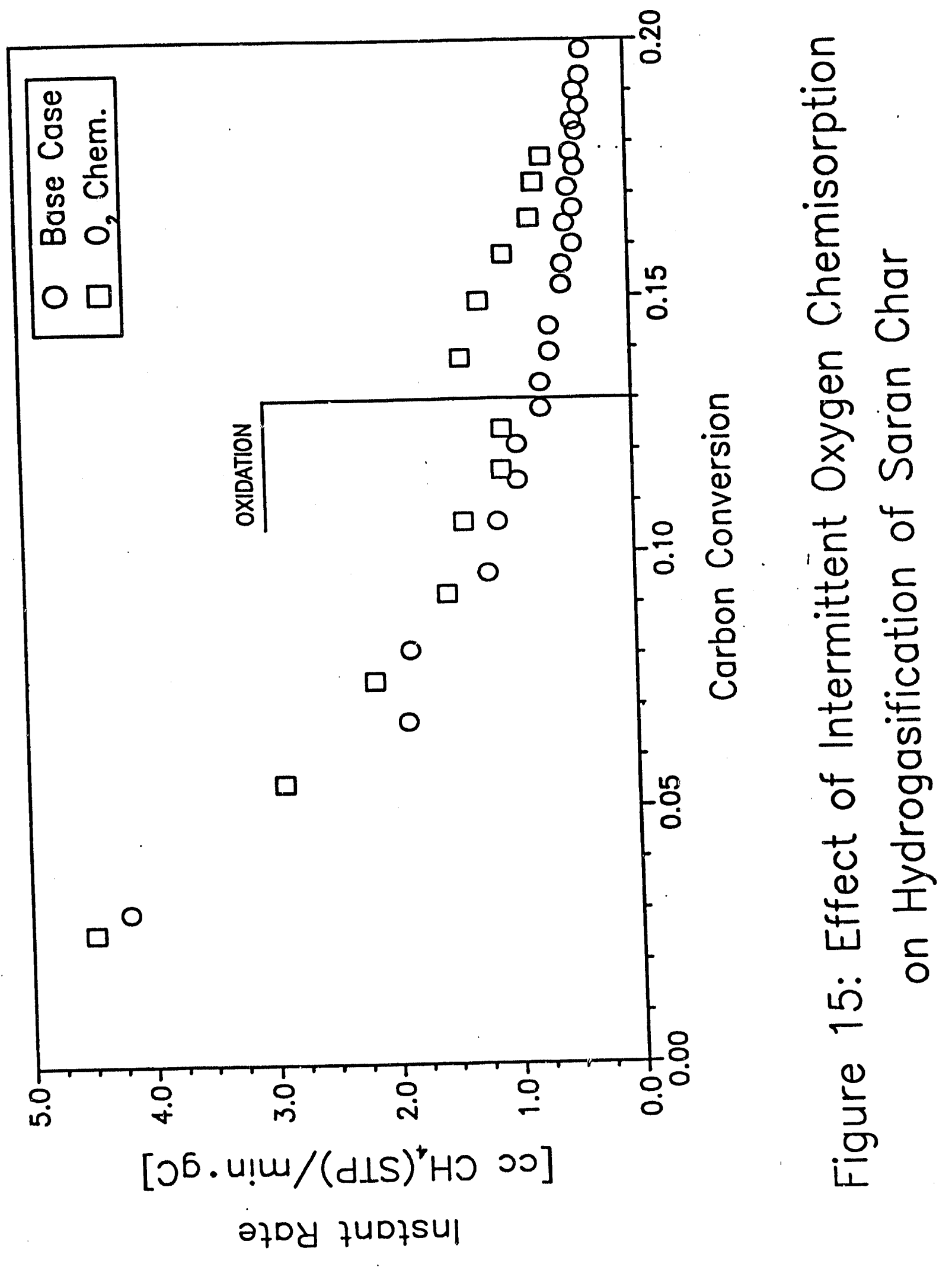




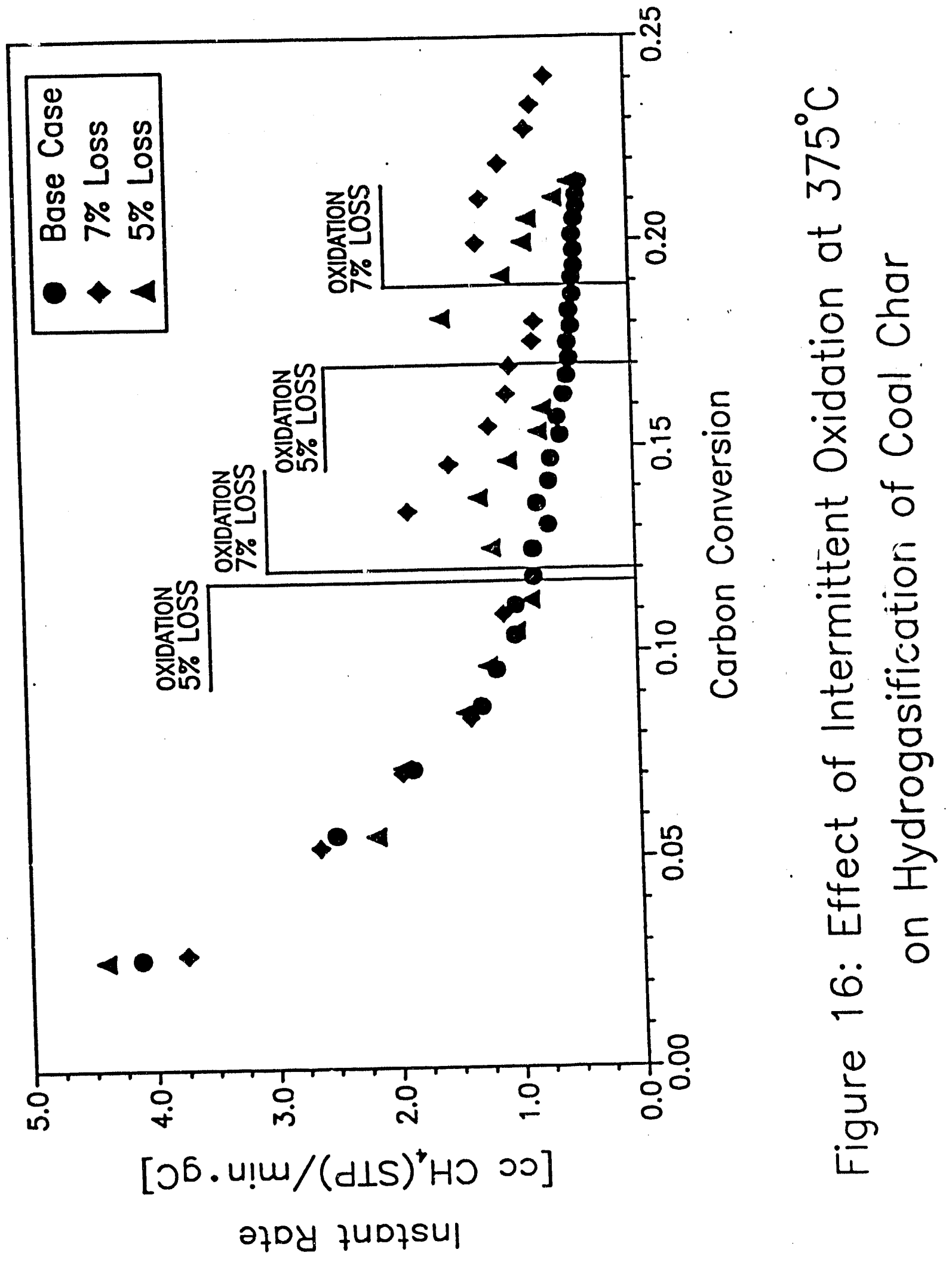




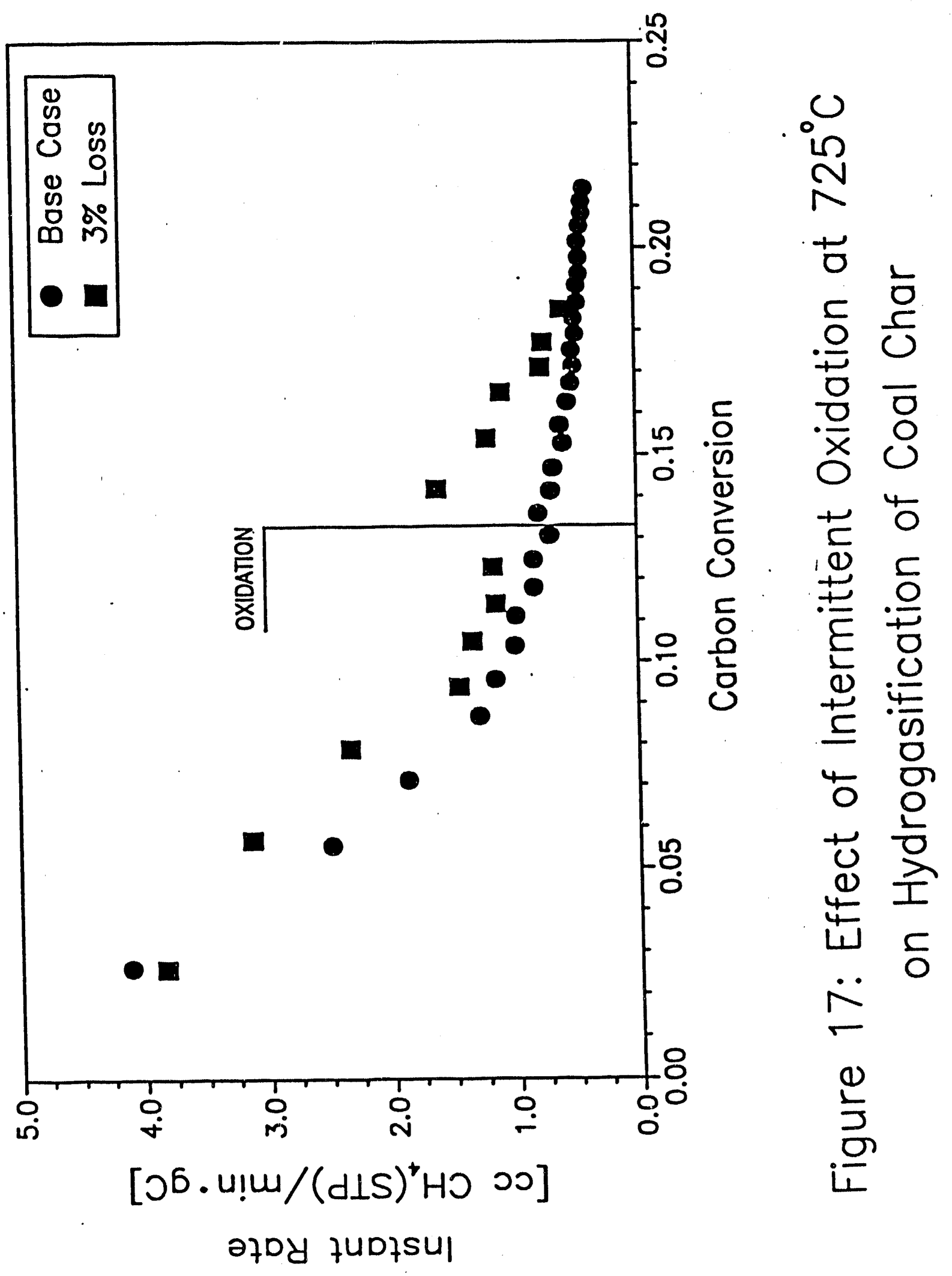


An advantage of using the newly designed sample mount during hydrogasification is having the option of adding hydrogen to the reactor as quickly as possible and not having some of the sample blow out of the holder before $500 \mathrm{psi}$ is achieved. The standard procedure used in this study for gasifying samples was developed before the design of the new sample mount, making slow addition of hydrogen starting at $600^{\circ} \mathrm{C}$ the best method. Figure 18 shows the effect on hydrogasification rate of adding 500 psi hydrogen very quickly to the reactor when it has just reached $725^{\circ} \mathrm{C}$. The initial recorded reactivity of coal char is almost twice as high as that of the base case, but the rest of the rate points fall closely to those of the base case.

\section{III.6 Reduced Gasification Temperature}

Figure 19 shows the effect of reducing hydrogasification temperature ta $600^{\circ} \mathrm{C}$ on the reaction rate of Saran char, coal char, and pre-oxidized coal char. The pre-oxidized coal char has been burned in air at $375^{\circ} \mathrm{C}$ and lost $5.7 \mathrm{wt} \%$ upon partial combustion. The Saran char reactivity is about twice that of the coal char, while the pre-oxidized coal char has a rate that is slightly higher than the coal char initially. The reactivity of all chars decreases rapidly in the same way it decreases during hydrogasification at $725^{\circ} \mathrm{C}$.

\section{III.7 Hydrogen Pretreatments}

Dissociative adsorption of hydrogen may poison the reaction of hydrogen with chars. Hydrogasification at reduced temperature and pressure and subsequent effects on hydrogasification rate at $725^{\circ} \mathrm{C}$ and $500 \mathrm{psig}$ are shown in Figures 20 and 21 . The duration of the pretreatment was 2.25 hours for all samples. This was the same length of time of all hydrogasifications in these figures, except the base case. The pretreatment shown in Figure 20 was initial gasification at $725^{\circ} \mathrm{C}$ and $10 \mathrm{psi}$ hydrogen. The rate during the pretreatment conditions was much lower than that of the base case, while the rate after standard gasification conditions were imposed appears to have become greater than that of the base case. The first pretreatment shown in Figure 21 was gasification of coal char at $600^{\circ} \mathrm{C}$ under 50 psi hydrogen, which did not produce a rate high enough to accurately record. The gasification rate of this sample after pretreatment was slightly lower than the base case. The final pretreatment was an initial gasification at $600^{\circ} \mathrm{C}$ and 500 psi hydrogen, which gave a low but measurable rate. Upon exposure to normal gasification conditions, which were $725^{\circ} \mathrm{C}$ and 500 psi hydrogen for this study, the sample reacted at a rate that was close to that of the base case. Overall, the effects of the hydrogen pretreatments on hydrogasification rate were minor.

\section{III.8 Catalyst Addition}

\section{III.8.1 Catalyzed Base Cases}

Figures $22 \mathrm{~A}$ and $22 \mathrm{~B}$ show the effect on hydrogasification rate of loading $10 \mathrm{wt} \%$ potassium carbonate onto the various chars. The catalyzed coal char reacted at a rate almost double that of the uncatalyzed coal char, and the rate decayed in a similar manner after 8 hours of gasification. The catalyzed Saran char and catalyzed demineralized coal char began hydrogasification at a rate slightly higher than that of the catalyzed coal char, but their rates did not decay with time. The catalyzed Saran char reacted at a steadily increasing rate until about $75 \%$ carbon conversion, where the rate dropped

abruptly. After 4 hours of hydrogasification, the catalyz + Saran char was over $90 \%$ converted. The catalyzed demineralized coal char reacted at a ate that increased rapidly until near completion after 2 hours, and had a higher rate than the Saran char. 


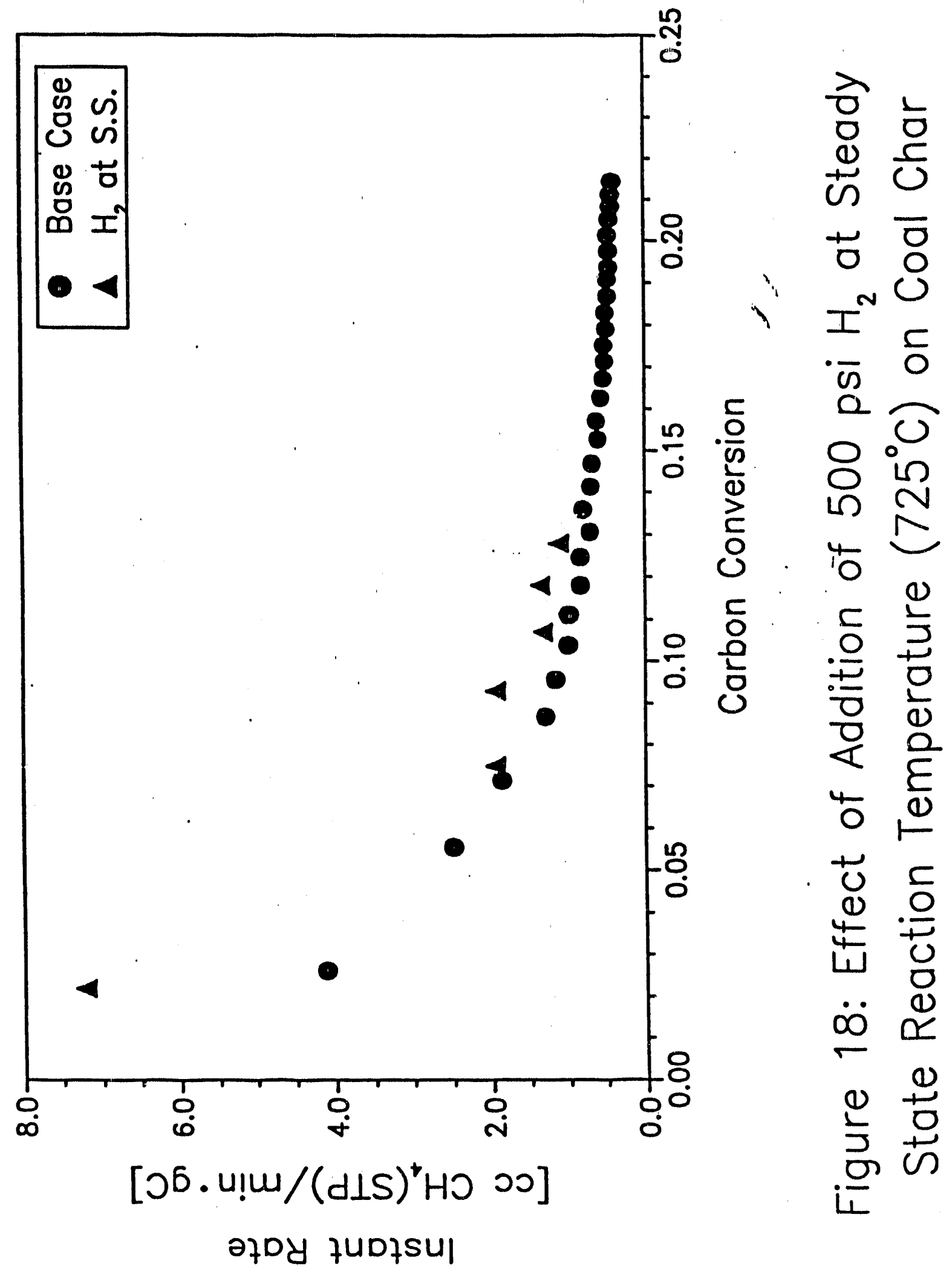




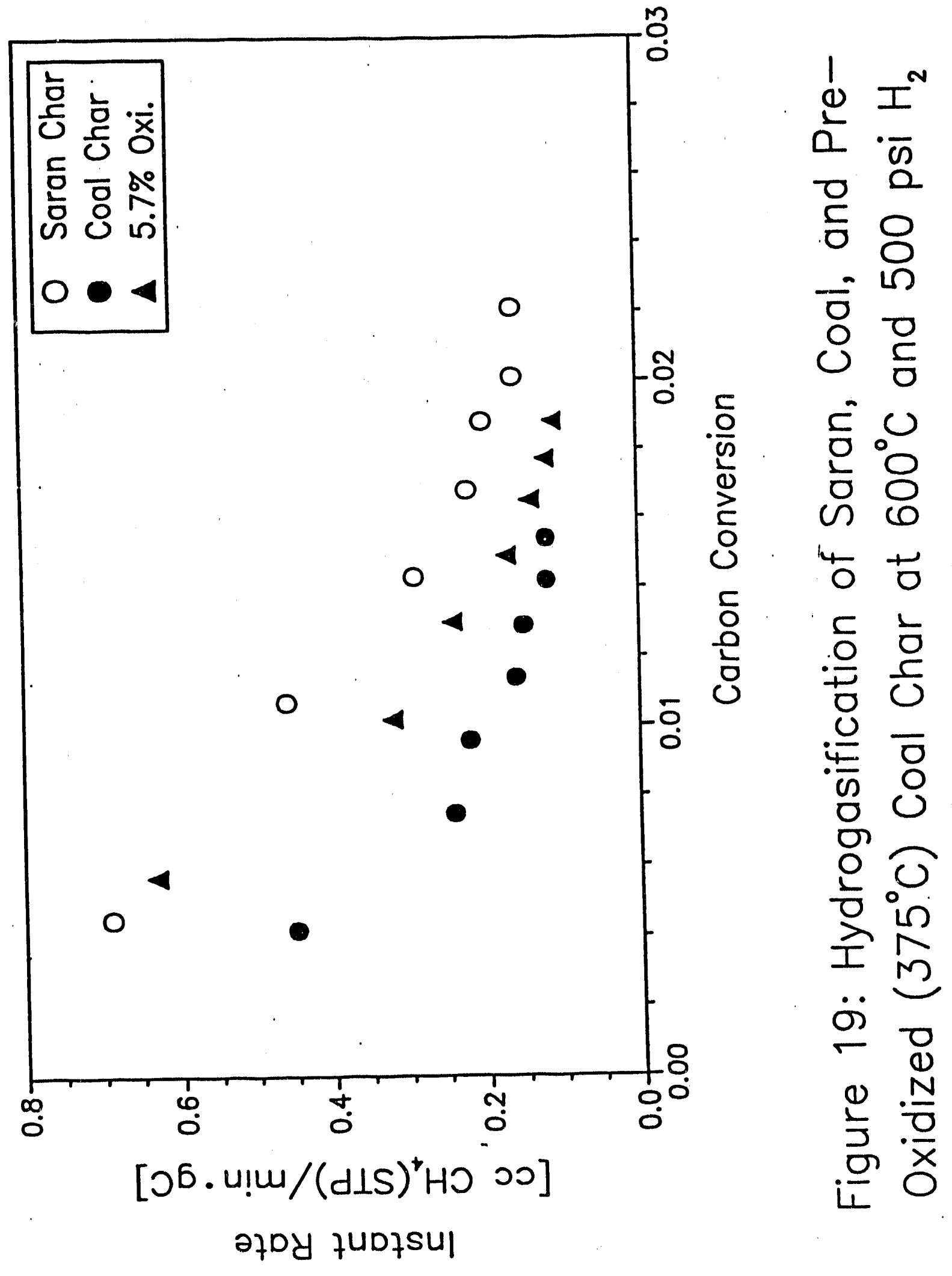




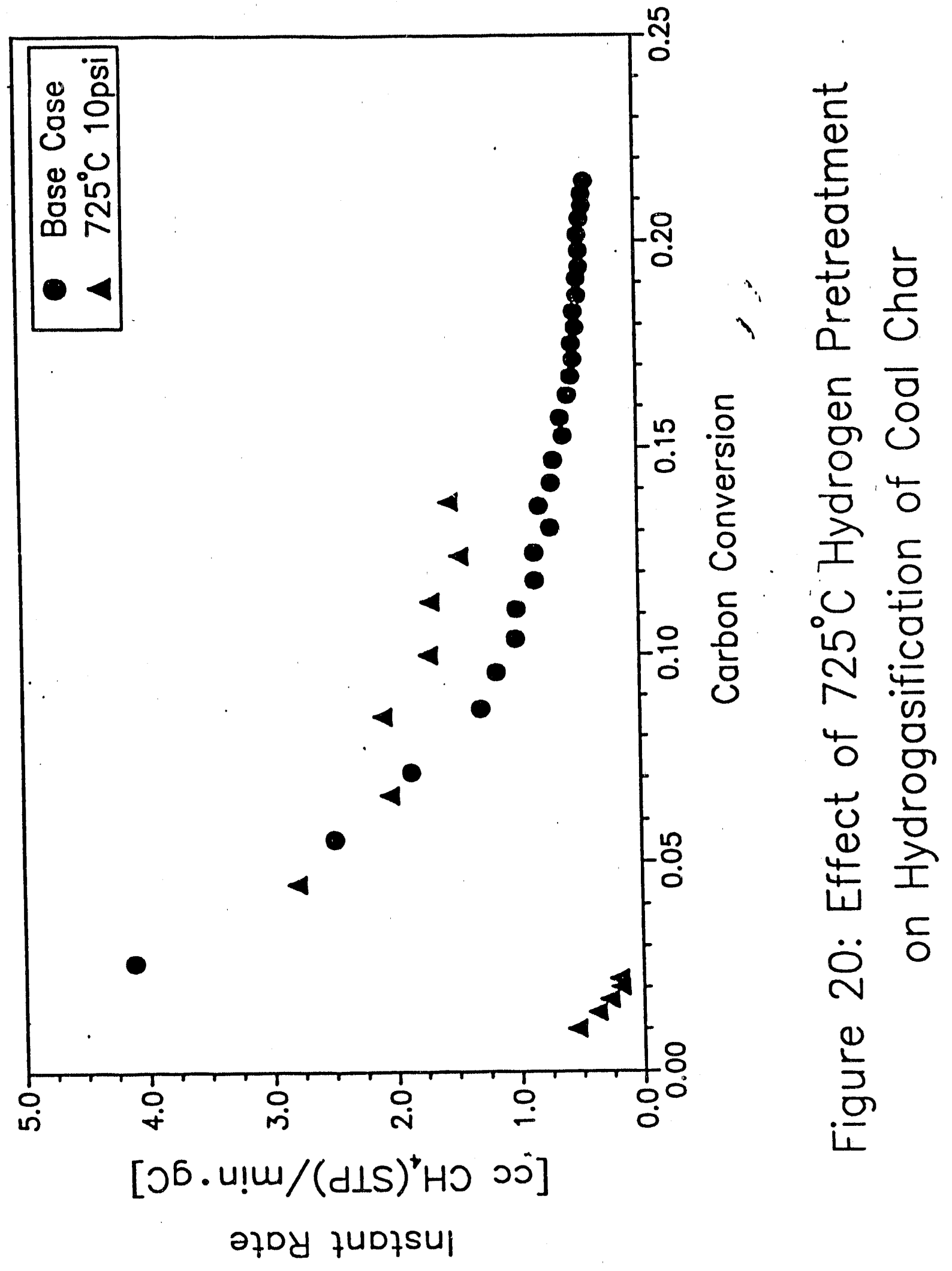




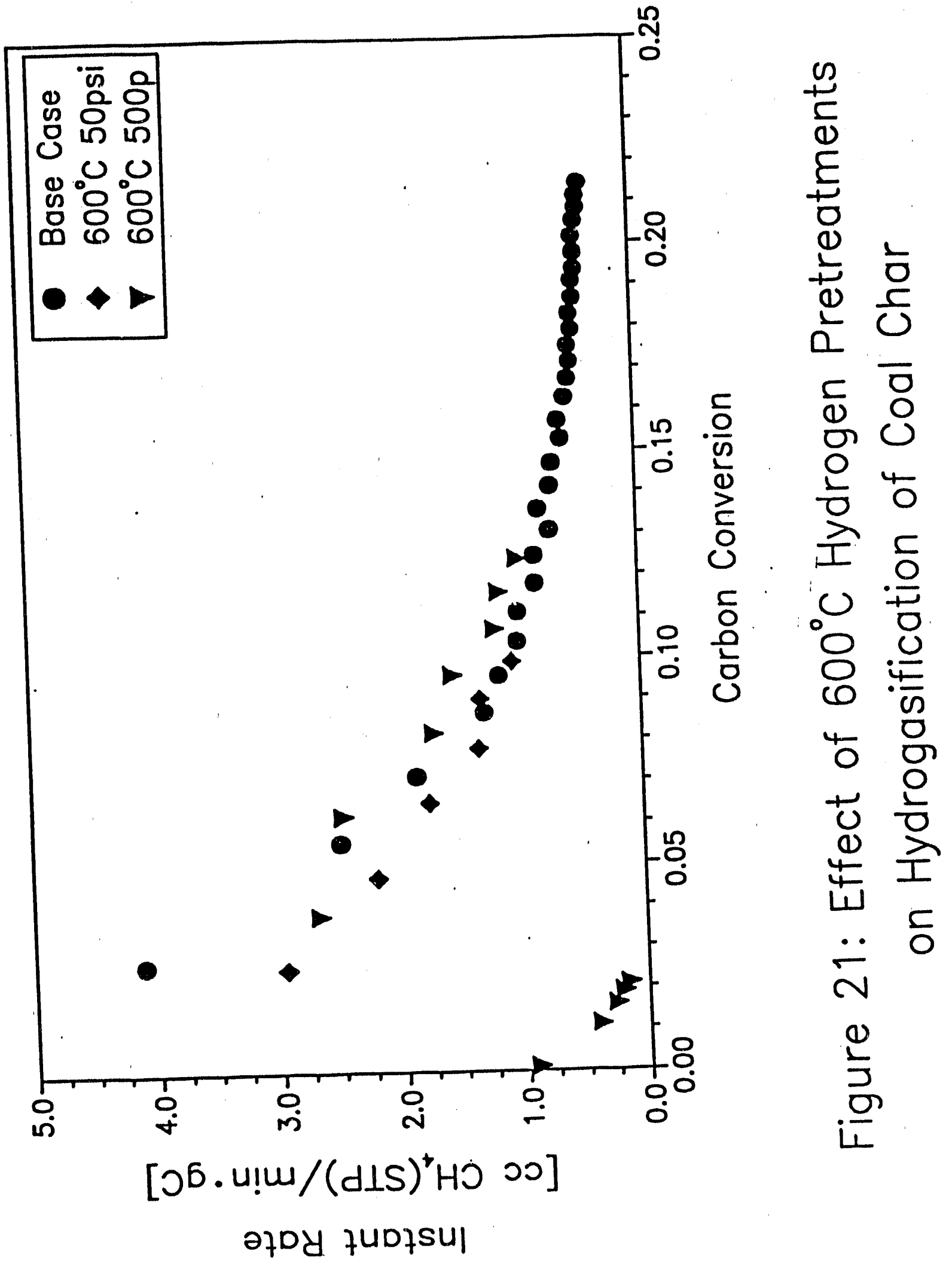




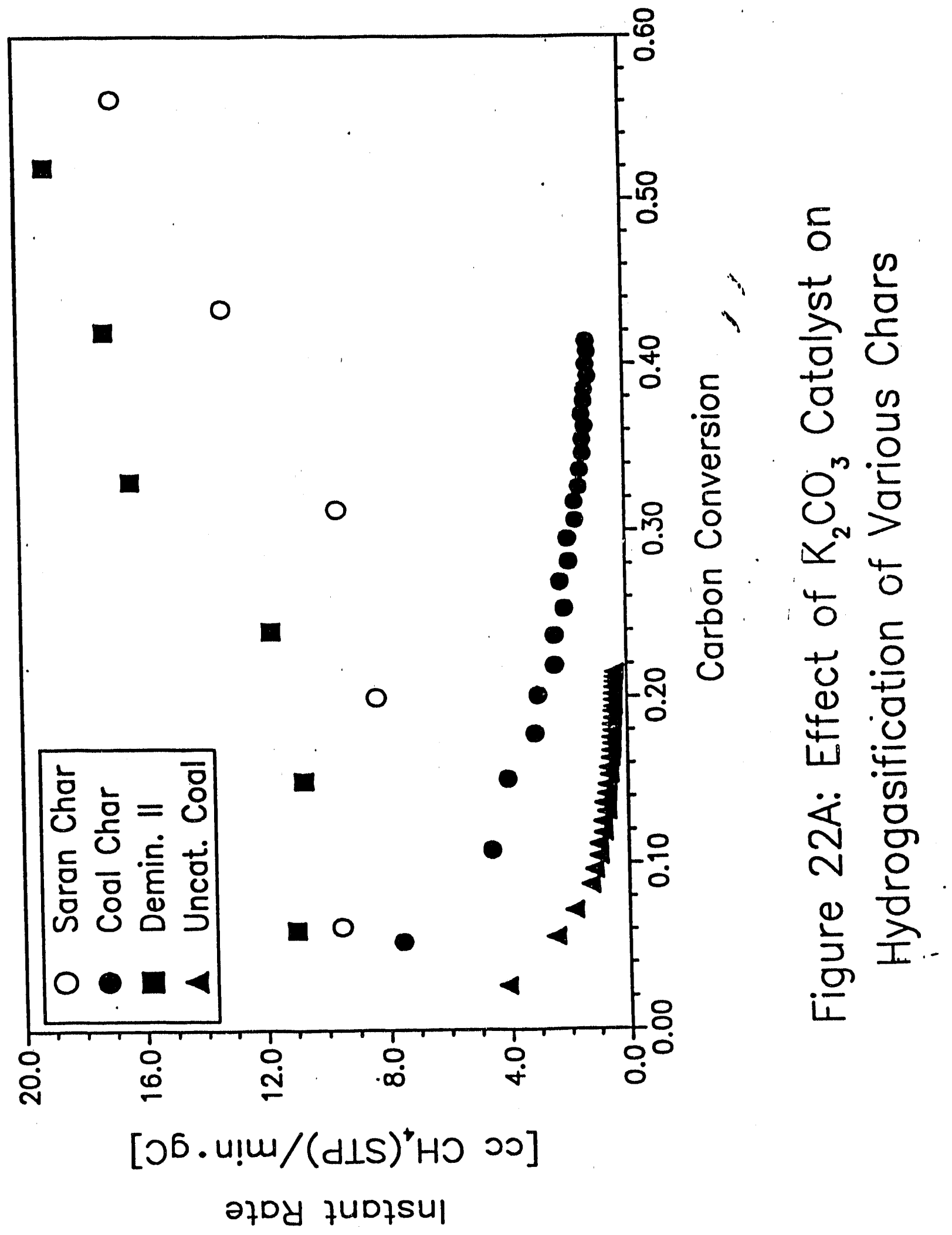




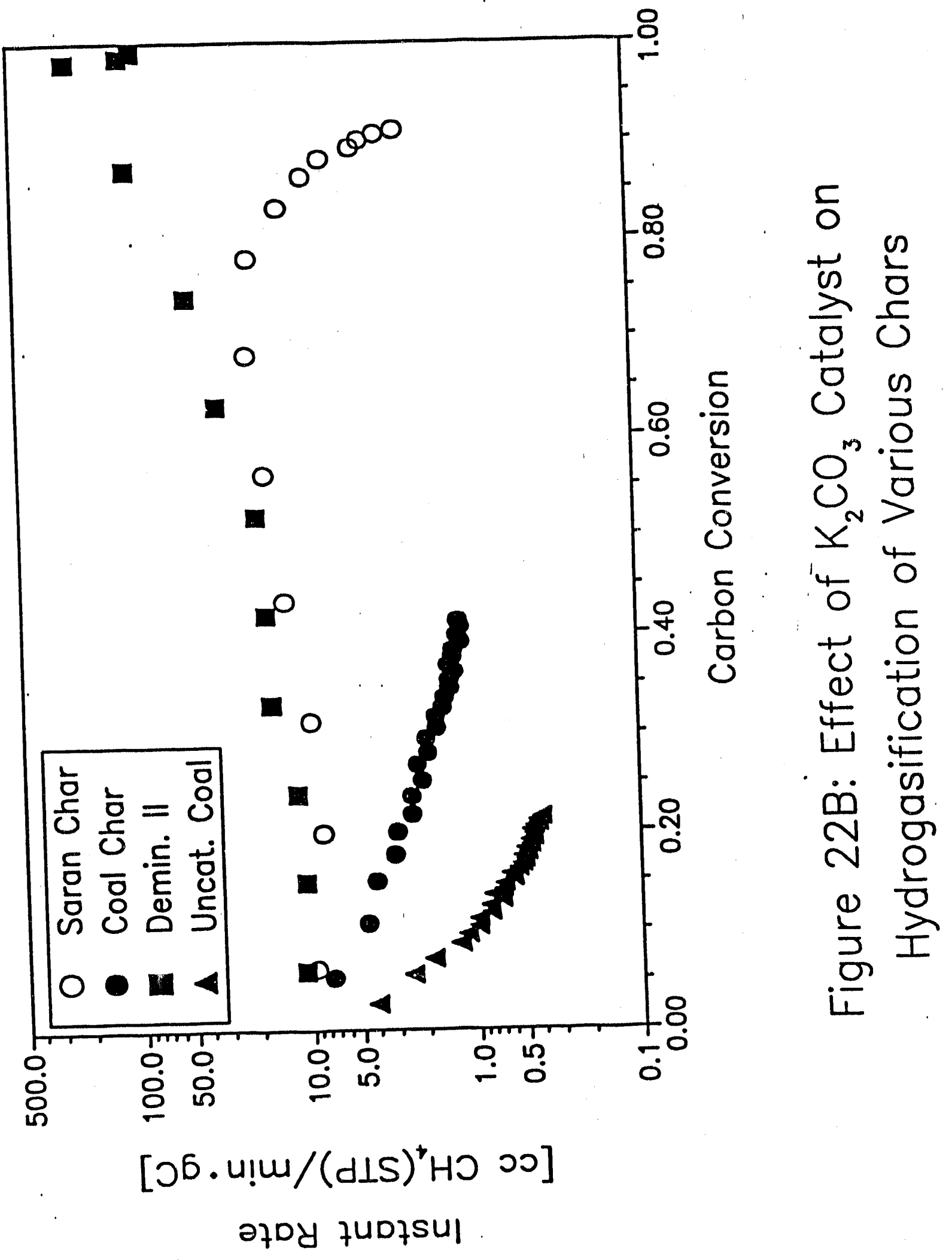




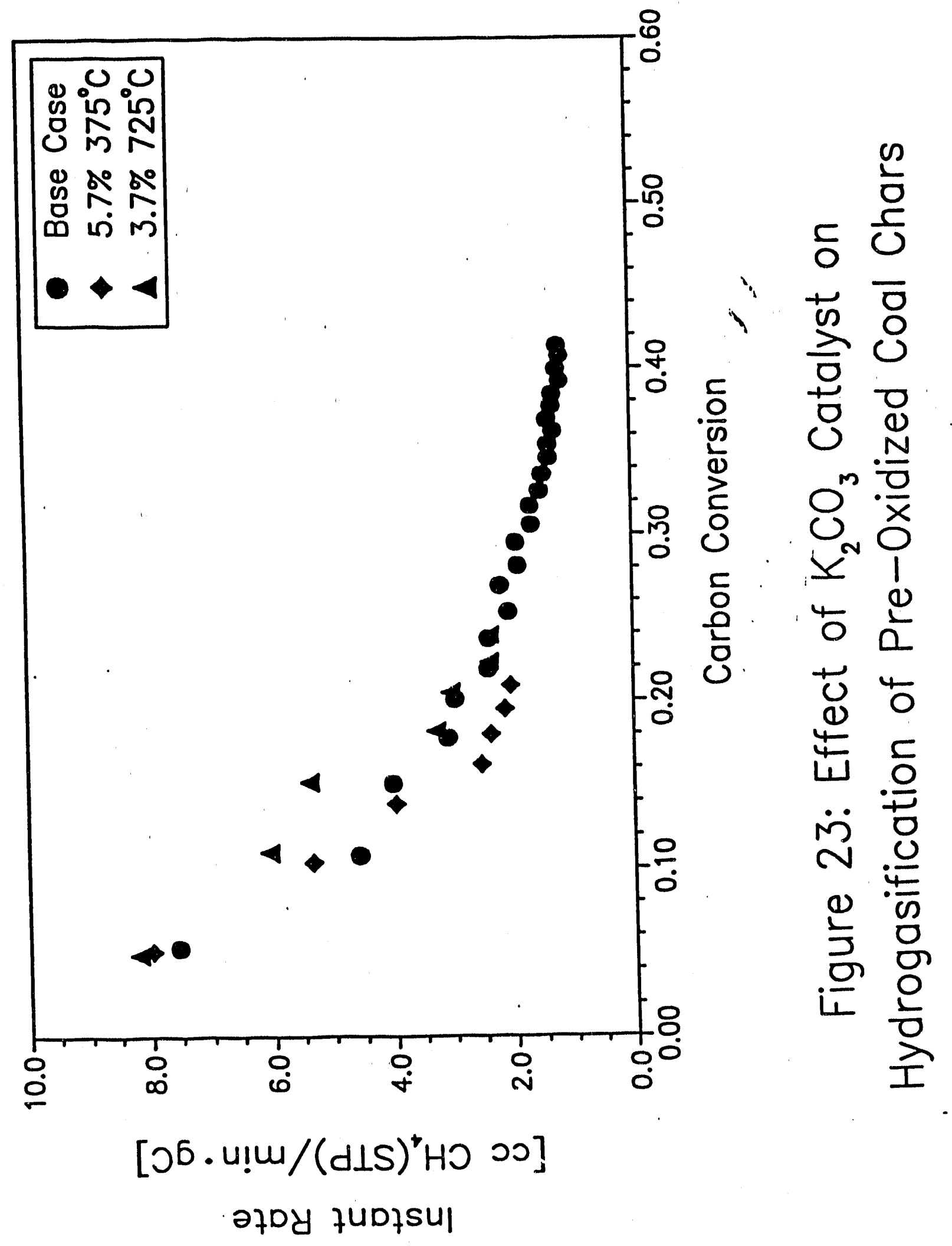




\section{III.8.2 Preoxidation of Catalyzed Chars}

The effect on hydrogasification rate of preoxidizing coal chars before catalyst Impregnation is shown in Figure 23. The first char had not been oxidized, while the second had been oxidized in air at $375^{\circ} \mathrm{C}$ and lost $5.7 \mathrm{wt} \%$ upon partial combustion. The third char had been oxidized in air at $725^{\circ} \mathrm{C}$ and lost $3.7 \mathrm{wt} \%$ upon partial combustion. Both preoxidized-catalyzed chars were gasified for 2.25 hours. No rate enhancement is evident over that of the catalyzed coal char base case.

\section{III.8.3 Intermittent Oxidation of Catalyzed Chars}

The effect on hydrogasification rate of intermittent oxidation of various catalyzed chars is shown in Figure 24. The catalyzed Saran char was oxldized at $375^{\circ} \mathrm{C}$ in alr after 2.25 hours of hydrogasification. The rate after intermittent oxidation decreased to less than one third that of the catalyzed base case, but the rates did not match up well before the intermittent oxidation. The catalyzed coal char was oxidized at $375^{\circ} \mathrm{C}$ in air after 2.25 hours of hydrogasification. It lost about 10 wt\% during partial combustion, which caused a large gap beiween data points. During the second gasification it started at a rate higher than that of the catalyzed base case coal char. but dropped below it after $3 \%$ carbon conversion. As with the catalyzed Saran char, the catalyzed coal char reaction rates did not match up well with each other before the intermittent oxidation. 


\section{DISCUSSION}

\section{IV.1 General Observations}

\section{IV.1.1 Temperature Effects}

It has been shown that the conditions chosen for hydrogasification in this investigation result in kinetic and not mass transfer rate limitations, with the exception of the first $2-3 \%$ carbon conversion. The activation energy calculated from the Arrhenius plot in Figure 3 is consistent with those found in literature $[17,18]$. The temperature range in which diffusion limitations dominate, which will be above a certaln threshold, is indicated by the section of the Arrhenius curve that has a slope which gives half the activation energy of the reaction. In this system, that transition occurs near $775^{\circ} \mathrm{C}$. This is $50^{\circ} \mathrm{C}$ higher than the gasification temperature chosen for this investigation. An interesting phenomenon illustrated by the Arrheniur plot is the apparent decrease in rate from a gasification temperature of $775^{\circ} \mathrm{C}$ to $800^{\circ} \mathrm{C}$. Hydrogasifications to produce these data points have been duplicated to ensure their validity. This unusual rate decrease with increased reaction temperature may due to the annealing effects at higher temperatures. Another possibility is the proportional increase in rates of reactions that are responsible for the consumption of active sites over the rates of reactions responsible for methane formation.

Gasification rates measured during runs with the newly designed sample mount are consistent with rates measured during runs with the original sample mount design. This demonstrates that mass transfer limitations are not taking place because of particle size, since larger sample particle sizes are required for the newly designed mount. A gasification run was made with the original mount containing a sample weight that was $40 \%$ of the usual starting weight to investigate the possibility of mass transfer limitations because of the sample bed depth. The rates curves are identical, indicating diffusion limitations do not occur because of the bed depth either.

\section{IV.1.2 Total Surface Area}

Figure 25 shows total surface area changing very little with carbon conversion for Saran char and coal char. Since the hydrogasification rate changes significantly within the $0-20 \%$ conversion range, it appears that rate is only a very weak function of total surface area. Analysis of Figure 26. however, indicates that this may not be the case in conversions above $20 \%$. The rate per unit total surface area appears to reach a constant level for coal at about $15 \%$, and may be leveling off for Saran char at about $25 \%$ conversion. The possibility of a mechanism in which at least two different modes of hydrogasification occur is supported if the rate is not a function of total surface area for the first $15-25 \%$ carbon conversion, but it is for the rest of the reaction.

\section{IV.1.3 Active Surface Area}

Figure 27 shows the active surface area of Saran char and coal char as a function of carbon conversion in hydrogasification. The coal char results are erratic, with the last data point being unusually high. Later measurements of just the coal asin after exposure to hydrogasification conditions revealed an active surface area of $74 \mathrm{~m}^{2} / \mathrm{g}$, which is very high relative to the coal. This results from reduction of coal ash during hydrogasification, and cannot be compensated for in the active surface area calculations because it is not known exactly how much of the ash is exposed at various stages during gasification. Thus, measurement of active surface area using oxygen chemisorption is not feasible for hydrogasified coal char.

The general trend of the Saran char data is similar to that of the total surface area data. Figure 28 shows the rate per unit active surface area as a function of carbon conversion. The 


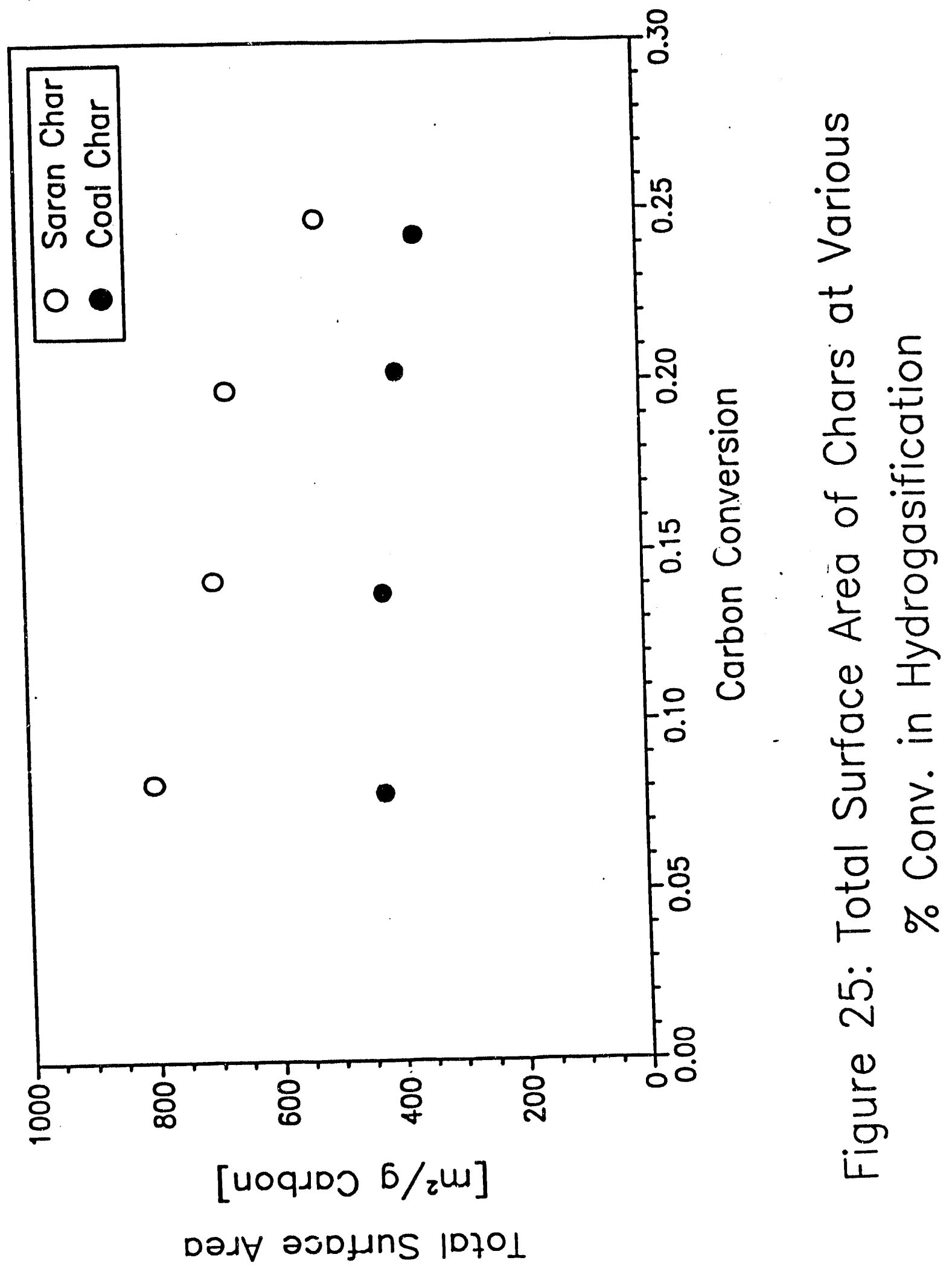




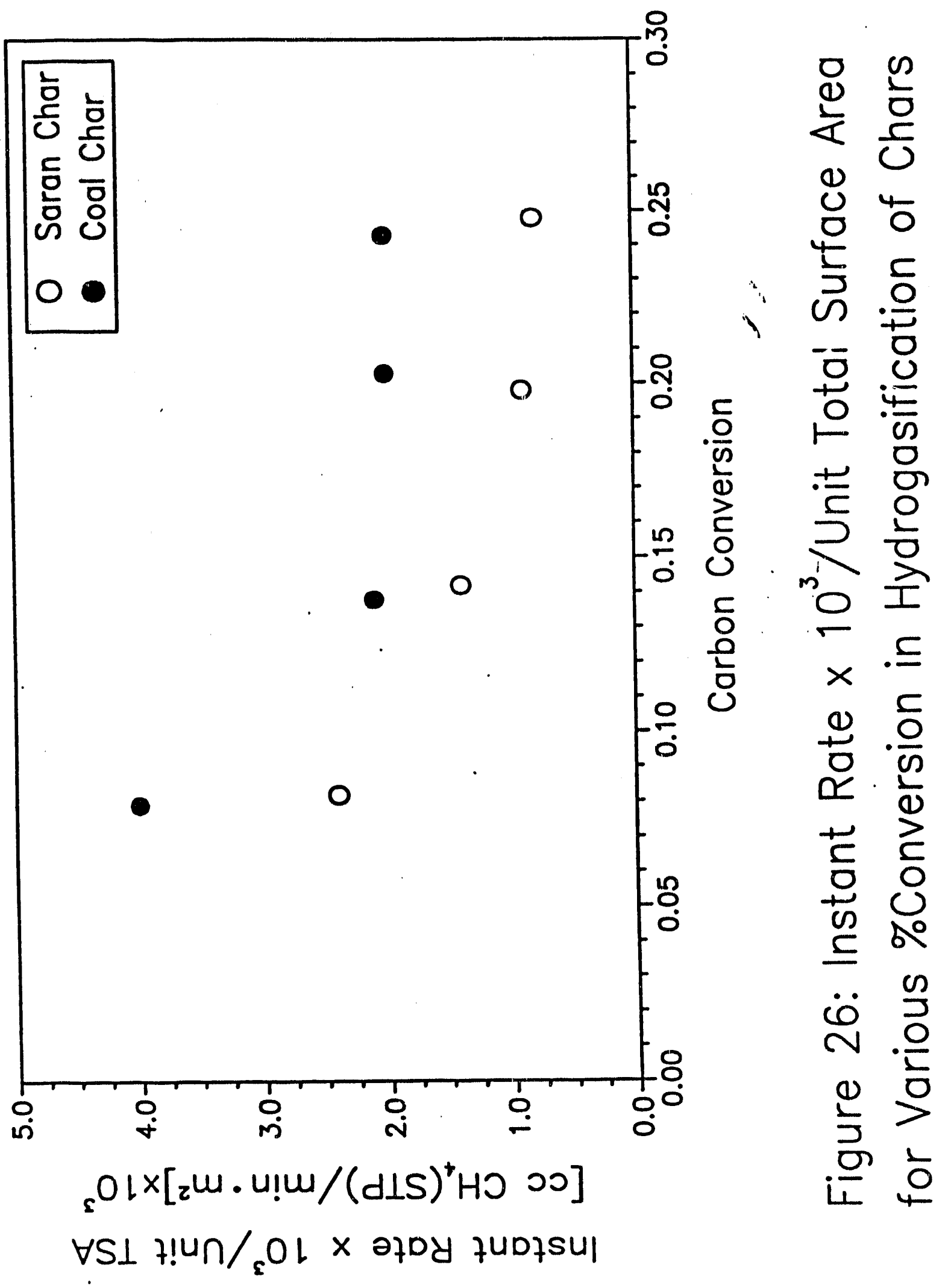




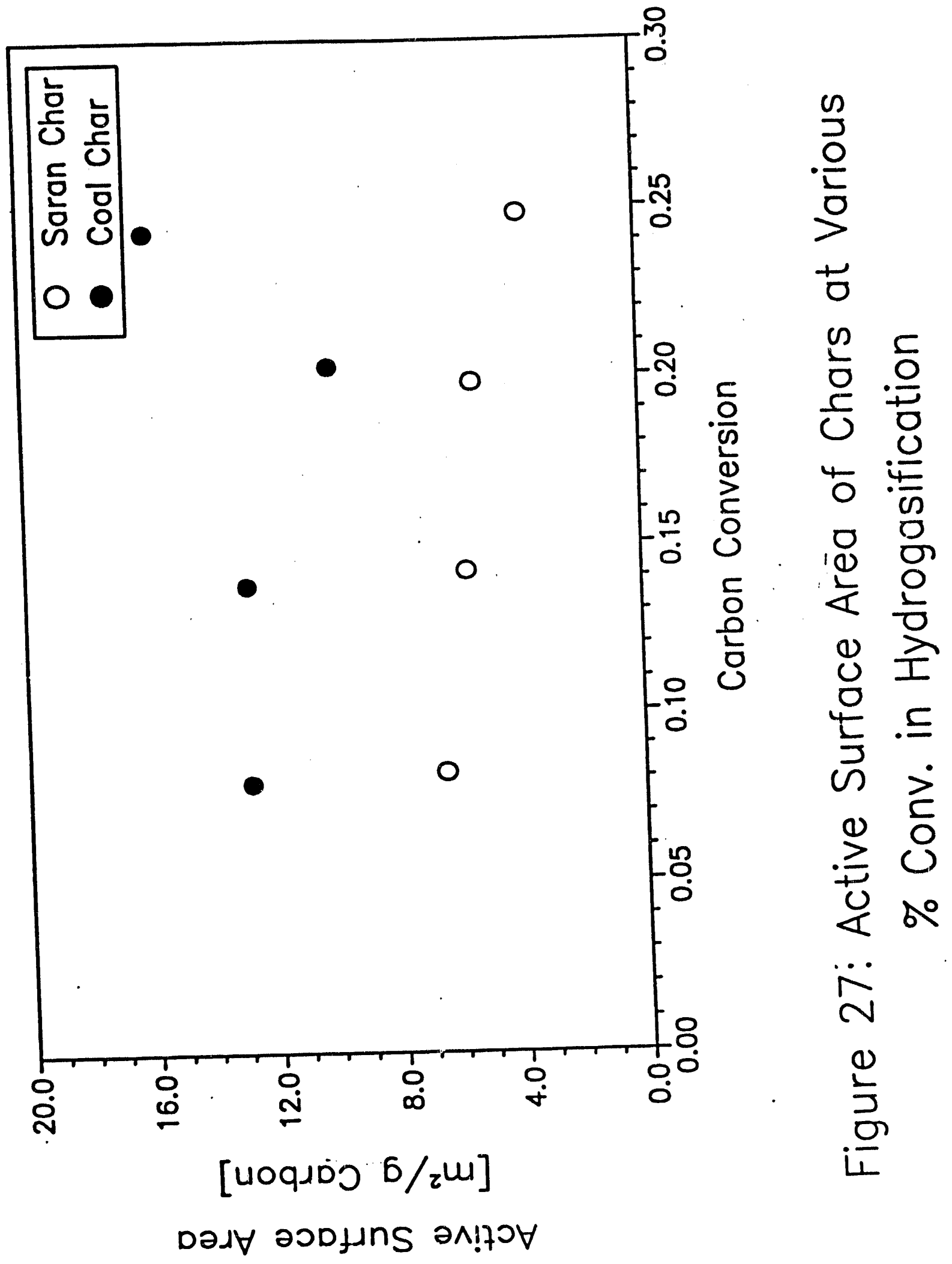




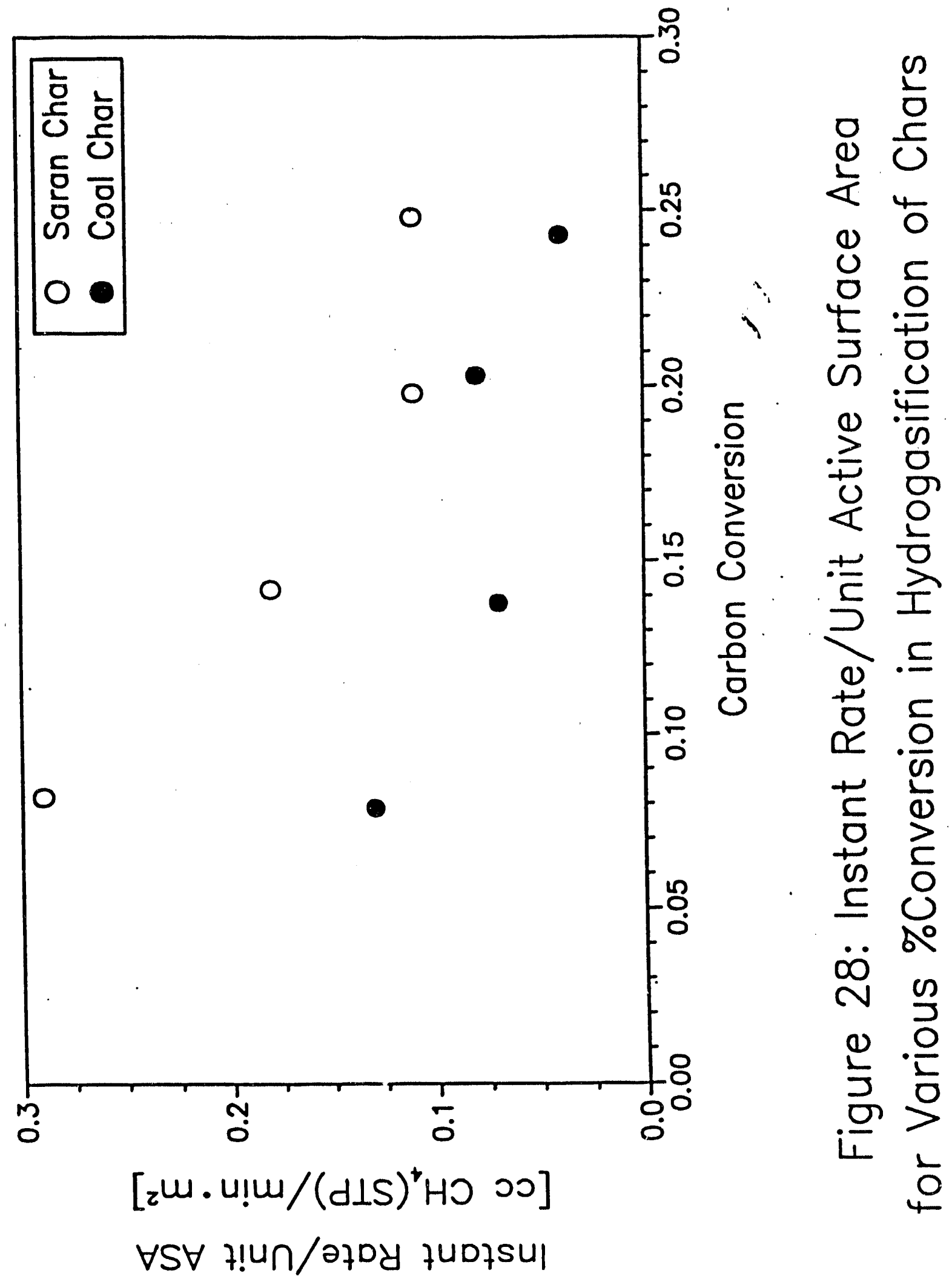


Saran char data indicate a possible leveling off of rate per unit active surface area in a manner similar to rate per unit total surface area in Figure 27.

It is apparent that the method used for active surface area measurement in this Investigation is not indicative of the active surface area that is important during hydrogasification. Table 3 shows the active surface area of two parallel runs of intermittently oxidized Saran char. The values given describe char properties at the end of each stage. According to the values given, the active surface area is lower at the beginning of a hydrogasification stage than at the end of that stage, and the active surface area is higher at the beginning of an oxidation stage than at the end of that stage. This is the inverse of what would be expected. The active surface area should decrease withhydrogasification since the rate decreases, because rate is thought to be a function of surface oxygen group concentration. The active surface area should increase after oxidation, since oxidation fixes oxygen functional groups on the char surface. Explanations for this include the possibility of oxygen binding more strongly to the highly reduced char surface after hydrogasification, or reaction of oxygen with surface hydrogen to produce water after hydrogasification.

TABLE 3

ACTIVE SURFACE AREA OF INTERMITTENTLY OXIDIZED SARAN CHAR - TWO DIFFERENT RUNS ${ }^{1}$

\begin{tabular}{|c|c|c|c|c|}
\hline $\begin{array}{l}\text { Stages } \\
\text { During } \\
\text { Experiment }\end{array}$ & \multicolumn{2}{|c|}{$\%$ Conversion } & \multicolumn{2}{|c|}{$A S A\left(m^{2} / g\right.$} \\
\hline $\begin{array}{l}\text { Starting: } \\
\text { Gasification \#1:2 } \\
\text { Oxidation \#1:3 } \\
\text { Gasification \#2: } \\
\text { Oxidation \#2: } \\
\text { Gasification \#3: }\end{array}$ & $\begin{array}{l}00.00 \\
14.5 \\
0.32 \\
19.9 \\
-1.24 \\
\text { NA }\end{array}$ & $\begin{array}{l}00.00 \\
14.7 \\
-2.51 \\
21.0 \\
-1.75 \\
24.7\end{array}$ & $\begin{array}{l}4.0 \\
7.8 \\
4.9 \\
6.1 \\
4.0 \\
\text { NA }\end{array}$ & $\begin{array}{c}4.0 \\
\text { NA } \\
4.3 \\
>5.1 \\
3.4 \\
6.6\end{array}$ \\
\hline
\end{tabular}

'Values are reported at the end of each stage of treatment.

${ }^{2}$ All gasifications are 2.25 hours at $725^{\circ} \mathrm{C}$ in 500 psi $\mathrm{H}_{2}$.

${ }^{3}$ All oxidations are 1 hour at $375^{\circ} \mathrm{C}$ in stagnant air.

\section{IV.1.4 Oxidation Effects}

It is evident that preoxidation via partial combustion in air does not enhance the hydrogasification rate of pyrolyzed chars at $725^{\circ} \mathrm{C}$. However, it does enhance the reaction rate of chars that have been pyrolyzed, then outgassed. Table 4 shows surface analyses of most of the chars used in this investigation. It is clear that oxygen is being fixed onto the char surfaces during partial combustion in air because the $\mathrm{O} / \mathrm{C}$ ratio increases in all but one case. The $\mathrm{O} / \mathrm{C}$ ratio for the outgassed samples is lower than the samples that have not been outgassed. The decreased Saran char gasification rate following outgassing is due to the decreased surface oxygen concentration and not the collapse of pore structure, since the total surface area increases slightly during outgassing. The coal char loses much more surface oxygen and total surface area upon outgassing. There may be a contribution of both phenomena to the lowering of the hydrogasification rate of coal char because less surface oxygen means fewer functional groups, and collapse of the pore structure may cause blockage of the reactant gas from these groups. 


$\begin{array}{lllll}\text { Sample } & \text { TSA } & \text { ASA } & \text { O/C Ratio } & \Delta \mathrm{pH}^{4} \\ & & & & \\ \text { SARAN CHAR } & 816 & 4.0 & 0.066 & -0.44 \\ \text { Oxidized } 375^{\circ} \mathrm{C}, 3.1 \% \text { Burnoff } & 815 & 6.1 & 0.108 & -2.54 \\ \text { Oxidized } 375^{\circ} \mathrm{C}, 7.7 \% \text { Burnoff } & 876 & 9.9 & 0.152 & -3.38 \\ \text { Outgassed } 1000^{\circ} \mathrm{C} & 870 & 1.5 & 0.043 & +0.55 \\ \text { Outgassed } 1000^{\circ} \mathrm{C} \text {, then } & & & & \\ \text { Oxidized } 375^{\circ} \mathrm{C}, 0.4 \% \text { Burnoff } & 762 & 2.3 & 0.080 & -2.42 \\ \text { Gasified } 725^{\circ} \mathrm{C} & 754 & \mathrm{NA} & 0.018 & +2.70 \\ & & & & \\ \text { COL CHAR } & 274 & 4.0 & 0.062 & +4.55 \\ \text { Oxidized } 375^{\circ} \mathrm{C}, 0.1 \% \text { Burnoff } & 218 & \mathrm{NA} & 0.052 & +0.82 \\ \text { Oxidized } 375^{\circ} \mathrm{C}, 5.7 \% \text { Burnoff } & 195 & \mathrm{NA} & 0.128 & -1.66 \\ \text { Oxidized } 725^{\circ} \mathrm{C}, 3.7 \% \text { Burnoff } & \mathrm{NA} & \mathrm{NA} & 0.093 & +2.88 \\ \text { Outgassed } 1000^{\circ} \mathrm{C} & 7 & 0.6 & 0.012 & +3.71 \\ \text { Outgassed } 1000^{\circ} \mathrm{C}, \text { then } & & & & \\ \text { Oxidized } 375^{\circ} \mathrm{C}, 0.5 \% \text { Burnoff } & 87 & 0.9 & 0.100 & +2.92 \\ \text { Outgassed } 725^{\circ} \mathrm{C} & \mathrm{NA} & \mathrm{NA} & \mathrm{NA} & +4.16 \\ \text { Outgassed } 725^{\circ} \mathrm{C}, \mathrm{O}_{2} \text { Chemisorbed } & \mathrm{NA} & \mathrm{NA} & \mathrm{NA} & +3.88 \\ \text { Gasified } 725^{\circ} \mathrm{C} & 313 & \mathrm{NA} & 0.052 & +3.46 \\ \text { Gasified } 725^{\circ} \mathrm{C}, \mathrm{Oxidized} 375^{\circ} \mathrm{C} & 316 & 6.3 & \mathrm{NA} & +0.91 \\ & & & & \\ \text { DEMIN. I } \mathrm{COAL} \mathrm{CHAR} & 322 & 1.3 & 0.066 & -0.63 \\ \text { Oxidized } 375^{\circ} \mathrm{C}, 2.3 \% \text { Burnoff } & 354 & 6.9 & 0.094 & -1.29 \\ \text { Oxidized } 375^{\circ} \mathrm{C}, 6.3 \% \text { Burnoff } & 376 & 6.7 & 0.092 & -2.75 \\ \text { Gasified } 725^{\circ} \mathrm{C} & 363 & \mathrm{NA} & \mathrm{NA} & +3.17\end{array}$

Units in $\mathrm{m}^{2} / \mathrm{g}$ Carbon

${ }^{2}$ Units in $\mathrm{m}^{2} / \mathrm{g}$ Carbon

${ }^{3}$ Oxygen in the form of metal oxides is not included in this ratio $\left(\mathrm{SnO}_{2}, \mathrm{Al}_{2} \mathrm{O}_{3}, \mathrm{SiO}_{2}\right.$, et.al.).

¿Units are difference in $\mathrm{pH}$ between a $0.1 \mathrm{M} \mathrm{KCl}$ solution containing the char and a standard $0.1 \mathrm{M} \mathrm{KCl}$ solution, both heat treated under reflux (ASTM method D3838-80).

There does seem to be some enhancement in rate for gasifications performed on nonoutgassed coal chars at $600^{\circ} \mathrm{C}$ during the first $2 \%$ carbon conversion, as seen in Figure 19. This
rate enhancement does not appear to occur at $725^{\circ} \mathrm{C}$ because steady state conditions are not reached until about $5 \%$ conversion, after the rate enhancement has already died out. Figures $29 \mathrm{~A}, 29 \mathrm{~B}, 30 \mathrm{~A}$, and $30 \mathrm{~B}$ show the rate data at $600^{\circ} \mathrm{C}$ normalized to $725^{\circ} \mathrm{C}$ via activation energy for Saran char, coal char, and preoxidized coal char. The highly deactivating nature of the hydrogasification reaction is very clearly illustrated.

Finally, oxygen present initially on the chars and following oxidative pretreatment is clearly shown to desorb during heatup to gasification conditions. Figure 31 shows the surface $\mathrm{O} / \mathrm{C}$ ratlo as measured by XPS for a coal char sample heated to different temperatures in the pretreatment reactor. The surface $O / C$ ratio decreases to that of the bulk coal by a ternperature of $600^{\circ} \mathrm{C}$, indicating that no excess surface oxygen remains on the sample above this temperature.

Intermittent oxidation via partial combustion in air does produce a noticeable hydrogasification rate enhancement at $725^{\circ} \mathrm{C}$. The rate after an intermittent oxidation never 


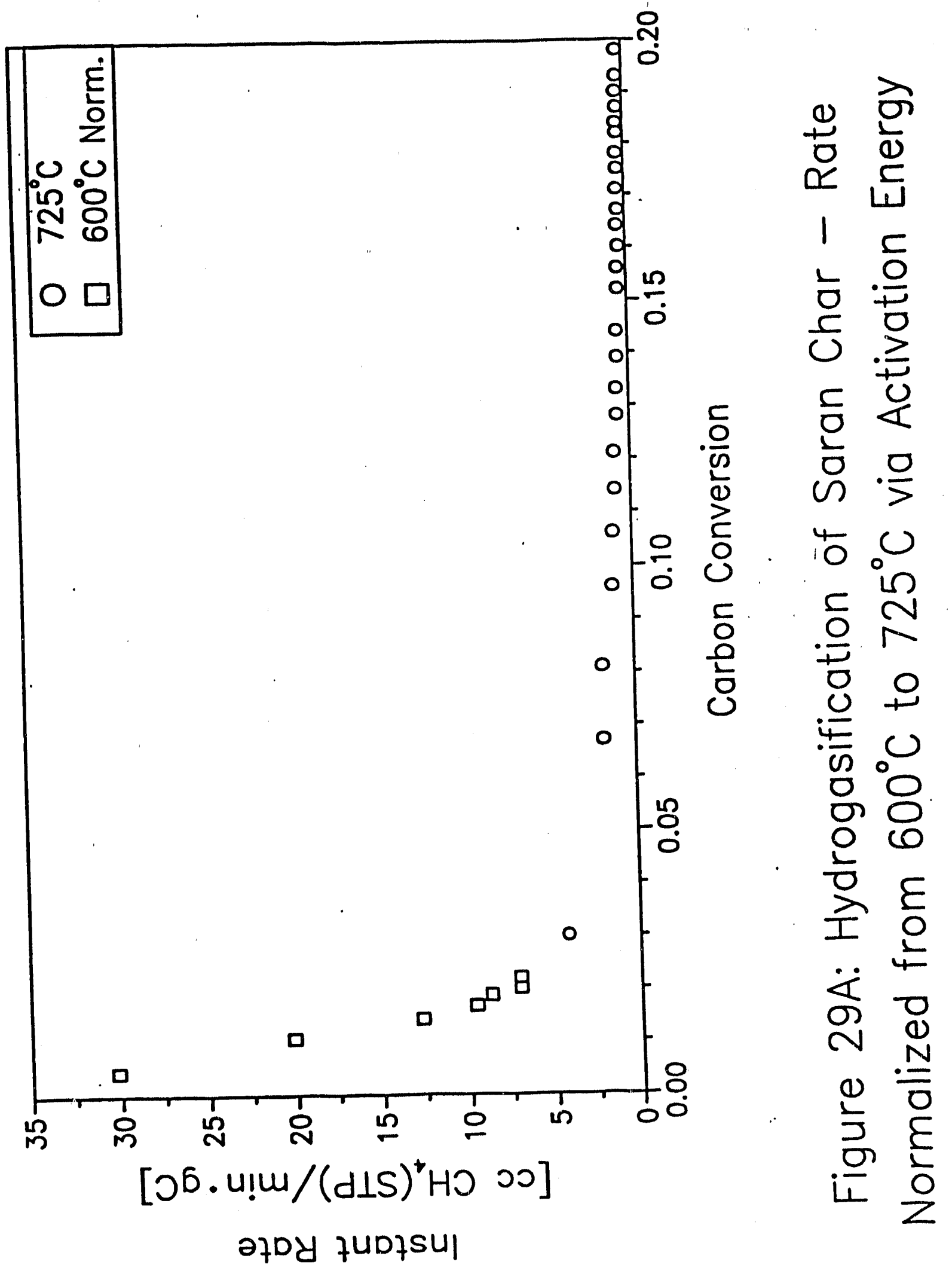




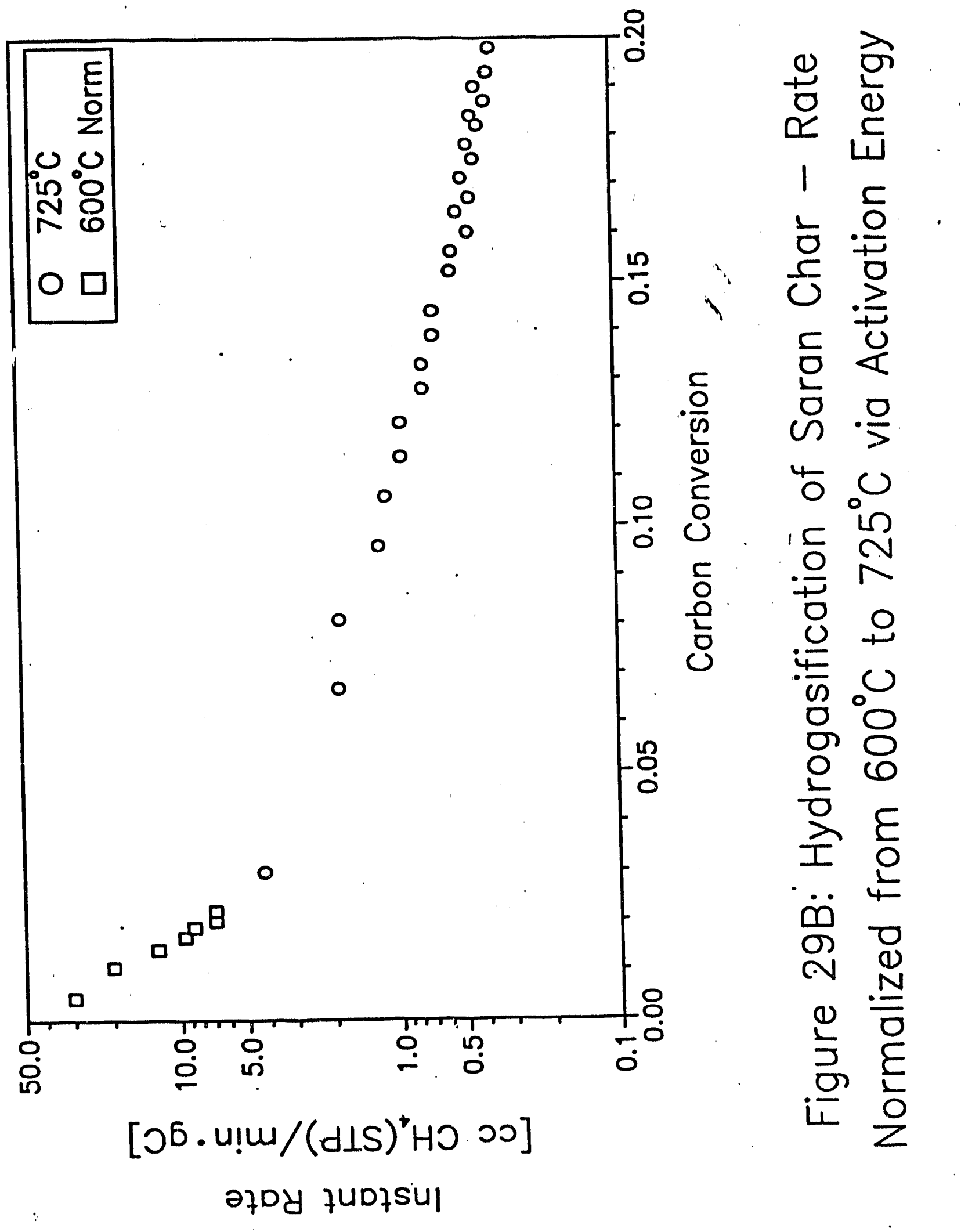




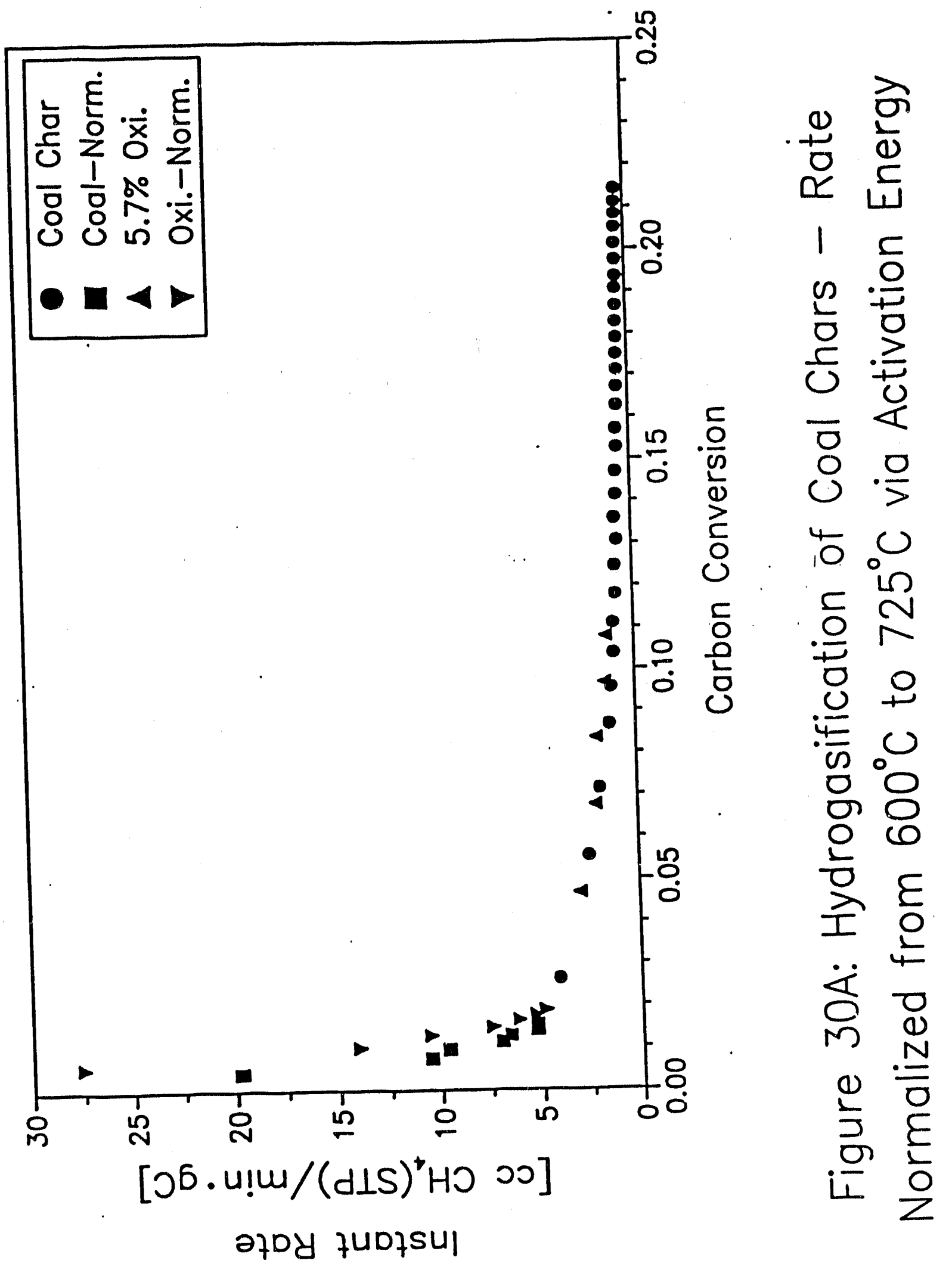




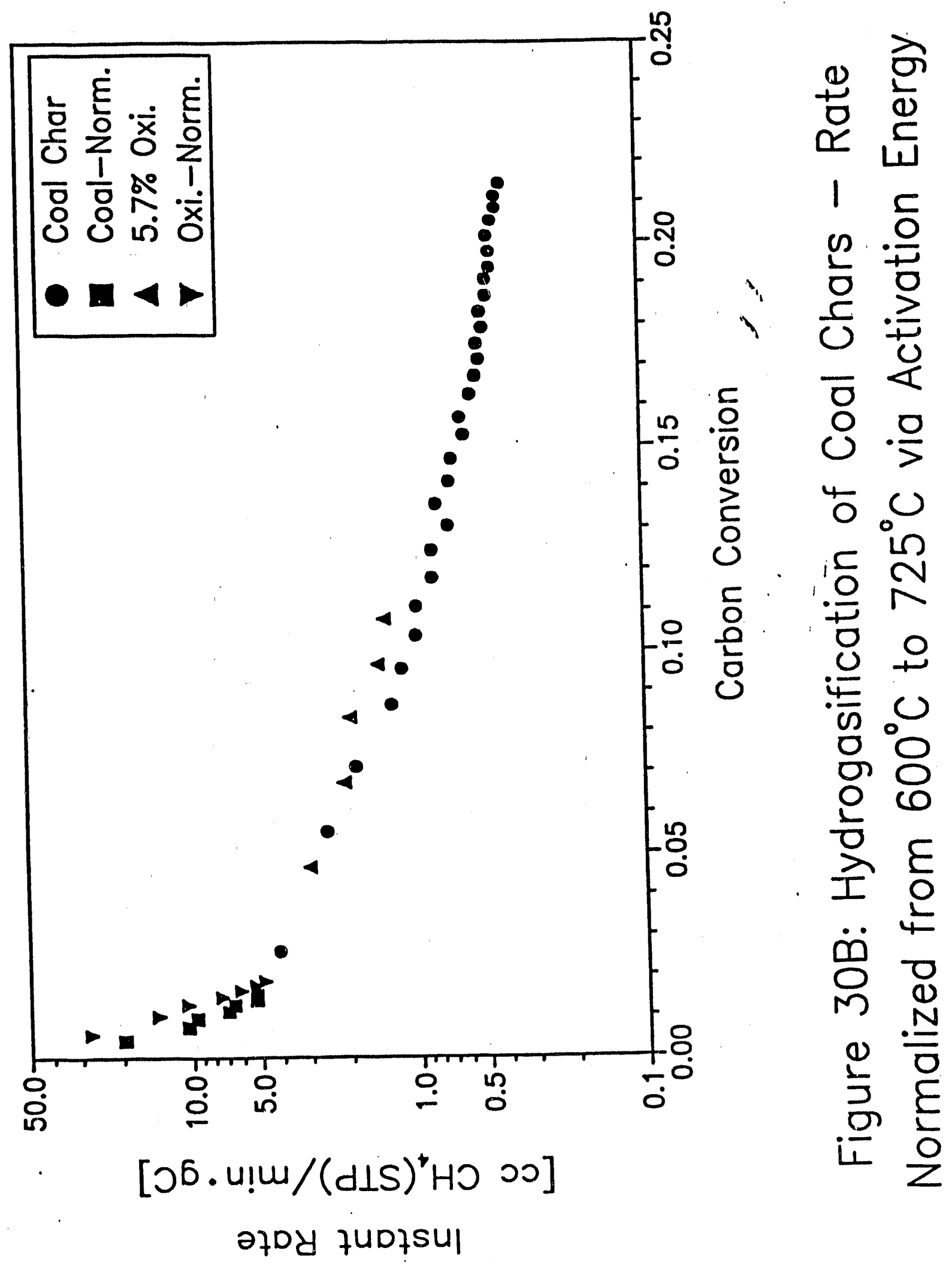




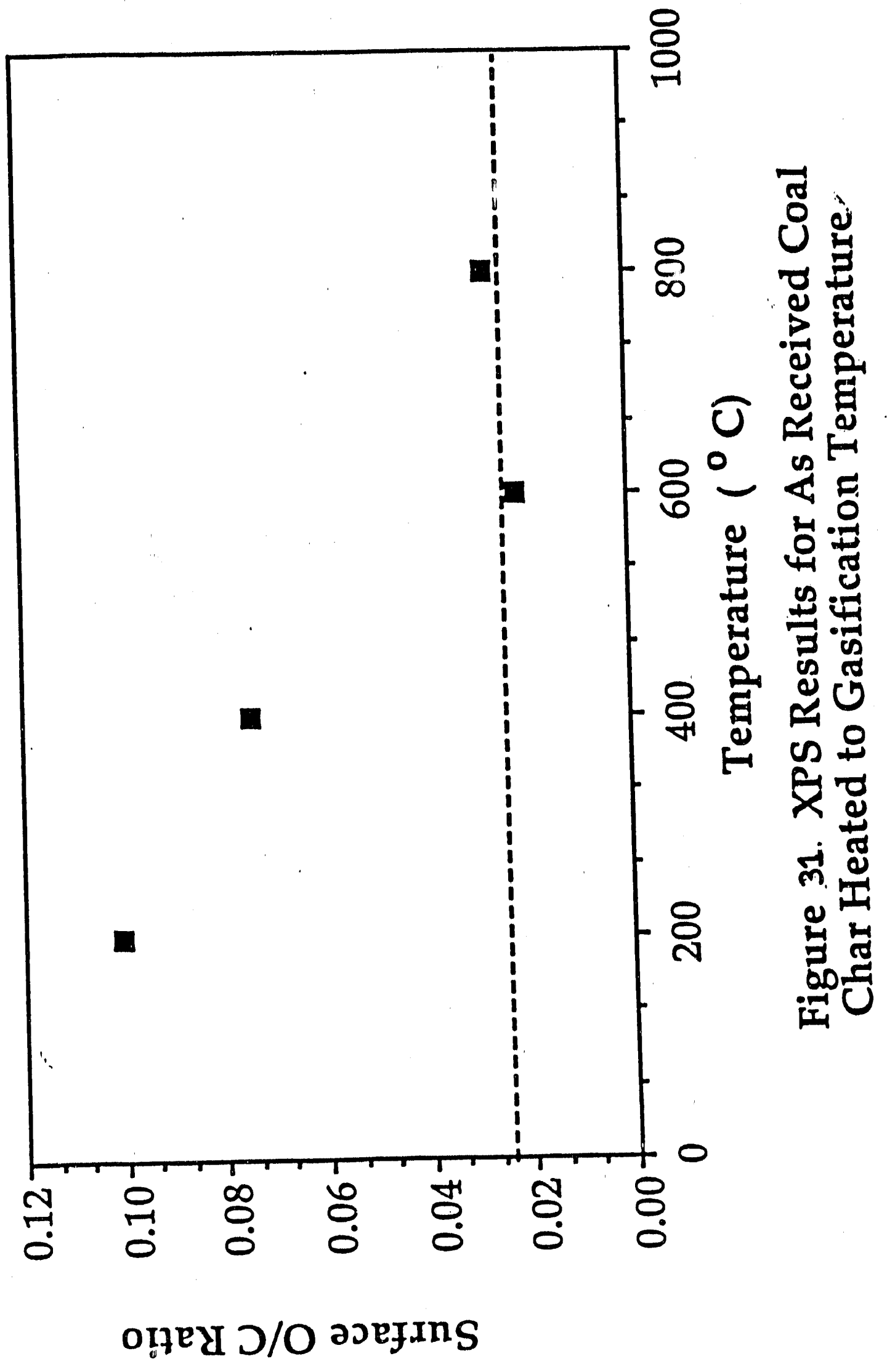


reaches the rate measured at the beginning of the first hydrogasification and only lasts for about $5 \%$ carbon conversion before it decays back to the base level. This seems to indicate that it takes roughly $5 \%$ carbon conversion to consume the additional aotive sites formed during oxidation. The intermittent oxidation performed on coal char at $725^{\circ} \mathrm{C}$ produced an enhancement comparable to the intermittent oxidations at $375^{\circ} \mathrm{C}$. This finding suggests that the nature of the functlonal groups may not be as important a factor as previously thought in determining the hydrogasification rate of chars, since acidic groups are formed at $375^{\circ} \mathrm{C}$ and basic groups at $725^{\circ} \mathrm{C}$ according to $\mathrm{pH}$ measurements.

\section{IV.1.5 Catalyst Effects}

It has been shown in this study that coal ash does not catalyze or poison coal char that has not been treated with potasslum carbonate. It has also been shown that potassium carbonate greatly catalyzes the hydrogasification of chars that contain very little or no mineral matter. In the latter stages of gasification, there may be a rate increase up to three orders of magnitude for Saran char and four orders of magnitude for demineralized coal char. Coal ash, which contains sulfur and aluminosilicates, strongly poisons the catalyst. Even though the gasification rate of the catalyzed coal char is twice the rate of the uncatalyzed coal char, the catalyzed coal char rate does not increase with conversion like the demineralized catalyzed coal char and the Saran char.

Preoxidation has no apparent effect on the catalyzed char reaction rate at $725^{\circ} \mathrm{C}$, which is the same result found for uncatalyzed chars. Intermittent oxidation of the catalyzed coal char produces a mild rate enhancement that decays quickly. This result is also similar to that observed for uncatalyzed chars.

\section{IV.1.6 Normalization of Hydrogasification Rate to O/C Ratio from XPS}

We have attempted to relate initial hydrogasification rate to the various surface properties determined, including total surface area, active surface area, and $\mathrm{O} / \mathrm{C}$ ratio as determined by XPS. Of these three parameters, the O/C ratio appears to be the only variable with which rate varies consistently. Initial absolute rates for coal char, Saran char, and demineralized coal char are divided by initial $\mathrm{O} / \mathrm{C}$ ratio as measured by XPS to give a normalized rate $\left(\mathrm{cm}^{3} \mathrm{CH}_{4} / \mathrm{min} \cdot\right.$ unit $\mathrm{O} / \mathrm{C}$ ) which varies by only a factor of two, from about 30 to 60 . The absolute rates vary by as much as a factor of five, from 0.8 to $4.0 \mathrm{~cm}^{3} \mathrm{CH}_{4} / \mathrm{min} \cdot \mathrm{gC}$.

\section{IV.2 Mechanistic Considerations}

A multi-stage reaction and the concept of creation of active sites by oxygen functional group desorption are both supported by this investigation. Hydrogen inhibition is not observed with any of the hydrogen pretreatments, indicating that dissociative hydrogen poisoning may not be the cause of the sharp hydrogasification rate decay with sample conversion. Previous studies have proposed a variety of two-stage reactions for char hydrogasification $[8,25,26]$. The best explanation for the phenomena observed in this study is a three-stage reaction for hydrogasification.

\section{IV.2.1 Proposed Model}

The dominant reaction during the first stage is the rapid hydrogasification of amorphous "secondary" carbons that are partially saturated with hydrogen, yet are probably not saturated with chemical bonds. One category of amorphous carbons is high molecular weight compounds that are not chemically bound to the char surface, but remain in char because they are not volatile 
enough to enter the gas phase during pyrolysis. The other category of amorphous carbons includes carbon structures that are partially saturated with hydrogen and chemically bound to the char base structure. If some of these groups gasify via active sites, the sites may propagate to the base structure during gasification.

The second stage involves hydrogasification of base char carbons via active sites formed by oxygen functional group desorption, and the preferential hydrogasification of carbons located on the armchair edges of aromatic planes. There is probably a great deal of overlap between these two categories of carbon. It is also possible that active sites propagate to the base char structure from the chemically bound amorphous carbons and contribute to the second stage gasification reaction.

Rate during the third stage of hydrogasification is low because the carbons that react are primarily those on the relatively unreactive zig-zag edges of the aromatic planes. There are very fow armchair edges because they have been consumed during the second stage. The only sources of surface oxygen functional groups are oxygen migration to the char surface or the uncovering of oxygen from the bulk char by removal of carbons. Because the char surface has become very non-reactive and homogeneous, the reaction rate becomes proportional to the fotal surface area.

Preoxidation does not increase or decrease the hydrogasification rate within the conversion range measurable by the equipment used in this investigation because two opposing effects roughly cancel each other out with respect to the char's reactivity with hydrogen. One force at work is a decrease in the ratio of amorphous carbons to those of the basal aromatic planes by somewhat preferential oxygen attack, and the other is the creation of more oxygen functional groups on the aromatic base structure.

Intermittent oxidation increases the hydrogasification rate, and brings the reaction from the third stage back to the second. No amorphous carbon structures are formed upon intermittent oxidation, so the rate will not be as high as that which is observed initially. Oxygen functional groups are formed on the char surface, which create active sites upon desorption. Oxidation also increases the ratio of armchair carbons to zig-zag carbons. This happens because oxygen, unlike hydrogen, does not preferentlally react with either type of edge carbon, thus leaving both present following oxidation. Since armchair carbons are more reactive toward hydrogen than zig-zag carbons, their ratio is an important parameter in determining the reactivity of a char.

It is also important to note that oxidation, in order to alter the char surface structure, must result at least in some consumption of carbon. We performed experiments using $\mathrm{HNO}_{3}$ as an oxidizing agent and also conducted partial chemisorption of oxygen onto char samples and then conducted hydrogasification. Neither of these methods of oxidation resulted in a rate enhancement, because neither of them result in char consumption and therefore change in surface structure during oxidation.

\section{IV.2.2 Supporting Observations}

There are several observations that support the proposed three-stage hydrogasification reaction in this study. Dissociative hydrogen poisoning and rate dependence upon pore structure within the first $20 \%$ carbon conversion have not been included in the proposed model. This is because they have been shown not to affect rate or correlate to rate within the first $20 \%$ carbon conversion respectively.

Initial rate decreases rapidly with conversion and cannot be matched with the intermittent treatments used in this investigation. This indicates that there may be more than one reaction stage present. Further, it supports the claim that there is a small amount of highly reactive char on the sample surface, which is consumed during the first $5 \%$ carbon conversion. If the high initial rate was due only to the number of oxygen functional groups on the char surface, then intermittent oxidation would restore the functional groups and increase the hydrogasification rate to its original value, but this is not observed. 
Preoxidation neither increases nor decreases the initial reaction rate as can be detected by the equipment used in this invesigation. The highly volatile material contained in the starting coal is drawn out of the bulk material upon pyrolysis, leaving pores. Most of the volatile material is carried away in the gas phase, but some carbonizes on the char surface. Because of the way amorphous carbon structures are formed, it would seem likely that most of the char total surface area would initially be coated with them, so gases would have to react with amorphous carbon structures before they could react with carbons of the basal aromatic planes. From a physical standpoint, it is likely that any reactant gas would preferentially attack the amorphous carbons. This proposed idea is supported by the facts that preoxidation has been shown to increase the concentration of surface functional groups, but it does not enhance the initial hydrogasification rate.

This study shows that hydrogasification rate declines rapidly and appears to become constant with total surface area after about $20 \%$ carbon conversion. The O/C ratio is low, and etch pit analysis performed by other researchers shows the predominance of zig-zag carbon configurations [29-32]. If oxygen functional groups are uniformly distributed throughout the basal cartion matrix, they should be uncovered by the consumption of overlying carbons at a fairly uniform rate and be distributed fairly evenly over the char surface. This means a roughly constant ratio of total surface area to active surface area caused by desorption of freshly uncovered oxygen groups. Since the hydrogasification rate is thought to be proportional to the active surface area, it should be proportional to the total surface area during the third gasification stage. Observations in this study appear to indicate constant rate per unit total surface area during the third stage of hyorojasification.

Intermittent oxidation has been shown to increase the $\mathrm{O} / \mathrm{C}$ ratio in this study. Other researchers have shown oxygen to form round etch pits $[29,32]$. As the oxygen attacks the zigzag edges, it must leave both zig-zag and armchair edges behind. This must increase the ratio of armchair to zig-zag carbons and partially cover the edges with oxygen functional groups, supporting the claim that partial oxidation serves as a source for regeneration of these configurations after they have been destroyed during hydrogasification. 


\section{COMMENTS ON METHODOLOGY AND PROBLEMS ENCOUNTERED}

In general, the research project was conducted as planned and outlined in the original grant proposal. Several departures from the plan were made, however, as a result of early experiments performed. Most significantly, the first result we obtained was that oxidation of asprepared chars resulted in only a very slight, if any, rate enhancement in hydrogasification. We therefore did not attempt any partial chemisorption of oxygen on as-prepared surfaces, as we would have been unable to detect any change in rate because there was none.

There were several other results that affected the experiments performed and that are important to note for future research in hydrogasification. First, the decline in hydrogasification rate with char conversion was steep enough to make isothermal gasification to high char conversion impractical. For instance, it took about two hours to achieve $12 \%$ char conversion, but about nine hours to reach $20 \%$. We thus were unable to look at high char conversions within the temperature bounds we set to assure intrinsic gasification rate measurements unaffected by mass transfer.

Next, the uptake of oxygen by reduced coal mineral oxides means that oxygen chemisorption cannot be used as a measure of active surface area on hydrogasified coal chars. We found that if we subjected coal ash alone to hydrogasification conditions, the oxygen uptake by the ash, which had been reduced, was very high. Further, our results of ASA measurements on intermittently oxidized Saran char showed a trend in ASA, from oxygen chemisorption, opposite to that of hydrogasification rate. This implies that there is interaction between adsorbed hydrogen and oxygen on the char surface during oxygen chemisorption, further strengthening the point that oxygen chemisorption is unsuitable for measuring ASA important in hydrogasification on any char. Finally, the fact that we did not observe any rate enhancement via continuous addition of oxygen to hydrogen probably resulted from the conservative concentration of oxygen we used. Because it appears that the oxygen present reacted with hydrogen before it could oxidize the carbon, it may be advantageous to attempt a second experiment with a higher oxygen concentration.

The other departures from the planned methodology were minor and not of major effect on the results. First, we did not use Auger spectroscopy to analyzed oxygen groups on the char surface, as XPS proved adequate for elucidating the surface O/C ratio. Also, we were not able to pelletize the coal char samples, so we were forced to place them on double-sided tape for analyses. This unfortunately precluded elevated temperature XPS analyses, so we used ceramic adhesive to affix char samples to the XPS mount in cases where we wanted elevated temperatures.

We were not able to completely demineralize the coal in this study using the standard methods reported in the literature, or at least we were not able to obtain quantitative analyses of the chars which gave us confidence that we had demineralized completely. However, we were able to demineralize to the extent that any residual minerals did not poison alkall carbonate catalyst used; demineralized char catalyzed gasification rate was nearly the same as Saran char catalyzed gasification rate.

Overall, we are satisfied that the proposal objectives have been met. The conclusions are provided in the next section. 


\section{CONCLUSIONS}

The major objective of this Investigation was to gain a more fundamental understanding of the hydrogasification reaction, and to determine ways to increase the reaction rate via char oxidation. In order to ensure that reaction kinetics and not mass transfer limited reaction, we chose a temperature of $725^{\circ} \mathrm{C}$ for most reactions. We obtained an activation energy for the reaction of about $72 \mathrm{kcal} / \mathrm{gmol}$ in the temperature range of $700-775^{\circ} \mathrm{C}$, close to values reported in the literature for intrinsic $\mathrm{C}-\mathrm{C}$ bond cleavage. We also determined that mass transfer limitations were not occurring due to particle size or sample bed depth.

Hydrogasification rates of Saran char and coal char were shown to decay rapidly with conversion, and were similar in magnitude. Rate for the first $2-3 \%$ carbon conversion could not be measured at $725^{\circ} \mathrm{C}$, but the sharp rate decay during the rest of the reaction was evident. The sharp rate decay in rate for the first $2-3 \%$ carbon conversion was exhiblted much more clearly by hydrogasification rates measured at $600^{\circ} \mathrm{C}$. For uncatalyzed hydrogasification, initial rate, normalized from $600^{\circ} \mathrm{C}$ to $725^{\circ} \mathrm{C}$ using the activation energy of $72 \mathrm{kcal} / \mathrm{gmol}$ indlcates that rate decays by a factor of thirty after $10-15 \%$ carbon conversion, and by a factor of one hundred after $20-25 \%$ carbon conversion. Reaction rate following outgassing ( $1273 \mathrm{~K}$ in vacuo for $12 \mathrm{hr}$ ) was an order of magnitude lower than that of fresh char.

The primary focus of this investigation was to study the role of oxidation in hydrogasification. It was found that partial combustion in air always increased the char surface oxygen concentration as measured by $\mathrm{pH}$ or XPS. These surface oxygen groups were found to desorb during heatup to hydrogasification conditions, supposedly leaving vacant active sites where hydrogasification could occur. This partial combustion in air increased the subsequent hydrogasification rate of chars that had been outgassed or previously gasified in hydrogen, but did not significantly increase the reaction rate of fresh chars. The effect was observed for both partially bumt chars and chars exposed to oxygen chemisorption at $300^{\circ} \mathrm{C}$, where little burnoff occurs. Further, the hydrogasification rate of chars that had been oxidized following outgassing or hydrogasification, although increased, was not restored to that shown initially by a fresh char.

To study hydrogen inhibition, several hydrogen pretreatments were done at conditions less severe than those chosen for standard gasification during this experimentation, so hydrogasification rates would be low. We wished to determine if strong, irreversible hydrogen adsorption on the char surface was responsible for the decline in gasification rate with conversion. Some pretreatments were performed at elther $725^{\circ} \mathrm{C}$ or $500 \mathrm{psi} \mathrm{H}_{2}$, but none resulted in rate inhibition at standard gasification conditions. This led us to rule out strong hydrogen adsorption as the reason for the decline in rate with conversion.

Coal minerals did not affect the uncatalyzed hydrogasification rate of coal char. The hydrogasification rates of all chars used in this investigation were catalyzed by potassium carbonate; however, it was found that coal ash greatly poisons this catalyst. Catalyzed Saran char and catalyzed demineralized coal char both had rates that started 2-3 times higher than the uncatalyzed chars and increased with conversion, giving ultimate rate enhancements of as much as 400 -fold at high conversions. The catalyzed coal char started at a rate that was about twice the uncatalyzed rates, and this rate declined with conversion in a pattern similar to that of the uncatalyzed char.

Comparison of gasification rate with char surface properties and structure showed that total surface area did not correlate with hydrogasification rate for the first $15-25 \%$ carbon conversion. This indicates that the chemical nature of the char surface is of fundamental importance in determining hydrogasification rate. Measurement of active surface area and surface oxygen concentration were thus examined as a basis of reaction rate.

Active surface area of chars was measured using oxygen chemisorption. While this gave reasonable results for ungasified chars, the ash present in coal, which was reduced during hydrogasification, had a very large oxygen uptake which interfered with ASA measurement of 
hydrogasified coal chars. The active surface area measurements for intermittently oxidized Saran char, which had no ash, were found to have trends opposite to the measured gasification rates. They showed a higher active surface area following hydrogasification, and a lower active surface area following intermittent oxidation. We suspect that this is because oxygen interacts with residual adsorbed hydrogen on the char surface during chemisorption at $300^{\circ} \mathrm{C}$. We are confident that our oxygen uptake measurements are valid, because we performed many experiments and repititions to optimize and verify our results. We must therefore conclude from our studies that oxygen chemisorption is not a useful tool for characterizing ASA of chars which have been subjected to the highly reducing conditions of hydrogasification.

We did correlate hydrogasification rate with $\mathrm{O} / \mathrm{C}$ ratio, a measure of surface oxygen concentration, measured by $X$-ray photoelectron spectroscopy. The variation in normalized rate was usually within a factor of two for absolute rates which varied by as much as a factor of six. We conclude that there is therefore some basis for basing rate on O/C ratio measured via XPS before or after gasification.

The observations in our studies supports a hydrogasification reaction that is composed of three stages in which each stage dominates during different ranges of carbon conversion. During the first stage, hydrogen reacts rapidly with the small amount of amorphous "secondary" carbon. This carbon is highly reactive because it is not completely saturated chemically. The second stage involves hydrogasification of base char carbons via active sites formed by functional group desorption, and hydrogasification of carbons located on the armchair edges of the base char, which is composed mainly of randomly aligned graphite crystalites. Active sites formed during the first reaction stage may propagate to the base char and contribute to hydrogasification during the second stage. Rate during the third stage of hydrogasification is low because the carbons that react are primarily those on the relatively unreactive zig-zag edges of the aromatic planes. There are very few active sites or armchair edges left. During the third stage, reaction rate is roughly proportional to the char total surface area because the surface is relatively unreactive and homogeneous, and the only source of functional groups is oxygen trapped in the bulk char.

Preoxidation does not change initial char reactivity toward hydrogen within the measurable range of carbon conversion in this investigation because two effects roughly cancel each other out. One effect is the increase in the number of oxygen functional groups from oxidation, which increases the overall char reactivity. The other effect is the initial, preferential attack of the "secondany" carbons by oxygen, which decreases the overall char reactivity.

Intermittent oxidation increases char reactivities for two reasons. It increases the number of oxygen functional groups on the char surface, and it increases the ratio of the armchair carbons to zig-zag carbons. The rate increase from intermittent oxidation lasts for about $10 \%$ carbon conversion, after this the surface oxygen concentration has declined back to that of the bulk char and the carbons in the armchair configurations have all been gasified.

summary, oxidation can be used as a means of enhancing hydrogasification rate of coal chars. The strong decline in rate with conversion indicates that the best rate enhancement is observed by oxidizing the char after it has been partially reacted in hydrogen. By conducting a series of cyclic hydrogasification/oxidations, the overall time to achieve complete char conversion will no doubt be reduced substantially. We showed that total gasification time in hydrogen to achieve $23 \%$ conversion at $725^{\circ} \mathrm{C}$ was reduced from about nine hours without oxidation to about five hours with two intermittent oxidations. Thus, the oxidation effect is significant; however, it remains to be seen from further work if it will become economical to include such an oxidition step in hydrogasification processes. 


\section{REFERENCES}

1. Steinberg, M., in '1987 Internatlonal Conference on Coal Sclence', (Eds J.A. Moulijn et al.), Elsevier Science Publishers B.V., Amsterdam, 11, 953 (1983).

2. Hirsch, R.L., J.E. Gallagher Jr., R.R. Lessard, and R.D. Wesselhoft, Science, 215, 121 (1982).

3. Mims, C.A., and J.J. Krajewskl, J. Catal., 102, 140 (1986).

4. Blackwood, J.D., Aust. J. Applled Scl., 199 (1962).

5. Blackwood, J.D. and D.J. McCarthy, Aust. J. Chem., 19, 797 (1966).

6. Blackwood, J.D., Aust. J. Chem., 15, 397 (1962).

7. Blackwood, J.D., Aust. J. Chem., 12, 14 (1959).

8. Blackwood, J.D., D.J. McCarthy, and B.D. Cullis, Aust. J. Chem., 20, 2525 (1967).

9. Blackwood, J.D., B.D. Cullis, and D.J. McCarthy, Aust. J. Chem., 20, 1561 (1967).

10. Makino, M. and Y. Toda, Fuel, 60, 321 (1981).

11. Cao, J.-R. and M.H. Back, Carbon, 20, 505 (1982).

12. Juntgen, H., Carbon, 19, 167 (1981).

13. Lizzio, A.A., H. Jiang, and L.R. Radovic, Carbon, 28, 7 (1990).

14. Huttinger, K.J. and J.S. Nill, Carbon, 28, 457 (1990).

15. Tomita, A., O.P. Mahajan, and P.L. Walker Jr., Fuel, 56, 137 (1977).

16. Zielke, C.W. and E. Gorin, Ind. and Eng. Chem., 47\#4, 820 (1955).

17. Otto, K. and M. Shelf, Chem. Eng. Commun., 5, 223 (1980).

18. Freund, H. Fuel, 64, 657 (1985).

19. Walker, P.L.Jr., Carbon, 24\#4, 379 (1986).

20. Adams, K.E., D.R. Glasson, and S.A.A. Jayawerra, Carbon, 27, 95 (1989).

21. Radovic, L.R., P.L. Walker, and R.G. Jenkins, Fuel, 62, 849 (1983).

22. DeKoranyl, A., Carbon, 27, 55 (1989).

23. Tong, S.B., P. Pareja, and M.H. Back, Carbon, 20\#3, 191 (1982).

24. Cypres, R., D. Planchon, and C. Braekman-Danhuex, Fuel, 64, 1375 (1985). 
25. Blackwood, J.D. and D.J. McCarthy, Aust. J. Chem., 20, 2003 (1967).

26. Feldkirchner, H.L. and H.R. Linden, I\&EC Process Design and Development, 2\#2, 153 (1963).

27. Wood, B.J. and K.M. Sancier, Cata. Rev. Scl. Eng., 26, 233 (1984).

28. Laine, N.R., F.J. Vastola, and P.L. Walker Jr., J. of Phys. Chem., 67, 2030 (1963).

29. Yang, R.T. and R.Z. Duan, Carbon, 23\#3, 325 (1985).

30. Pan, Z.J. and R.T. Yang, J. Catal., 123, 206 (1990).

31. McKeo, D.W. in 'Chemlstry and Physics of Carbon', (Eds P.L. Walker Jr. and P.A. Thrower), Marcel Dekker, New York, 16\#1 (1981).

32. Yang, R.T. and K.L. Yang, Carbon, 23\#5, p.537 (1985).

33. Cao, J.R and M.H. Back, Carbon, 30\#6, 505 (1981).

34. Shaw, J.T., Proc. Intern. Conf. Coal Sclence, 209 (1981).

35. Gilberson, R.C. and J.P. Walker, Carbon, 3, 521 (1966).

36. Biderman, D.L., A.J. Miles, F.J. Vastola, and P.L. Walker Jr., Carbon, 14, 351 (1976).

37. Huttinger, K.J. Fuel, 62, 166 (1983).

38. Mims, C.A. and J.K. Pabst, ACS Dlv. Fuel Chem. Prepr., 25\#3, 263 (1980).

39. Mims, C.A. and J.K. Pabst, Fuel, 62, 176 (1983).

40. Huttinger, K.J. and R. Minges, Fuel, 65, 1122 (1986).

41. McKee, D.W. and D. Chatterji, $12^{\text {th }}$ Blennial Conference on Carbon, Pittsburg, PA, 189191 (1975).

42. Huttinger, K.J. ACS Dlv. Fuel Chem. Prepr., 34\#1, 56 (1989).

43. Carangelo, R.M., P.R. Solomon, and D.J. Gerson, Fuel, 66, 960 (1987).

44. Hauge, R.H., L. Fredin, J. Chu, and J.L. Margrave, ACS Dlv. Fuel Chem., 28\#1, 35 (1983).

45. Walker, P.L.Jr., Carbon, 28, 261 (1990).

46. Phillips, R.F., F.J. Vastola, and P.L. Walker Jr., Carbon, 8, 197 (1970).

47. Hart, P.J., F.J. Vastola, and P.L. Walker Jr., Carbon, 5, 363 (1967).

48. Treptau, M.H. and D.J. Miller, Carbon, 29, 531 (1991). 
49. Toomajian, M., M. Lussier, and D.J. Miller, ACS DIv. Fuel Chem. Prepr., 36\#1, 139 (1991).

50. H. Zoheldl and D.J. Miller, Carbon, 25, 809 (1987).

51. Ergun, S., J. Phys. Chem., 60, 480 (1956).

52. Saber, M.J., J.L. Falconer, and L.F. Brown, Fuel, 65, 1356 (1986).

53. Hashimoto, K., K. Miura, J.J. Xu, and A. Watanabe, Chem. Lett., 5, 555 (1984).

54. Muhlen, H.-J., K.H. vanHeek, and H. Juntgen, Fuel, 65, 591 (1986).

55. Tromp, P.J.J., F. Kapteijn, J.J. Boon, and J.A. Moulijn, Int'l Conf. on Coal Scl., 537 (1987).

56. Keleman, S.R. and H. Freund, ACS Dlv. Fuel Chem. Prepr., 32\#1, 318 (1987).

57. Treptau, M.H. and D.J. Miller, ACS Div. Fuel Chem. Prepr., 34\#1, 176 (1989).

58. Zoheidi, H. and D.J. Miller, Carbon, 25, 256 (1987).

59. Noh, J.S. and J.A. Schwarz, Carbon, 28, 675 (1990).

60. Ohtsuka, Y., K. Itagaki, K. Higashiyama, A. Tomita, and Y. Tamai, Neaoyo Kyokalshl, 60,437 (1981).

61. Harbour, J.R., M.J. Walzak, W. Limburg and J. Yanus, Carbon, 24\#6, 725 (1986).

62. Papirer, E., S. L, and J.-B. Donnett, Carbon, 25, 243 (1987).

63. Cao, J.R. and M.H. Back, Carbon, 23\#2, 141 (1985).

64. Bohem, H.P., E. Diehl, W. Heck, and R. Sappok, Angew. Chem. Inter. Edit., 3\#10, 669,(1964).

65. Voll, M. and H.P. Bohem, Carbon, 9, 481 (1971).

66. Blackwood, J.D. Carbon, 12, 14 (1959).

67. Studebaker, M.L. and R.W. Rinehart Sr., Rubb. Chem. Tech., 45, 106 (1972).

68. Garten, V.A., D.E. Weiss, and J.B. Willis, Aust. J. Chem., 10, 309 (1957).

69. Barton, S.S. and B.H. Harrison, Carbon, 13, 283 (1975).

70. Barton, S.S., D. Gillespie, and B.H. Harrison, Carbon, 11, 649 (1973).

71. Barton, S.S., G.L. Boulton, and H. Harrison, Carbon, 10, 395 (1972).

72. Puri, B.R., D.D. Singh, J. Nath, and L.R. Sharma, Ind. Eng. Chem., 50, 1071 (1958). 
73. Purl, B.R. and R.C. Banasal, Carbon, 1, 457 (1964).

74. Kolthoff, I.M. J. Am. Chem. Soc., 54, 69 (1932).

75. Nemerovets, N.N., V.F. Surovikin, S.V. Orekhov, G.V. Sazhin, and N.G. Sadovnichuk, Solld Fuel Chem. (Russlan), 14\#4, 120 (1980).

76. Sellitt, C., J.L. Koenig, and H. Ishida, Carbon, 28, 221 (1990).

77. King, A., J. Chem. Soc., 1489 (1937).

78. Garten, V.A. and D.E. Weiss, Aust. J. Chem., 8, 68 (1955).

79. Mlura, K., M. Makino, and P.L. Silveston, Fuel, 69, 580 (1990).

80. Dollimore, J., C.M. Freedman, B.H. Harrison, and D.F. Quinn, Carbon, 8, 587 (1970).

81. Tomita, A. and Y. Tamai, J. Catal., 27, 293 (1972).

82. Tomita, A. and Y. Tamal, J. Phys. Chem., 78, 2254 (1974).

83. Tomita, A., N. Sato, and Y. Tamai, Carbon, 12, 143 (1974).

84. McKee, D.W., Carbon, 12, 453 (1974).

85. Nahas, N.C., Fuel, 62, 239, (1983).

86. Kubiak, H., H.J. Schroter, A. Sulimma, and K.H. vanHeek, Fuel, 62, 242 (1983).

87. Baker, R.T.K., R.D. Sherwood, and E.G. Derouane, J. Catal., 75, 382 (1982).

88. Nishiyama, Y., T. Haga, O. Tamura, and N. Sonehara, Carbon, 28\#1, 185 (1990).

89. Huttinger, K.J. and P. Schleicher, Fuel, 60, 1005 (1981).

90. Baker, R.T.K. and J.J. ChludzinskJ Jr., Carbon, 19, 75 (1981).

91. Gothel, P.J. and R.T. Yang, J. Catal., 101, 342 (1986).

92. Holstein, W.L. and M. Boudart, J. Catal., 72, 328 (1981).

93. Zoheidi, H., Ph.D. Dissertation, Michigan State University, East Lansing, MI (1987).

94. Lang, R.J. and R.C. Neavel, Fuel, 61, 620 (1982).

95. McKee, D.W. and D. Chatterji, Carbon, 13, 381 (1975).

96. McKee, D.W. and D. Chatterii, Carbon, 16, 53 (1978).

97. McKee, D.W., C.L. Spiro, P.G. Koski, and E.L. Lamby, Fuel, 62, 218 (1983). 
98. . Veraa, M.J. and A.T. Bell, Fuel, 57, 194 (1978):

99. Wood, J.B., R.H. Fleming, and H. Wise, J. Am. Chem. Soc., 63, 1600 (1984).

100. Wood, J.B., R.D. Brittain, and K.H. Lau, Carbon, 23, 73 (1985).

.101. Long, F.J. and K.W. Sykes, J. Chem. Phys., 47, 361 (1950).

102. Wen, W.Y., Cata. Rev. Scl. Eng., 22, 1 (1980).

103. Sams, D.A., T. Talverdian, and F. Shadman, Fuel, 64, 1208 (1985).

104. Mims, C.A. and J.K. Pabst, Proc. Int. Conf. on Coal Sclence, Verlag Gluckauf GmbH, Essen, 730-736 (1981).

105. Mims, C.A., K.D. Rose, M.T. Melchior, and J.K. Pabst, J. Am. Chem Soc., 104, 6886 (1982).

106. Yuh, S.J. and E.E. Wolf, J. Am. Chem. Soc., 63, 1604 (1984).

107. Saber, J.M., J.L. Falconer, and L.F. Brown, J. Catal., 90, 23 (1984).

108. Wood, R.E. and G.R. Hill, ACS Dlv. Fuel Chem. Prepr., 17, 1 (1972).

109. Gardner, N., E. Samuels, and K. Wilkes, Adv. Chem. Ser., 131, 217 (1974).

110. Matsumoto, S. and P.L. Walker Jr., Carbon, 27, 395 (1989).

111. Formella, K., P. Leonhardt, A. Sulimma, K.H. vanHeek, and H. Juntgen, Fuel, 65, 1471 (1986).

112. Bruno, O., L. Cavani, and G. Passonl, Fuel, 65, 1473 (1986).

113. Toomajian, M.E., Masters Thesis, Michigan State University, East Lansing, MI (1991).

114. Bishop, M. and D.L. Ward, Fuel, 37, 191 (1958). 
APPENDIX A

HYDROGASIFICATION RATE CALCULATIONS 


\section{APPENDIX A}

\section{HYDROGASIFICATION RATE CAICUIATIONS}

The method used to calculate hydrogasification rate of chars in this study involved 11 steps. Before an experiment, the char was weighed and calibration data collected. During a reaction, sample collections were timed and taken at discrete intervals. After the experiment, the rate was calculated by dividing the amount of methane collected at each sampling by the collection time. A plot of time vs. rate was drawn on graph paper, and manually integrated by counting the number of squares below the curve up to each individual data point. Frorn this, percent carbon conversion and instant rate were calculated. The 11 steps are listed below, followed by an example.

1. Initial char weight was taken, then the initial weight of carbon in the char was determined by the following equation:

Initial wt. Carbon $=$ (Initial wt. Char) (\& Carbon in Char)

2. A calibration was made to detexmine the area of a chart recorder peak for a. known amount of methane. An electronic integrator reported the area under a peak in terms of counts (\# cts. cal.).

3. The amount of methane present in the full calibration loop at STP was calculated by using the following equation:

\#CC $\mathrm{CH}_{4} \mathrm{cal} .=(1.81 \mathrm{cc} 100 \mathrm{p})\left(4.98 \mathrm{CH}_{4}\right)\left(\frac{273 \mathrm{~K}}{295 \mathrm{~K}}\right)\left(\frac{740 \mathrm{mmHa}}{760 \mathrm{mmHg}}\right)$

$\neq \mathrm{CC} \mathrm{CH}_{4} \mathrm{Cal} .=0.0799 \mathrm{CC} \mathrm{CH}_{4}$ (STP)

4. The total amount of methane taken in one sample during the reaction was determined at STP once the calibration was made and the attenuations were set: 
\#cc $\mathrm{CH}_{4}(\mathrm{STP})=\frac{(0.0799) \text { (\#) cts, sample) (atten, sample) }}{\text { (\#) cal.)(atten. cal.) }}$

5. The absolute rate was calculated by dividing the total amount of methane from a sample collection by the collection time and the initial weight of carbon in the sample:

$$
\text { Absolute Rate }=\frac{[\mathrm{CCCH} \text { (STP)] }}{(\text { Coll. Time })(\text { Initial Wt. C) }}
$$

6. The time at which each sample collection was taken was recorded during the reaction. A plot of absolute rate vs. time was drawn on graph paper.

7. A curve was drawn through the data points. The squares under the curve were counted between the beginning of the reaction and a given data point, as a means of manually integrating the curve to determine the area under the curve that corresponds to the given data point.

8. The value of one square on the graph was determined by the chosen scale:

$$
\text { Block Value }=\left|\frac{\text { amount of time }}{\text { unit length }}\right| \frac{\text { Abs. Rate }}{\text { unit length }} \mid
$$

9. The total amount of methane given off per unit weight of carbon in the char up to a particular data point was then determined by multiplying the number of blocks under the curve by the value of each block:

$$
\mathrm{CH}_{1} / \text { Unit } \mathrm{Wt} \text {. Carbon }=\text { (Block Value) (Blocks) }
$$

10. This was converted to 8 carbon conversion by the following equation:

$$
\text { \& C Conv. }=\frac{(\mathrm{CH} / \text { Unit Wt. C })(12.011 \mathrm{gC} / \mathrm{mol})(1008)}{22,400 \mathrm{cc} / \mathrm{mol}(\mathrm{STP})}
$$

11. Once the \& carbon conversion was known for the different samples, the instant rate could be calculated from the absolute rate:

Inst. Rate $=(100 \%)$ (Abs. Rate) $/(100 \%-z$ Carbon Conv. $)$

An example of the values calculated in determining the instant rate as a function of $\%$ carbon conversion during hydrogasification is given on the following page. The example is of the base case coal char. 
Table A.1: BASE CASE COAL CHAR HYDROGASIFICATION RATE DATA AND CALCULATIONS

Initial Wt. Carbon $=(0.1965 \mathrm{~g}$ Char $)(74.728$ Carbon $)$

Initial wt. Carbon $=0.1468 \mathrm{~g}$

* Counts Calibration $=160$

Attenuation of calibration set at 8 .

\begin{tabular}{c|c|c|c|c}
$\begin{array}{c}\text { Sample } \\
\text { Number }\end{array}$ & $\begin{array}{c}\text { Time } \\
\text { into } \\
\text { Run } \\
\text { (min) }\end{array}$ & $\begin{array}{c}\text { Coll. } \\
\text { Time }\end{array}$ & Atten. & $\begin{array}{c}\text { Counts } \\
\text { of } \\
\text { Counts }\end{array}$ \\
\hline \hline 1 & 5 & 1 & 32 & 75 \\
2 & 20 & 1 & 32 & 294 \\
3 & 37 & 1 & 32 & 173 \\
4 & 52 & 1 & 32 & 127 \\
5 & 72 & 1 & 16 & 173 \\
6 & 82 & 1 & 16 & 154 \\
7 & 103 & 1 & 8 & 266 \\
8 & 119 & 1 & 8 & 259 \\
9 & 135 & 1 & 8 & 217 \\
10 & 153 & 1 & 8 & 216
\end{tabular}

Block Value $=(5.0 \mathrm{~min})\left(0.1 \mathrm{cc} \mathrm{CH}_{4} / \mathrm{min} \cdot \mathrm{g} \mathrm{C}\right)$

Block value $=0.5 \mathrm{ccCH}_{4} / \mathrm{g} \mathrm{C}$

\begin{tabular}{c|c|c|c|c}
$\begin{array}{c}\text { Sample } \\
\text { Number }\end{array}$ & $\begin{array}{c}\text { Abs.1 } \\
\text { Rate }\end{array}$ & $\begin{array}{c}\text { Blocks } \\
\text { to } \\
\text { Point }\end{array}$ & $\begin{array}{c}\text { z } \\
\text { Conv. }\end{array}$ & $\begin{array}{l}\text { Inst.2 } \\
\text { Rate }\end{array}$ \\
\hline \hline & & & & \\
1 & 1.02 & 2 & 0.05 & 1.02 \\
2 & 4.00 & 98 & 2.63 & 4.11 \\
3 & 2.35 & 207 & 5.56 & 2.49 \\
4 & 1.73 & 267 & 7.15 & 1.86 \\
5 & 1.18 & 324 & 8.68 & 1.29 \\
6 & 1.05 & 357 & 9.57 & 1.16 \\
7 & 0.90 & 387 & 10.39 & 1.00 \\
8 & 0.88 & 414 & 11.11 & 0.99 \\
9 & 0.74 & 440 & 11.80 & 0.84 \\
10 & 0.74 & 465 & 12.47 & 0.84
\end{tabular}

1. Units $[=] \mathrm{cc} \mathrm{CH}^{4} / \mathrm{min} \cdot \mathrm{g}$ Carbon Initial

2. Units [ $=] \mathrm{cc} \mathrm{CH}_{4} / \mathrm{min} \cdot \mathrm{g}$ Carbon Instant 


\section{APPENDIX B}

\section{SCHEMATICS OF EQUIPMENT USED}




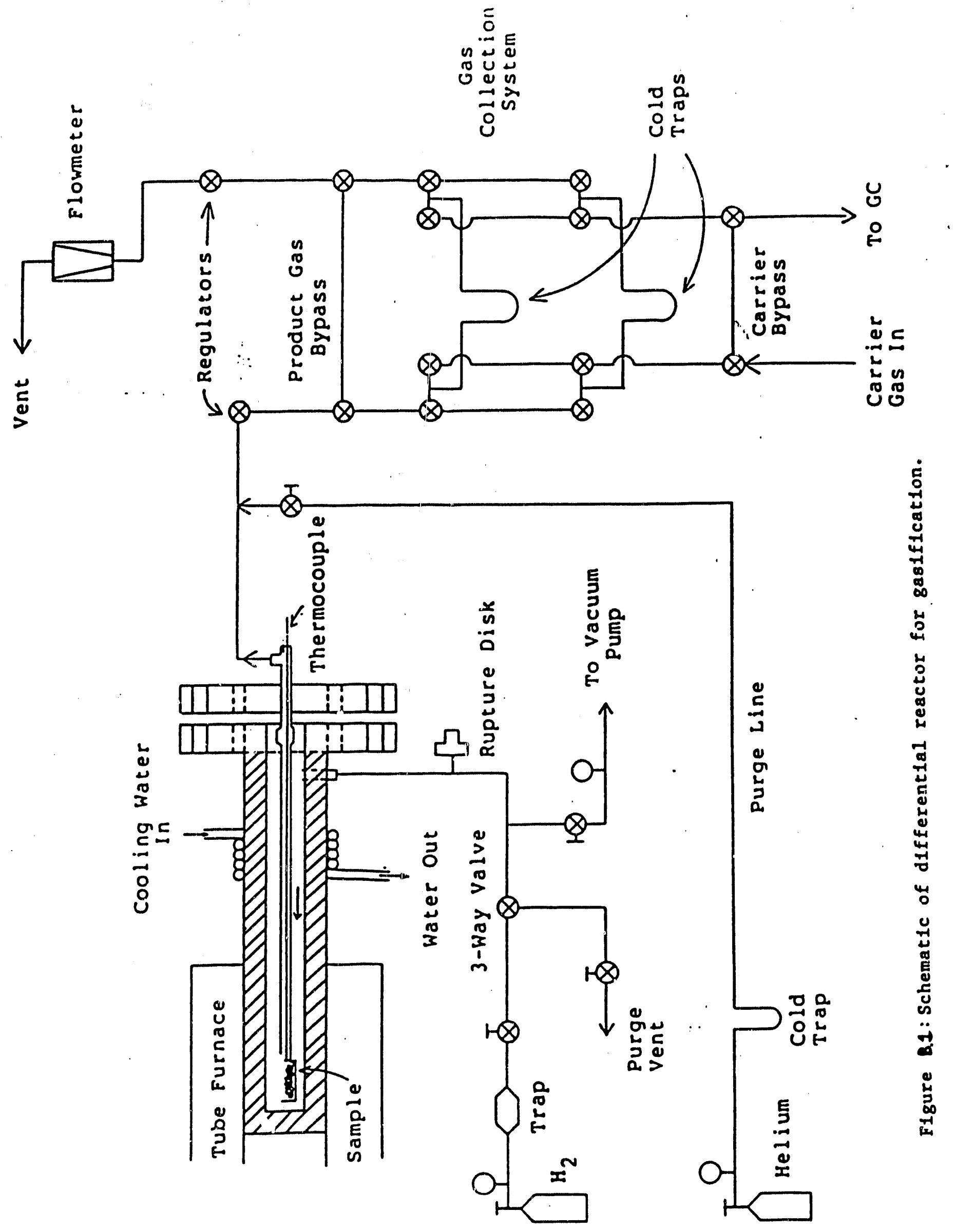


FIGURE B.2. VACUUM PRETREATMENT REACTOR

TOP VIEW

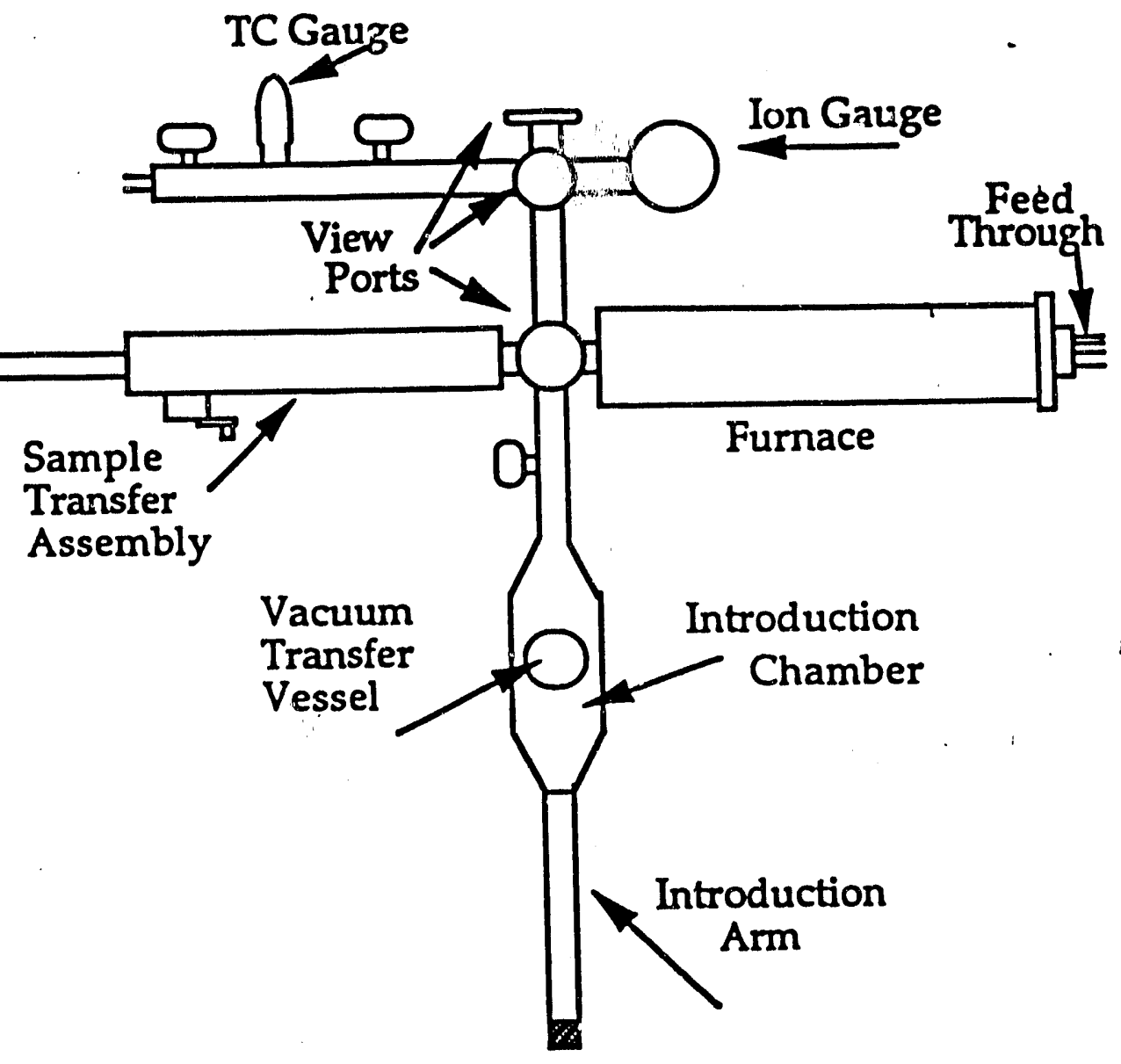

\section{SIDE VIEW}

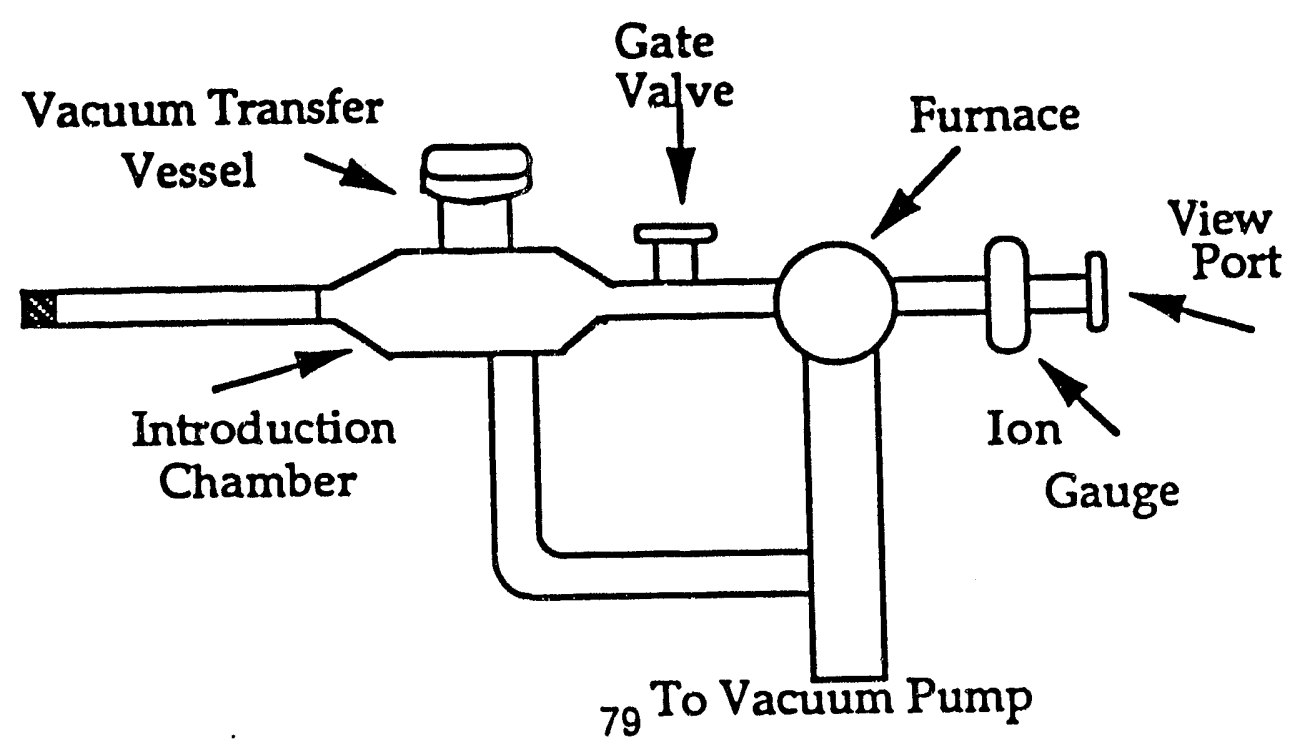



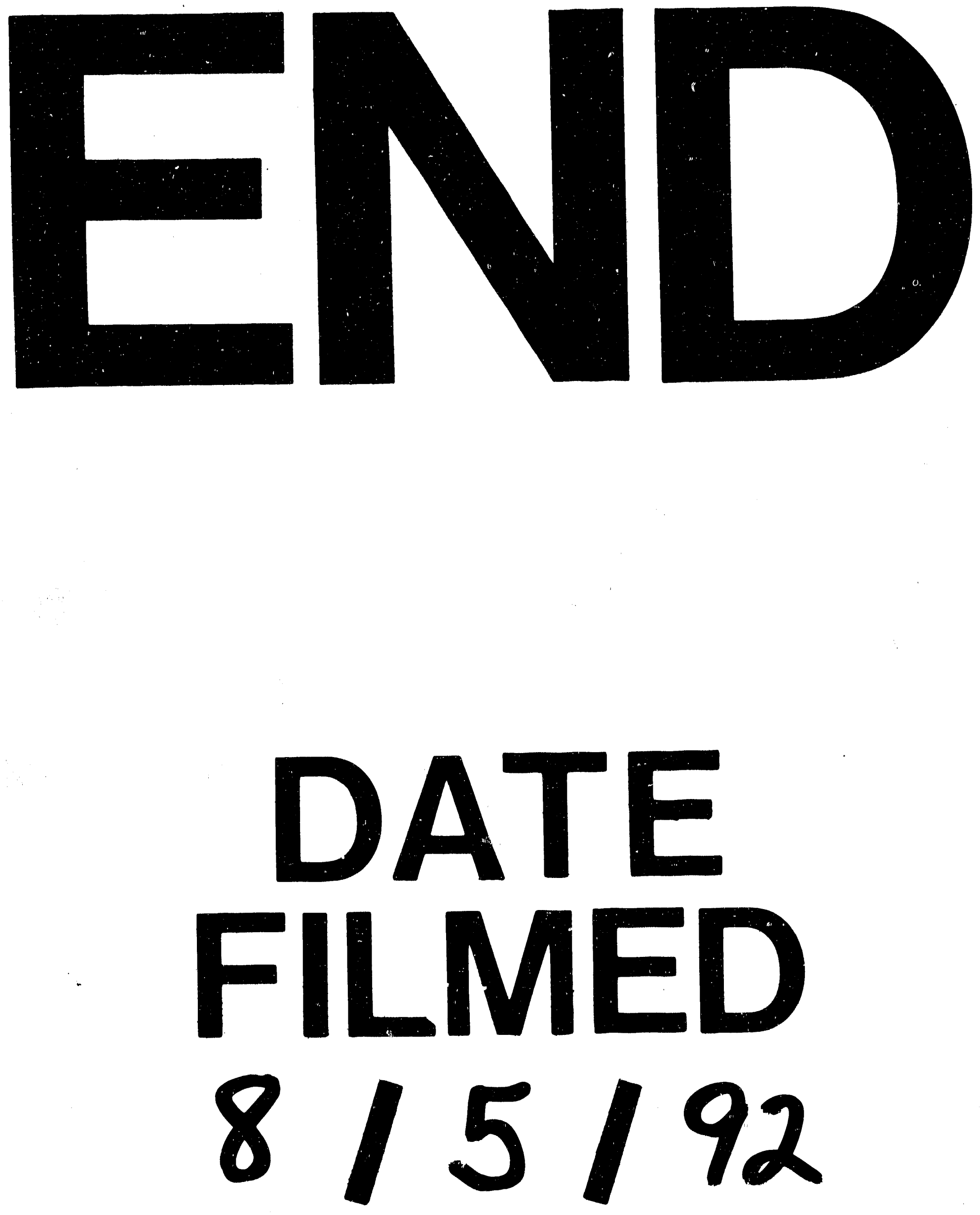

I 
